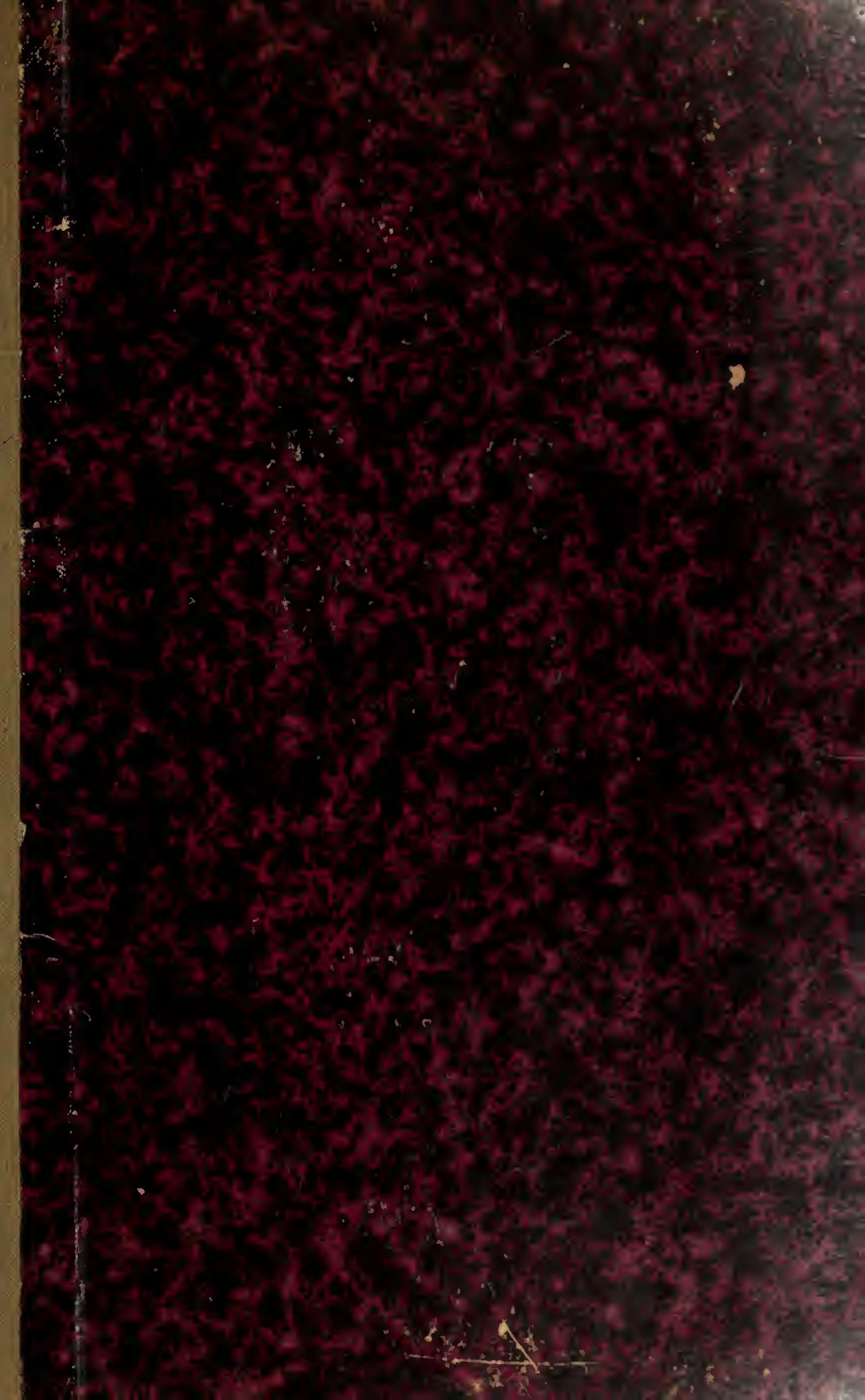


HARTARD UNIVERSITY.

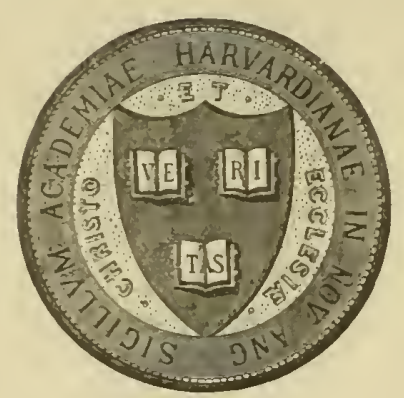

L I B R A R Y

OF THE

MUSEUM OF COMPARATIVE ZOÖLOGY. 14,395

Ftarvard ôlege library

Decermer 19,1899 


$$
\text { 14,398. DER GESCHLECHISREITE }
$$

SAEUGE'THIEREIERSTOCK.

vos

D . C. H. S T R A T Z.

EINE VON DER UTRECHTER GESELLSCHAFT FÜR KUNST UND WISSENSCHAFT (GEKRÖNTE PREISSCHRIFT.

HAAG ,

M A R TINUS NIJHOFF.

1 เละ 

DER GESCHLECHTSREIFE

SA EU GETH IEREIERST O C K. 



\section{DER GESCHLECH'TSREIFE}

\section{SAEUGETHIEREIERSTOCK.}

vox

D. C. H. S S T R A T \% .

EINE VON DER UTRECHTER GESELLSCHAFT FÜR KUNST UND WISSENSCHAFT

GEKRÖNTE PREISSCHRIFT.

HAAt',

M A R'I N US NIJ HOFF.

1 เง!ล. 
( MAY $27 ; 1899$

IBRARY.

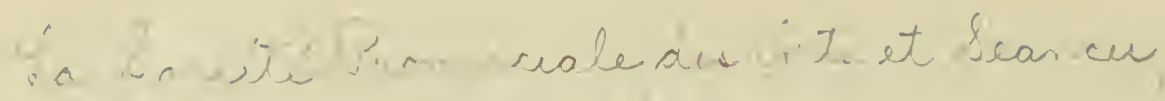

Hicest-

1899, chov. 14.

Transpured to the

Joil OHousenm. 


\section{DER GESCHLECHTSREIFE SAEUGETIIIEREIERSTOCh.}

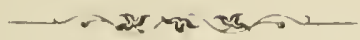

Mit lebhaftem Mitleiden für nach mir kommende Autoren entschloss ich mich, die reiche Literatur über den Säugethiereierstock mit einer weiteren Arbeit zu vermehren. Im Jahre 1870 berichtet WALDEYER bereits über 226 einschlägige Schriften, seitdem ist die Zahl derselben ins Unendliche gewachsen, ohne dass indessen die Qualität des Producirten stets gleichen Schritt hielt mit der Quantität.

Während es bei der älteren Literatur möglich ist, hervorragende Autoren und deren Befunde als gesicherte Meilensteine hinzustellen, so darf bei den neueren Schriften nicht stets und nicht absolut eine Kritik ausgeübt werden, da der jeweilige Standpunkt des Verfassers, der Einfluss dieser oder jener dem Zeitgeist entsprechenden Auffassung, endlich auch die Wahl und die Behandlung des Materials eine grosse Reihe von Factoren abgeben, die ebenso oft die richtige Werthschätzung, als anderseits verurtheilende Kritik unmöglich machell.

Eine weitere Schwierigkeit liegt in dem Umstande, dass bei der Bearbeitung des Säugethiereierstockes Zoologie, Anatomie, Pathologie und Gynäcologie sich betheiligt lıaben, wodurch das Material noch mehr zelstreut, der jeweilige Standpunkt ein noch schwieriger zu beurtheilender wurde.

Wenn ich es trotzdem versuche, eine kurze und übersichtliche Darstellung ler bisherigen Literatur zu geben, so entspringt dieser Versuch dem eingangs erwähnten Gefühle, wobei ich den leblıaften Wunsch hege, dass es mir glücken möge, mich nicht vom rechten Wege ableiten zu lassen.

Obgleich es sich hier nur um den geschlechtsreifen Eierstock der sïugethiere hamdelt, so basiren doch eine ganze Reihe der in Betracht kommenden Thatsachen auf Untersuchungen, die einerseits in das Gebiet der Entwickelungsgeschichte, andererseits in andere Klassen des Thierreiches linübergreifen; - als klassisches Beispiel erwithne ich hier nur Van Benedens Monographie über die Entwickelung von ascaris megalocephala - es wïrte 
zu weit führen, sie alle eingehend zu würdigen; und eine Nachlässigkeit in dieser Beziehung bitte ich mir zu verzeihen, ebenso wie ich um Entschuldigung bitte, für den Fall, dass ich der einen oder anderen das Thema speciell betreffenden Arbeit nicht gedacht haben sollte.

Ich will nun versuchen, die gefundenen Thatsachen in kurzen Zügen zusammen zu stellen:

\section{Wichtigste Schriften der "Aelteren Literatur” bis 1874.}

Im Jahre 1672 entdeckte Regnerus DE GraAf $(\mathbf{1}, \mathbf{2})$ das erste Sïugethierei (beim Kaninchen) in der Tube, beschrieb die nach ihm benannten Gract'schen Follikel und sprach die Vermuthung aus, dass die Eier denselben entstaminen.

Im Jahre 1827 sah und beschrieb E. von BAER (3) das ovulum in den Follikeln des Eierstocks.

Im Jahre 1834 entdeckte Coste $(\mathbf{4}, 5)$ das Keimblïschen innerhalb der Eizelle.

Im Jahre 1835 sah WAGNeR (6) zuerst den Keimfleck.

Im Jahre 1838 beschrieb VALEntin (7) die als Valentin-Pflïger'sche Schläuche bekannten Gebilde im ovarium.

Erst im Jahre 1863 entdeckte und beschrieb S'chroes (8) die Primair-Follikel, unter dem Namen von Corticalzellen.

In demselben Jahre erschien die epochemachende Arbeit von Pfuäcrer (9), del* nachwies, dass die vielbesprochenen Pflüger'schen Schlüuche, die Primuirfollikol und die Graf'schen Follikel gemeinschaftlich vom Keimepithel abstammten.

Im Jahre 1870 bestätigte WALDeyer $(\mathbf{1 0}, \mathbf{1 1})$ die Pflügerschen Befunde und erwei. terte dieselben, indem er nachwies, dass bei Neugeborenen (Mensch, Hund, Katze, Kaninchen) anch im Keimepithel noch Eizellen vorhanden waren, wodurch der Zusammenhang sämmtlicher parenchymatöser Elemente des Ovariums unzweideutich bewiesen ist.

In den beiden Werken von Pfuäger (die Eierstöcke der Säugethiere und des Menschen) und von WALDEYER (Eierstock und Ei) findet die Literaturgeschichte des Ovariums einen gewissen, noch heute massgebenden Abschluss und man kann constatiren, dass alle späteren Forscher, auf ihren Arbeiten weiterbauend im Grossen und Ganzen ihre Auffas. sung stets bestätigen mussten.

Von Schriften, die vor WALDEYer und PFLüGER geschrieben sind, verdient jedoch eine classische Arbeit von His (12) aus dem Jahre 1865 besonderer Beachtung. Daselbst findet sich eine Beschreibung und Abbildung der Blut und Lymphgefïsse des Ovariums, und speciell des corpus luteum, die bis zum heutigen Tage, weder übertroffen ist, noch irgend etwas von ihrer Richtigkeit verloren hat.

Endlich ist noch eine umfassende Arbeit von H. Ludwig (13) zu erwähnen, der auf Grund zahlreicher und mühsamer Untersuchungen alle früheren Resultate in dem allgemein gültigen Ausspruche vereinigte: „Alle Eizellen, sowohl als alle mit der Eizelle 
in Follikel eingeschlossenen Zellen sind Modificationen ursprünglich gleichartiger '/s:llan des Keimlagers" (p. 479).

Bei Ludwig findet sich ein Literaturverzeichniss von 386 Nummern, bei WALDEYK ein solches von 226, wie bereits eingangs erwähnt ist, zugleich auch eine eingehend; Wûrdigung der citirten Schriften.

War somit die Hauptsache, nämlich das Entstehen, die Entwickelung und Reifung der Eizelle im Ovarium zu einem gewissen Abschluss gebracht, so blieben doch eine ganze Reihe anderer Fragen noch unerledigt, die in der jetzt folgenden Literaturepoche das Hauptinteresse in Anspruch nahmen.

\section{Literatur über Follikelatresie.}

Im Vordergrunde stehen hierbei, sowohl was die Zahl, als die erreichten Resultate betrifft, die Untersuchungen über Follikclatresie.

Der ersten Beobachtung ReinhardTs (14) von Körnchenzellen aus dem Jahre $18+7$ folgte zunächst GroHe (15) mit der Entdeckung der fettigen Entartung des Follikelepithels.

Dann war es wiederum PFLüGER (9), der die spärlichen Beobachtungen sammelte, und erweiterte, indem er das Eindringen der Nagelzellen in die Eihöhle beschrieb, zu. gleich mit Veränderung des Eiinhalts.

Slaviansky (16) creirte 1874 die Bezeichung "Follikelatresie” und beschrieb eine Art Sclerose, bei der sich Pigmentablagerung und hyaline, mit einander communicirende Streifen formtell.

Eine neue Erweiterung erhielt die Lehre der Follikelatresie durch Flemmis (17) 1885, der die Chromatolyse des Follikelepithels mit der Bildung von Richtungskörperchen (Karyolyse) in classischer Weise behandelte und zunächst für das Kaninchen feststellte.

Bei ihm findet sich auch ein Verzeichniss der Literutur über Follikelutresie bis 1885.

Im Jahre 1887 beschäftigte sich PALADiNo (18) in einer eingehenden Arbeit unter anderen auch mit den degenerativen Processen, wobei er das Hauptgewicht auf die hyaline Degeneration legt, neben der er directe, fettige und granulöse Degeneration und Atrophie beschreibt.

1889 beschreibt RugE (19) offenbar, ohne Paladino zu kennen, in schöner Weise regressive Metamorphosen an Eiern von siredon pisciformis und salaniandra maculata: unregelmässige Einbuchtungen, Verschwinden des Eikerns, Wucherung der Blutgefïsse um das Ei hin, Eindringen von Blutgefässen (Wanderzellen) Bildung heller Strassen, Pigmentschollen, Verschwinden des Dotters, der von den eingewanderten Blutzellen aufgenommen, erweicht und mit ihnen für die Resorption vorbereitet wird.

Auch bei Ruge findet sich eine nähere Besprechung mehrerer hier nicht angefülıten Schriften, speciell eine Widerlegung von Lindgreen, der das Einwandern von Granu. losazellen in das Ei als progressiven Process zum Zweck der Ernihrung auftisst.

Ruges Auffassung schliessen sich bezüglich lindgreen van Beneden, WALDEFER (Alchiblast und Parablast. Arch. mikr. Anat. 22. p. 29) u. a. an. 
1891 werden die Befunde Flemmings durch seinen Schüler SchotTLăsder (20) bestätigt, für Mäuse, Ratten, Hunde, ein Meerschweinchen und ein TVeib, und ausserdem erweitert, da ScHOTTLäNDER hier und in einer weiteren Arbeit nicht nur grosse, sondern auch mittlere und kleinere Follikel in Chromatolyse gesehen hat.

Die Einleitung der Arbeit bildet eine Besprechung del einschlägigen Literatur.

Im Jahre 1894 endlich erschien eine sehr schön geschriebene Arbeit von HENYEGUY (21, 23), der den bisher beschriebenen Formen der Atresie die „dégénérescence par frag. mentation" hinzufügt, dabei betont er schliesslich, dass diese ebenso wie alle andern Processe bei den Säugethieren sich auf alle mögliche Weise combiniren können, dass dagegen das Eindringen von Phagocyten, das bei dotterreichen Eiern andrer Wirbelthiere Regel ist, bei den mammalia wohl auch vorkommt, jedoch selten.

Seine Beobachtungen erstreckten sich auf Ratten, Mäuse und Katzen, Kaninchen, cavea, rhinolophus, talpa, sorex vulgaris, und ein Känguruh.

Sie decken sich im Allgemeinen mit den letzten Beobachtungen von JAxosiK (24, 25) und CRETy (26) ebenso wie mit denjenigen von Mrvaarzini (27) über Reptilien.

Schliesslich sei noch erwähnt, dass NATHAN LöwextHAL (28) 1889 auch chromatolytische Vorgänge in Primairfollikeln und in Eizellen des Follikelepithels gesehen haben will. Obgleich eine solche Möglichkeit nicht geleugnet werden kann, so lassen doch die meisten seiner Abbildungen mehr an Mitosen, als an degenerative Vorgänge denken.

\section{Literatur über das corpus luteum.}

Weniger zahlreich sind die Arbeiten über das corpus lutcum. Ich schliesse dieselben hier an, weil einige der neueren Bearbeiter mit mehr oder weniger Entschiedenheit auf die Analogie der dabei stattfindenden Processe mit denjenigen bei Follikelatresie hinweisen.

Der erste, der das corpus luteum ausführlich beschrieb und seine Elemente von der sog. theca intima ableitete, war von BAER (3); zu seiner Ansicht bekannten sich Koeldiker (Handbuch der Gewebelehre, 1867) His (12) und später Slariarisk (29) PflüGER (9) und Schroen (8) leiteten das corpus luteum aus der wuchernien Granulosa ab.

WALDEYER $(\mathbf{1 0}, \mathbf{1 1})$ nahm gewissermassen eine vermittelnde Stellung ein, indem er die Hauptmasse den Granulosazellen zuschrieb, die eine starke Gefảss und Bindege. webewucherung. von der tunica interna empfangen sollte.

Im Jahre 1884 finden wir bei Bexckiser (30) der zugleich eine treffende Beschreibung der Literatur liefert, einige sehr sorgfältige Beobachtungen über das corpus luteum des Schweines.

Bezüglich des Schweines kommt er zu dem Resultate:

Die Bildung des corpus luteum beruht auf Hypertrophie und Hyperplasie der Elemente der theca interna (Binnengewebszellen, Gefässe) welche schon vor der Follikelberstung beginnt, und nach derselben bis zu einem gewissen Höhepunkt weiterschreitet. Die membrana granulosa geht physiologisch bei der Berstung zu Grunde. Das Coagulum ist ein inconstanter und für die Bildung unwesentlicher Bestandtheil des corpus luteum. 
Im folgenden Jahre erweiterte BExckiser (31) seine Befunde lurch am mensch. lichen Ovarium gefundene karyolinetische P'rocesse in den Gefüssendothelien und Latcinzellen Im .Jahre 1887 würdigt PALADlNo (18) das corpus luteum einer eingehenden Brotrachtung. Er beobachtet eine Periode von Vorbereitung bereits vor der völligen Peife des lol. likels, und erklärt das Entstehen des corpus luteum durch Sprossung und Vascularisation der vorbereiteten theca, wodurch der Bluterguss allmählig ersetzt wird.

Er unterscheidet corpus luteum verum, das nach Platzen des lollikels entstandene corpus luteum von dem corpus luteum falsum, dem atresirten Follikel.

Endlich hat SchotrLäNder (32) im Jahre 1893 den heutigen Stand der Frage dahin 7usammengefasst, dass das corpus luteum ohne Betheiligung von Epithel und Wanılezellen durch Wucherung von epithelioiden Zellen der theca interna sprungreifer Follikel entsteht. Eine Verfettung der Thecazellen scheint, wenn überhaupt, erst sehr spät einzutreten. Die Ausbildung des gelben Körpers beruht vorzugsweise auf einem Wucherungsprocess, doch kann wohl zu gewissen Zeiten trotzdem eine Retraction des einwachsenden Bindegewebes stattfinden.

Von früheren Werken sei ausser His (12) hier noch VAN BENEDEN (33) erwähnt, dessen Beobachtungen wie es scheint, in diesem Punkte nicht die genügende Beachtung gefunden haben. Er hat den Vorzug, dass er vollkommen objectiv beobachtet. Das corpus luteum besteht nach ihm aus zahlreichen Blugefässen, Bindegewebe und interstitiellen Zellen, die die Maschen des Netzes füllen. Er macht keine weitgehenden Schlüsse, da ihm sein Material nicht genügt, und endigt mit: „nous croyons à l'identité des processus qui caractérisent d'une part la metamorphose régressive des follicules, de l'autre la formation des corps jaunes."

Bevor hier die Acten über das corpus luteum geschlossen werden, sei daraufhingewiesen, dass LEOPOLd $(34,35,36)$. (Archiv f. Gynäcologie Bd. 11, 21 und 45) vorzägliche Abbildungen menschlicher corpora lutea in allen Stadien veröffentlicht hat.

Wie aus dem Angeführten ersichtlich, ist ein Abschluss über die Frage noch nicht erreicht. Wie uns scheint, liegt der Schwerpunkt in dem van Beneder gegebenen Hinweis auf die Zusammengehörigkeit dieses Processes mit der Follikelatrophie. Wir wollen darauf später zurückkommen.

\section{Postfoetale Entwickelung von Ureiern aus dem Keimepithel.}

Die Waldeyersche Entdeckung der Eizellen im Keimerithel gab zu zahlreichen Controlluntersuchungen Veranlassung. In mehreren der citirten Arbeiten finden wir darauf bezügliche Stellen.

Waldeyers Arbeit hatte die Möglichkeit offengelassen, dass sich auch nach dem livetalleben stets noch neue befruchtungsfähige Eier durch Einsenkung aus dem Keimepithel bilden könnten.

Es ist interessant, zu sehen, welche Resultate spaitere Autoren mitgetheilt haben: Harz (37) fand sie bei arvicola arvalis, cavea, Katze und Rind im embryonalen 
Zustand, sowie bei sehr jungen Thieren, bei älteren Individien derselben Gattung fand el sie nicht, ebensowenig beim Fohlen, bei einer Stute, einem Schwein, einem menschlichen Fötus, einem Hasen.

PaladiNo (18) fand sie stets in grösserer oder geringerer Anzahl bei weiblichen Kindern, bei Frauen von 18, 24, 32 und 40 Jahren, bei Schweinen, Pferden, Kühen. Schafen, Ziegen, Hasen, Katzen Hunden und Kaninchen.

VAN BENEDEN (33) fand sie stets bei Fledermäusen.

WAGENER (38) fand sie stets bei Hunden.

Schottländer (32) fand sie nicht bei 7 weiblichen Ovarien (wobei jedoch zu be. merken ist, dass kein einziges seiner Objecte einwandsfrei ist, worauf später unten zurückgekommen wird.)

Wie aus diesen wenigen Daten bereits ersichtlich, herrscht noch keine grosse Uebereinstimmung.

\section{Zeichen der Reife des Eierstockseis.}

Die grossen Fortschritte, die die Lehre von der Eireife und Befruchtung in den letzten Jahren gemacht hat, hat auch für den Begriff des reifen Eierstockseis eine neue Auffassung nöthig gemacht. Die wichtigste, allgemein gültige Beobachtung ist die grosse Monographie von van Bexedex (39) über die Eireifung bei Ascaris.

Ihm schliessen sich an Vax Bexeddr und Julin (40) mit Beobachtungen über Fledermäuse, Rein (41) mit dem Kaninchenei, W. HeAfe (42) mit Talpa u. a. m.

Als Resultat ihrer Untersuchung scheint das für alle Săugethiere gültige Gesetz hervorzugehen, dass die Eireifung mit dem völligen Heranwachsen des Follikels noch nicht abgeschlossen ist, sondern das in der Eizelle auch ohne Befruchtung gewisse bisher noch nicht beobachtete Processe von Kerntheilung als Zeichen der völligen Reife regelmässig statthaben.

Wir werden darauf später zurückkommen, hier sei nur erwähnt, dass Heape sich sogar veranlasst sieht, $\mathrm{zwischen}$ ripe ovurian ovum und mature ovarian ovum zu unterscheiden.

Den ersten Schritt zu diesem Resultat haben bereits PFLüGer (9) und KüLlikeR (43) gemacht, die im Eidotter zwei Schichten, eine äussere dunklere, und eine innere hellere beschrieben. KöLLIKER beschrieb auch zuerst die radiaire Streifung der Zona pellucida, die wie von kleinen Kanälchen durchzogen scheine. HEApE wies nach, dass diese Kanälchen in directem Zusammenhang stehen mit dem Innern der sie umgebenden, epithelartig angeordneten Granulosazellen.

Nach Heape ist nun das Zeichen des ripe orum, dass diese Granulosazellen sich von der Eizelle ablösen und der Dotter deutlich die Deutoplasmaschicht zeigt, während das von ihm abgebildete mature ovum einen sehr deutlichen perivitellinen Spaltraum, dunkle Körnung, Pseudopodienformung des Protoplasmas nach der Eimembran hin, und endlich last not least, einen weiblichen Promuclens und zuei Richtungskürper zeigt.

Wichtig zur Beurtheilung der Reifungserscheinungen ist noch die Beobachtung von 
Baybecke (44) an Fischeiern, wobei durch Einwirkung von Essigsäure ein Kern irn IÆaioplasma auftritt, sowie eine stielartige Verbindung des Eikerns mit der Eimembran.

Balbiani (45) fand dasselbe bei Geophilen, und fasst den äusseren Kern als eine eingewanderte Granulosazelle auf.

Ein Abschluss ist also auch in dieser Frage noch nicht erzielt.

Nicht unerwähnt darf eine hierhergehörige Arbeit NAGEL's (46) bleiben, die durch ein ausführliches, wenn auch nicht imıner übersichtlich und zutreffend besprocienes Litfraturverzeichniss Werth erhält.

\section{Das Epoophoron.}

Von den Elementen des fertigen Ovariums verdient noch eines einer kurzen Be. sprechung, nämlich die bekannten Hilusdrüsen, die WALDEYER (10) als Epoophoron beschrieben hat. Die Ansicht KörLikers, der daraus das Follikelepithel ableitete, schien damit endgültig widerlegt zu sein. In der That dienen alle späteren Arbeiten nur dazu, um Waldeyers Befunde zu bestätigen.

Paladino (18) fand sie stets mit dem Hilusgewebe mehr oder weniger tief in das Ovarium eindringen, MAC LEOD (47) fand sie bei Talpa und vesperugo pipistrella völlig vom Keimlager getrennt, van Beneden (33) ebenso bei den von ihm untersuchten Fledermäusen, Bors (48) fand dasselbe beim Pferd.

Eingehend hat Harz (37) diese von ihm Segmentalzellen genannten Gebilde bei Feldmaus, Ratte, Meerschwein, Hase, cebus capuninus, Pferd, Katze, Schaf, Rind, Schwein, Hapale und Mensch untersucht und gefunden, dass sie je nach der Thiergattung mehr oder weniger tief ins Ovarium hinein reichen, jedoch mit der Bildung des Follikelepithels nichts zu machen haben.

Bei HARz findet sich auch eine ziemlich vollstänảige Literaturangabe und eingehende Besprechung derselben.

\section{Nackte Eier und Doppeleier.}

Von selteren, nicht stets constatirten Befunden verdienen noch die sog. nackten die Doppeleier eine eine kurze Erwähnung.

Die nackten Eizeilen PflüGers (9), die Kölliker und nach ihm so manche andere misleiteten, so u. a. auch Foulis (on the developemt of the Ova and structure of the Ovary in man and other Mammalia. Qu. J. Micr. Science 16, 1876) und HArz, dürften wohl bei dem gegenwärtigen Stand der Lehre über Atresie ausgespuckt haben und können als degenerirte Eizellen angesehen werden.

Die Doppeleier, deren erstes von Schroen (8) bei der Kat\%e gefunden und sehr getreu abgebildet wurde, sind von verschiedenen, vox Schottläsder (32) NAger (46) u. a., auch gesehen worden, jedoch so äusserst selten, dass sie als ein zufälliger Befund aufgefasst werden müssen. Ob diese Eier Veranlassung geben künnen zur Zwillingschwangerschaft, ist noch nicht bewiesen, da dieselben noch nicht in reifem Zustande angetroffen sind. 


\section{0varium bei Menstruation, Gravidität \& Puerperium.}

Es sind hiermit die wichtigsten Fragen, die sich auf Theile des geschlechtsreifen Ovarium beziehen, in grossen Zügen besprochen. Wenn wir nun dazu übergehn, das Ovarium als ganzes zu betrachten und seine Veränderungen durch Menstruation, Schwan. gerschaft und Puerperium zu studiren, so müssen wir uns gestehn, dass darüber noch sehr wenig brauchbares Material in der Literatur zu finden ist.

Eine befriedigende und überzeugende Erklärung des Verhältnisses zwischen Ovulation und Menstruation besteht nicht. Alles, was darüber geschrieben ist beruht auf Hypo. thesen und entbehrt einer strengen anatomischen Grundlage und Beweisführung.

Als Grund hierfür ist die ausserordentlich schwierige Beschaffung des Materials anzusehn.

Die einzige werthvolle Arbeit hierüber stammt von W. HEAPE (49) her, der 42 Exemplare menstruirender Weibchen von Semnopithecus entellus untersucht hat, speciell jedoch die Uterusmucosa.

Im Ovarium hat er nur 2 "recent discharged follicles” gefunden, jedoch keine [ntersuchung auf reife, noch nicht gesprungene Follikel gemacht.

Beide corpora lutea entstammen den letzten Stadien der Menstruation.

Sein Schluss, dass nicht bei jeder Menstruation auch Eireifug stattfindet, scheint uns demnach nicht berechtigt; richtiger hätte er sich unserer Ansicht nach mit der Bemerkung begnügen können, dass die Menstruation der Follikelberstung vorangeht.

LEOPOLD's $(34,35,36$, oben erwähnte Arbeiten über dasselbe Tliema müssen sehr vorsichtig genossen werden und haben mehr casuistischen Welth.

Wissen wir beinahe nichts von den Verhältnisse von Ovulation und Menstruation, resp. dem Verhalten des Ovariums hierbei, so sind wir bei der Gravidität nicht viel besser unterrichtet.

DE Sinery (50) hat 1877 eine Definition der Šchwangerschaftsveränderungen im Ovarium zu geben versucht, jedoch erwähnt er, dass seine Angaben sich nır auf das Ovarium der Frau beziehen, während er bei cobaia und einigen andern Thieren keine Teränderung durch Schwangerschaft bemerken konnte.

Beim Weibe findet DE SIxETY das Characteristicum in einer rerhältnissmässig stärkeren Schwellung (Hypertrophie) der membrana propria im corpus luteum. Er fügt hinzu: „J'ajouterai que le nombre des Follicules atrèsiés m' a paru beaucoup plus considérable chez la femme pendant la grossesse yu' à l' état de vacuité."

PALADINo (18) hat keine Verïnderungen des Ovariums durch die schwangerschaft wahrgenommen.

Schotruänder (32) hat, wie bereits oben erwähnt, 7 nicht ganz einwandsfreie Ovarien untersucht, worunter 6 von schwangeren oder puerperalen Frauen abstammen. Diesen Umstand hat er scheinbar weiter nicht beachtet. Bei allen Ovarien fand er, wie bereits erwähnt, keine Ureier im Keimepithel, und ferner beinahe gar keine Kerntheilungs. figuren im Follikelepithel. 
Schulin (51) giebt an, dass ihm der Säftezufluss zum Ovarium während dor (ira visität vermindert scheint, weshalb auch das corpus luteum langsamer resorbirt würds.

Scrmoen (8) fand bei brünstigen Katzen viel mehr Primairfollikel als bej schwangeren Katzen.

AEBY (52) fand Eierstockspindeln reichlicher in der Brunst, resp. IEnstruation.

Auf diese spärlichen Angaben beschränkt sich die Ausbeute der heutigen litcratur.

Es sind in der hier gegebenen Uebersicht einige Einzelheiten noch nicht erwähnt worden, die die Deutlichkeit der Darstellung trüben wülden. Jiese werden jedoch später eingeflochten werden. Das beigefügte Literaturverzeichniss beabsichtigt auch keinesivegs: dem Anspruch auf Vollständigkeit zu genügen, sondern will ıul die vichtigsten einschlä. gigen Werke in chronologischer Reihenfolge dem Leser vorführen. (Ausführliche Literatur. angaben finden sich in den citirten Werken 9, 10, 13, 17, 19, 30, 33, 43, 46, 51).

Als zu erledigende k'ragen, auf welche hin das zu bearbeitende Material geprüft werden musste, blieben somit aufgestellt:

1. Wie lange und unter welchen Umständen findet eine postembryonale Entwickelung von Primordialeiern aus dem Keimepithel statt?

2. Welche Processe finden bei der Follikelreifung statt

(t. in der Eizelle?

b. im Follikelepithel?

c. im Stroma?

3. Welchen Antheil nehmen Paremchym und stroma

". bei der Follikelatresie?

b. bei der Bildung des corpus luteum?

4. Wie verhält sich das Ovarium als ganzes und in seinen Theilen

a. zur Menstruation?

b. zur Befruchtung?

c. zur Schwangerschaft und zum Puerperium?

d. zum Lebensalter?

Zur Beantwortung dieser Fragen stand das reichhaltige Material des zoologischen Museums z:u Utrecht zur Verfügung. Sämmtliche daselbst bewahrten Präparate, wurden, wie von Hubrecht bereits a. a. o. el'wähnt ist, unmittelbar nach dem Tod ihrer 'Träger zunächst mit Pikrinschwefelsäure behandelt und dann in starken Alcohol eingelegt. Dadurch war eine einheitliche Verwerthung der gefundenen Resultate mit grösstmöglicher Genauigkeit gestattet.

Bei einer vorläufigen Orientirung in dem reichhaltigen Material schien es am empfehlenswerthesten mit Tupaja javanica zu beginnell, von welchem Thier z. Z. 46 ? weibliche Genitalien vorlanden waren.

Die geringe Grösse der Organe gestattete eine rasche Orientirung, die zur Controlle nöthigen Untersuchungen der zugehörigen Uteri waren bereits in gewissem Sinne abge. schlossen 1); das Verhältniss zwischen Stroma und Paremchym bot die günstigsten Vel*

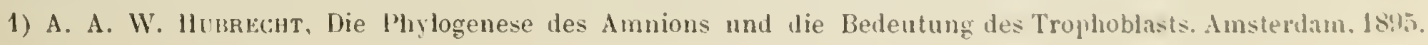


hältnisse um beide neben einander zu studiren. Endlich zeigte sich, dass Tupaja trotz seiner Kleinheit deutliche Zeichen einer mit Bluterguss verbundenen Menstruation besass, was in Verband mit dem bei diesem tropischen Thier constatirten Fehlen einer eigentlichen Brunstzeit viel Analogien mit dem höchsten lebenden Wesen, dem TVeibe bot und anderer. seits dort in viel einfacherer Form studirt werden konnte und versprach, manche Cebelgänge der einzelnen Thierformen zu vermitteln.

Als zweites Object wurde Sorex vulgaris gewählt, von dem s. Z. 143 weibliche Genitalien vorhanden sind.

Auch hier war die Arbeit bereits vorbereitet durch die Untersuchung der Uteri ${ }^{i}$ ).

Trotz vielel Analogien mit Tupaja versprach Sorex weitere Resultate, da derselbe insofern eine niedere Stufe einnahm, als das Stroma im Verhältniss zum Parenchym weniger entwickelt ist. Ein weiterel Unterschied bestand durch die Brunst, die bei Sorex im Gegensatz zu Tupaja vorhanden ist.

Als drittes Specimen diente endlich Tarsius spectrum, von dem beinahe 600 weibliche Exemplare vorhanden waren. Derselbe ist ebenso wie Tupaja ohne Brunstzeit und mit blutiger Menstruation begabt, ausserdem gestattete er durch mächtigere Entwickelung der corpora lutea manche diesbezügliche Fragen zu beantworten, die mit Tupaja allein nicht zufriedenstellend erledigt werden konnten.

Die Untersuchung nahm beinahe 2 Jahre in Anspruch; die Zuziehung weiterel Species schien zwar anfangs sehr erwünscht, doch gestatteten die sich deckenden Befunde der 3 genannten Thiere in Verband mit den bereits bekannten Resultaten manche weiter. gehenden Schlüsse, so dass auch so schon ein gewisser Abschluss erreicht werden konnte.

Die Untersuchung gestaltete sich zu einer mehr weniger synthetischen, in der die gefundenen Resultate mehr und mehr zu einem organischen Ganzen zusammentraten. Wir haben versucht im folgenden diese Entwickelungs-Geschichte möglichst getreu vor dem Auge des Lesers zu entrollen.

Die mikroskopischen Präparate wurden mit sämmtlichen Details direct unter dem Zeichenprisma übertragen, und zwar zur besseren Vergleichung alle in einer Vergrïsserung von 48 (Zeitz T. O. Obj. II) fül die Uebersichtsbilder und in einer Vergrüsserung von $\$ 00$ (Zeitz T. O. Obj. IX) für die Einzelheiten. Einige ganz wenige Ausnahmen sind jedesmal besonders bemerkt.

Diese Arbeit wurde Ende 1896 abgeschlossen. Bei der jetzt in 1895 erfolgten Drucklegung ist keine Abaenderung im Texte vorgenommen worden. Daraus erklaert sich, dass inzwischen erschienene Arbeiten nicht erwähnt sind.

Während der Bearbeitung des vorliegenden Materials ist die Literatur, soweit dieselbe zu unserer Kenntniss gelangte, um wenig vermehrt worden.

Nur eine sehr sorgfältige, bereits im 'T'ext erwähnte Arbeit von Sobotta über das corpus luteum der Maus im anatomischen Anzeiger 1895, X, p. 482 hat berechtigtes Auf-

1) S. A. W. Hubrec:ht, De Placentatie ran de spitsmuis. The Derelopment of the Germinal layer of sorex rulgaris. 
selıen gemacht. Sobotta leitet gleich mir das corpus luteum ab aus Granulosazellen und der wuchernden theca interna.

In der neu bearbeiteten Anatomie von QuAin haben S'Härer und Sysrigrox die Sobotta'schen Befunde ohne weiteres übernommen und die Analogic auch für den Mensch festgestellt, während NAGEL in dem eben erscheinenden Sammelwerk von BARDELEEEX Sobotta's Beobachtungen für die Maus bestelien lissst, jedoch das menschliche colpus luteum ausschliesslich von der theca interna ableitet.

\section{T U P A J A.}

Um so objectiv wie möglich vorzugehn, wurde zunächst von verschiedenen Ovarien von 'I'upaja ohne Berücksichtigung der individuellen Verhältnisse eine griissere Anzahl von Uebersichtsbildern angefertigt, von denen die wichtigsten auf Tafel 1, fig. 8-15 reproducirt sind. Das Ovarium von Tupaja hat eine mehr oder wenigel unregelmässig eiförmige Gestalt, deren Oberfläche durch die Reifungsprocesse der Follikel beinahe gar nicht, durch die Bildung der corpora lutea nur sehr wenig beeinflusst wird. Auf den beigegebenen Durchschnitten, wie auf allen folgenden, sind die Follikel roth, die corpora lutea gelb gezeichnet; in allen Fällen, in denen die Differentialdiagnose etwa Schwierigkeiten bereitete, wurde dieselbe erst mit einer stärkeren Velgrösserung gestellt, und darauf das Präparat gezeichnet.

Was zunächst auffiel, war die ausserordentliche Verschiedenheit in Bezug auf die Zahl der Primairfollikel, die die Ovarien, ganz abgesehen von jeweiliger Form und Grösse darboten. Ein Blick auf Fig. 8 u. 10 einerseits auf Fig. 15 andererseits genügt, um diesen, Unterschied sofort deutlich zu machen. Ich glaube nicht fehlzugehn, wenn ich annehme, dass das Spärlicherwerden der Primairfollikel nichts anderes als ein Zeichen herannahenden Alters ist. Paladino und andere haben dieses Factum bei Menschen, deren Alter bekannt war, festgesetzt. Wenn nun auch keine der untersuchten Tupajas einen Taufschein vorweisen konnte, so waren doch die sicher jugendlichen und jungfräulichen Tupajas als solche deutlich $\mathrm{zu}$ erkennen und dann auch stets mit einer ansserordentlich grossen Zahl von Primairfollikeln versehn, sodass ich keinen Anstand nahm, aus der Anzahl derselben einen Rückschluss auf das Alter der Trägerin zu machen.

Ein weiterer Umstand, der auch seine Analogie beim menschlichen Weibe hat, ist der, dass mit der Abnahme der Primairfollikel eine Zunahme des Stromas Hand in Hand geht, was ebenfalls aus den 'Tafeln ersichtlich ist.

Ich will hier gleich vorwegnehmen, dass ich mit stïrkeren Vergrösserungen in sämmtlichen untersuchten Ovarien Eizellen im Deckepithel nachweisen konnte, loch auch diese um so zahlreicher, ja zahlreicher die Primairfollikel vorhanden waren. 
Bei den grösseren Follikeln fällt auf, dass der liquor folliculi im Verhältniss zur Eizelle und zum Granulosaepithel verhältnissmässig wenig entwickelt ist, selbst nicht in den grössten Follikeln. Diese letzteren finden sich meist zwei bis drei, ja oft auf Serienschnitten in noch grösserer Anzahl in einem Ovarium, ivas ebenfalls bei den corpora lutea zu constatiren ist.

In einer Serie, der die Fig. 9 entnommen ist, liessen sich sogar 5 corpora lutea constatiren neben zwei grossen Follikeln

Durchschnittlich näheren sich in jedem Ovarium zugleich etwa 5 Follikel der Reife, wie man sich. leicht aus einem 'Blick auf die ganz vvillkürlich herausgegriffenen Durch. schnitte der Tafel I überzeugen kann. Fast jeder derselben zeigt neben einander in buntel Abwechslung fünf corpora lutea, resp. grössere Follikel, die das übrige Gewebe dominiren. Unter der grossen Zahl der untersuchten Ovarien fiel mir nun zunachst ein stets wiederkehrender Typus auf, wie ihn die Figur 8 repräsentirt. Dieser Typus zeigte bei sonst völlig analoger Entwickelung gar keine corpora lutea, oder doch so spärliche Reste dass dieselben nur bei stärkerer Vergrösserung als solche erkannt werden konnten. Hand in Hand damit gingen eine auffallend grosse Anzahl degenerirter Follikel von allen Abmessungen, deren Metamorphose meist soweit fortgeschritten war, dass sie sich selbst bei dieser schwachen Vergrösserung mit Leichtigkeit erkennen liess.

Ein weiterer, jedoch viel weniger häufiger Typus hat ebenfalls kein corpus luteum, daneben jedoch lauter scheinbar gesunde Follikel von allen Grössen.

- Als ich nun daran ging, die Befunde der Ovarien mit denen der zugehörigen Uteri zu vergleichen, so konnte ich zunächst die überraschende Thatsache feststellen, dass sämmtliche Ovarien, die corpora lutea enthielten, zu Uteri gehörten, die entweder nicht schwanger oder im ersten Stadium der Schwangerschaft waren, dass hingegen hochschwangere Uteri abgesehn von spärlichen Resten keine corpora lutea zeigten und fiisch puerperale Uteri überhaupt nicht. Mit beginnender Schwangerschaft stieg zugleich die Zahl der auch mit schwacher Vergrösserung walrnehmbaren atresirenden Follikel, um am Ende der Schwangerschaft und im Beginne des Puerperiums ihren Höhepunkt zu erreichen.

Je weiter das Puerperium fortschritt, was an der mehr und melı sich vollendenden Regeneration des Uterusepithels zu constatiren war, desto häufiger konnten wieder normale Follikel und frische corpora lutea walırgenommen werden.

Die Reihe derjenigen Falle, die nur scheinbar normale Follikel, aber keine corpora lutea zeigte, gehörte zu jugendlichen und jungfräulichen Uteri.

In einem Falle endlich, dessen Ovarium in Fig. 9, abgebildet ist, fand sich im Uterus neben einigen desquamirten Epithelien ein grösseres Blutcoagulum, wälnend der Stand der Uterusdrüsen, die Glätte der Serosa und das Fehlen einer Placentarstelle ein eventuelles Puerperium mit Sicherheit auszuschliessen gestatteten. Wir hatten es hier demmach mit Menstruation zu thun.

Neben diesem Fall, auf den ich später ausführlich zurückkomme, fand sich ein zweiter, bereits von HuBREchT l.c. erwähntel und theilweise abgebildeter der ron höchstem Interesse ist. 
Das ebenbefruchtete Ei, in dem der männliche und der weibliche Vorkern nuch nicht vereinigt sind, liegt in der Tube; im Ovarium findet sich der frisch gebrostr.nt: f*l. likel. Fig. 10 gibt den Durchschnitt des betreffenden Eierstocks.

Mit Berücksichtigung der weiter unten zu busprechenden Controlluntersuchungen ınit stärkeren Vergrösserugen liess sich nun eine Reihe von 'I'ypen für die vorschiedenen Phasen des Gescllechtsleben in Ovarium in folgender Reihe aufstellen:

\section{Juugfratuliches 0varium. Taf. I. Fig. 8.}

Utr. Mus. Cat. $\mathrm{N}^{\prime \prime}$ Tupaja $\mathrm{N}^{0} .382$ a. I. IV. 7.

Utenss klein, glatt, mit kleinen Verdickungen an den Hörnern, kein Zeichen von Schwangerschaft.

Ourrien 222 serienschnitte.

3 reife Follikel, - zahlreiche mittelgrosse mit mehr weniger deutlichen Zeichen von Atresie - kein corpus luteum, sehr viel Primairfollikel, zahlreiche Eizellen im Deckepithel.

\section{Ovarium bei Ier Menstruation. Taf. I, Fig. 9.}

Utr. Mus. cat. $\mathrm{N}^{0}$. Tupaja $\mathrm{N}^{0} .252$.

Utem rundlich verdickte Uterushörner, geschwollen, Bloedcoagulum und desqua. mirtes Epithel im Uteruslumen. Menstruation.

Ovarien 143 Serienschnitte.

1 reifer, sehr grossel Follikel; 2 grosse Follikel, 2 gleichgrosse mit Degeneration der Eizelle; zahlreiche mittelgrosse Follikel, worunter einzelne mehr oder wenigel degenerirt; ein stark zurückgebildetes corpus luteum, - sehr viele Primairfollikel, zahlreiche Eizellen im Deckepithel.

\section{Ovarium bei der Befruchtumg. Taf. I, Fig. 10.}

Utr. Mus. Cat. No. Tupaja. No 214.

Uterus: rundlich verdickte Uterushörner. Gefässe verdickt und mit Blut gefüllt; im Uteruslumen desquamirtes Epithel in grosser Masse, mit Blutkoerperchen gemischt: in der Vagina ein grosses Blutcoagulum.

Tube: in der einen Tube ein befruchtetes Ei.

Ovarium: 113 Șerienschnitte.

1 frisch gesprungener Follikel, 1 ganz frisches corpus luteum, 1 älteres, 1 befruchtungsfähiger, 1 reifer Follikel mit degenerirter Eizelle, mittelgrosse Follikel alle degenerirt, zum Theil die Eizellen, zum Theil das Follikelepithel. Karyokinetische Figur einer Eizelle im degenerirten Follikel (s. u.)

Primairfollikel sehr zahlreich, meist normal, viele Eizellen im Deckepithel. 
4. Orarium im Beginn der Schwangerschaft. Taf. I, Fig. 11.

Utr. Mus. Cat. No. Tupaja No. 203.

Uterus: beide Hälften gleichmässig verdickt; bei Lupenvergrösserung deutlich geschwellte Blutgefässe sichtbar.

4 sehr junge Embryonen im Uterus.

Ovarium 82 Serienschnitte.

2 ganz frische corpora lutea. 1 reifer Follikel mit hyaliner Degeneration der Eizelle und verdickter Zona pellucida, mittelgrosse Follikel sämmtlich in Degeneration begriffen. Einige kleinere Follikel scheinbar normal. Zahlreiche Primairfollikel und Eizellen im Deckepithel.

5. Ovarium in der Ersten Haelfte der Grariditaet. Taf. I, Fig. 12.

Utr. Mus. Cat. No. Tupaja No. 244 a. III. 19.

Uterus verdickt. 1 Embryo im Lumen.

Ovarium 79 Serienschnitte.

2 frische corpora lutea.

4 grosse Follikel, bei zweien die Eizelle allein, bei den andern auch das Follikelepithel degenerirt, zahlreiche mittelgrosse Follikel grösstentheils degenerirt. Mässig viel Primairfollikel, dementsprechend weniger Eizellen im Deckepithel.

i. Ovarium am Ende der Graviditaet. Taf. I, Fig. 13.

Utr. Mus. Cat. $\mathrm{N}^{0}$. Tupaja No. 260, 6. VI. 12.

Im Uterus ein beinahe ausgetragener Fötus.

Ovarium 128 Serienschnitte.

Kein deutliches corpus luteum, im stroma blos einige, beinahe resorbirte Ueberreste, keine reifen oder grösseren Follikel. Zahlreiche mittelgrosse und kleinere Follikel, alle in mehr oder weniger weit gefürdertem Zustand von Atresie. Zahlreiche Primairfollikel, grösstentheils normal, dementsprechend auch häufig Eizellen im Deckepithel.

\%. Ovarium im Beginn des L'uerperiums. Taf. J, Fig. 14.

Utr. Mus. Cat. No. Tupaja N". 33. a. III, 6.

Utcrus stark verdickt, gerunzelt, von blauer Farbe, mit der Loupe Blutgefisse erkennbar. Lumen mit Fibrinpfropf und Detritus gefüllt. Epithel in Regeneration. Placentarstelle noch zu erkennen.

Ovarium 54 Serienschnitte.

Kein corpus luteum, kein reifer Follikel. Zahlreiche mittelgrosse Follikel in stark degenertirtem Zustande. 
Wenig Primairfollikel und wenig Eizellen im Deckepithel.

Aus diesen 7 Typen ergiebt sich im Wesentlichen alles, was bei schwacher Vergrösserung am Ovarium zu erkennen ist. Von dem oben erwähnten Standpunkte ausgehend, lässt sich ausserdem feststellen, dass 1, 2, 3, 4 und 6 jugendliche Individuen waren, während 5 und 7 bereits in reiferen Alter sich befanden zur \%eit ihres Todes.

Zur weiteren Uebersicht seien hier noch in kurzem die Daten weiterer Durchschnitte gegeben.

Utr. Mus. Cat. No. Tupaja N". 67. Taf. I, Fig. 15.

Gravidität im ersten Stadium: ein Embryo im Oviduct. Im Ovarium derselben Śeite ein corpus luteum, alle Follikel atresirt.

Die sehr spärliche Anzahl der Primairfollikel lässt auf höheres Alter der Trügerin schliessen.

Utr. Mus. Cat. $N^{n}$. Tupaja $\mathrm{N}^{\prime \prime} .140$.

Spätpuerperculer, runzeliger Uterus mit völlig regenerirtem Epithel. Blut in der Mucosa uteri lässt auf einen abgelaufenen menstruellen Process schliessen.

Wie Fig. 15 von einem älteren Individuum: 1 corpus luteum deutet auf eine abgelaufene Ovulation hin; 1 mittelgrossel Follikel ist scheinbar normal, die kleineren sind hyalin degenerirt; auch die Hilusgefässe haben stark hyalin verdickte Wände.

Utr. Mus. Cat. $\mathrm{N}^{0}$. Tupaja $\mathrm{N}^{n} .24$.

Spät puerperaler Uterus mit vïllig regenerirtem Epithel.

Im Ovarium ein reifer scheinbar normaler Follikel, während sonst zahlreiche atretisch sind.

Utr. Mus. Cat. No ${ }^{0}$ Tupaja $N^{0} .205$.

Erste Hälfte Gravidität. Embryonen in Utero.

Im einem Ovarium auf 24 Durchschnitten fünf colpora lutea.

Utr. Mus. Cat. $\mathrm{N}^{0}$. Tupaja $\mathrm{N}^{0}$. 320.

Elstes Stadium Gravidität. In den Ovarien 4 frische corpora lutea.

Utr. Mus. Cat. $\mathrm{N}^{0}$. Tupaja $\mathrm{N}^{0} .238$.

Spütpuerperaler Uterus mit regenerirtem Epithel und Epithelpfropf (Placentareste?) im Lumen.

Ein reifer, scheinbar normaler Follikel und 3 corpora lutea auf 71 Schnitten.

Utr. Mus. Cat. No. Tupaja No. 265.

Erste Hälfte Graviditüt: ein grösserer Embryo. 3 corpora lutea, die bereits grösstentheils resorbirt sind. Alle grösseren Follikel atretisch.

Utr. Mus. Cat. N". Tupaja No. 318. 129 Serienschnitte.

Utr. Mus. Cat. $\mathrm{N}^{0}$. Tupaja $\mathrm{N}^{0}$. 248. 126 Serienschnitte.

In diesen beiden letzten Fällen wurde in den Uteri nichts gefunden, was auf Schwangerschaft, Puerperium oder Menstruation deutet. In der That sprechen auch die noch ziemlich frischen corpora lutea als Zeichen der eben verstrichenen, andererseits die normalen, anwachsenden Follikel als Zeichen der herannahenden Ovulation mit grosser Wahrscheinlichkeit für ein intramenstruelles Stadium. 
Auf' Grund der gegebenen Befunde lässt sich jetzt, beiläufig erwähnt, bereits eine Frage, für Tupaja wenigstens, entscheiden, die zuerst DE SINETY im Jahre 1877 (a. o.) angedeutet hat.

Trie oben elwähnt, suchte DE SiNETY hanptsächlich gestützt auf Befunde am Ienschen, gewisse Characteristica des Corpus luteum als Kennzeichen der Veränderung des Ovariums durch die Schwangerschaft aufzustellen und fügt hinzu, dass es ihm den Ein. druck gemacht habe, dass auch die Zahl der atretischen Follikel viel zahlreicher in als ausserhalb der Schwangerschaft seien.

Bei Cavia cobaia und einigen anderen Thieren konnte er dies nicht finden.

Für Tupaja lässt sich nun behaupten, dass nicht nur die regelmässige Atresie aller grösseren Follikel auch in der Schwangerschaft vorhanden 1st, sondern dass die Atresie sämıntlicher Follikel sogar das wichtigste Kennzeichen der stattgehabten Befruchtung abglebt. Mit anderen Worten: bei Tupaja atresiren nach erfolgter Befruchtung sämmtliche Follikel, sobald sie eine gewisse Grösse erreicht haben, es findet während der Schwangerschaft keine Eireifung mehr statt.

Bevor wir jedoch die weiteren schlussfolgerungen aus dem bereits Gesagten ziehen, ist es wünschenswerth, die gewonnenen Befunde durch die weiteren Detailuntersuchungen zu vervollständigen und nun zunächst den Lebenslanf der Eizelle ron ihrem ersten Entstehen an bis zur Resorption ihrel im Corpus luteum zurückgebliebenen Hülle innerhalb des Eierstockes zu verfolgen.

Die Tafeln III - V enthalten die verschiedenen Phasen der fortwährenden Umwandlung der Elemente des Ovariums in ihren wichtigsten Erscheinungen.

Bei cher Darstellung sind hier jedoch die sog. Hilusdrüsen oder Harz'schen segmen. talzellen nicht weiter berücksichtigt, da die obenerwähnten Untersuchungen von $W_{A} \mathrm{~L}^{*}$ deyer, Paladío, Mac Leod, var Benedex, Borx und Harz zur Genüge bewiesen haben, dass dieselben nur eine entwickelungsgeschichtliche, keineswegs aber irgend welche functionelle Bedeutung für das Ovarium haben. Der Tollständigkeit halber sei jedoch erwähnt, dass sie in sämmtlichen Ovarien von Tupaja $\mathrm{zu}$ finden waren, und stets nit den Hilusgefïssen zusammen in das Stroma eintretend, sich zwischen den Follikeln mehr weniger tief durch das Stroma hinziehen, wie aus Taf. I ersichtlich ist.

Sehn wir von den Hilusdrüsen im Weiteren ab, so blei ben als wesentliche Elemente des geschlechtsreifen Ovariums las Parenchym und das stroma der näheren Betrachtung vorbehalten.

Wir vermeiden es absichtlich, schon hier auf eine weitere Discussion über den Begriff Parenchym und Stroma einzugehn, und wollen hier nur anführen. dass wir uns im folgenden auf den Standpunkt Ludwigs stellen, wonach unter Parenchym alle Derivate des Keimlagers, unter stroma alles vom Hilus her eintretende Bindegewebe gemeint ist.

Die hier gegebene Untersuchung ist das Endresultat sämmtlicher Beobachtungen von tausenden von Einzelobjecten, und die bildlichen Beispielen sind mit Absicht so gewählt, das sich analoge Verhältnisse beinahe auf jedem beliebig rorgenommenen Objecte zurückfinden lassen. 
Der Entwickelungsgang stellt sich, einheitlich betrachtet, folgendermassen dar.

Im Deckepithel finden sich im geschlechtsreifen Eierstock von Tupaja zu allen Zeiten Eizellen, die zunächst durch Grösse und hellere Farbe von ihren Nachbarn sich unterscheiden. Bei jugendlichen Individuen ist auf jedem Durchschnitt unter 10 bis 15 Cylinderzellen mindestens eine, die sich in genannter Weise auszeichnet.

Auf Taf. III, Fig. 1 sehn wir neun Keimzellen von der Oberfläche eines jugend. lichen Tupajaovariums. Die zweite Zelle von rechts her ist bereits heller und grösser als die andern; die sechste von rechts her hat bereits einen solchen Einfluss auf ihre Nachbarzellen, dass dieselben sich in leichtem Bogen über sie linkrümmen.

In Fig. 2 ist dieses Verhältniss noch deutlicher; l'ig. 3 und 4, die von einem etwas schräg verlaufenden Schnitte herstammen, illustriren auf das deutlichste, wie die Nachbarzellen allmählig eine Umhüllung um die jugendliche Eizelle formen; auf derselben Figur sieht man neben den beiden, deutlich durch Grösse und Farbe characterisirten Eizellen rechts eine dritte, die, obgleich nur wenig grösser und heller als ihre Nachbarzellen, doch mit grosser Wahrscheinlichkeit als ein jüngeres Stadium einer Eizelle auf. zufassen ist.

Kehren wir zu Fig. 2 zurück, so sehn wir neben der noch völlig im Keimlager liegenden Eizelle mehr nach rechts zwei wenig grössere, die sich mit den sie umgebenden dunkleren Deckzellen in das Bindegewebe einsenken, ein Vorgang, den Paladino sehr zutreffend als "una invaginazione dell' epitelio germinativo" bezeichnet.

Obgleich sich im Stroma in dieser Zeit noch keine kariokinetischen Kernfiguren mit Sicherheit nachweisen lassen, so beweisen doch verschiedene grössere und hellere Zellen derselben, dass es auch in diesem frühen Stadium für das freundliche Entgegen. kommen des Keimepithels nicht ganz unempfänglich ist.

Neben den beiden erwähnten Eizellen finden sich rechts und links zwei rundliche Haufen von dunklerem Epithel, die sich bei Verstellung der Mikrometerschraube als Epithel ganz junger, durch das Stroma isolirter Primairfollikel erkennen lässt. Fig. 5 zeigt einen gleichgrossen Primairfollikel im Durchschnitte.

In seiner ersten Entwickelungsstufe stellt somit der Primairfollikel ein Gebilde dar, dessen noch verhältnissmässig kleine Eizelle von einer dicken Lage von Keimepithel um. geben ist.

Nun folgt ein stärkeres Wachsthum der Eizelle, wodurch die Epithelzellen ausge. zogen und abgeplattet werden. Dieser Vorgang wird durch Durchschnittsbilder, wie Fig. 6, 7, 8, sowie die vier grösseren Follikel von Fig. 2 bewiesen, weil auf denselben trotz der grösseren Ausdehnung des Follikels doch die Zahl der durchschnittenen Zellen übereinstimmt mit der von Fig. 5 .

Gleich SchotтläNder (32) kann auch ich constatiren, dass die Eizellen nicht gleichmässig kugelförmig sind, wie NAGEL u. a. angeben.

Nach SchotrtäNder spricht das Wechseln von kreisförmigen und elliptischen Durch. schnittsbildern für die gemeinschaftliche Eiform.

Ohne mir über ScноттLäNDER's Befunde an andern Thieren ein Urtheil zu erlauben, 
muss ich für Tupaja constatiren, dass die kreisförmigen Durchschnitte einen Durchmesser haben, welcher dem grössten Durchmesser der Ellipsen entspricht, demnach müssen die Eizellen die Form einer von oben und unten her abgeplatteten Kugel haben, und nicht die eines Ei's oder einer Ellipse, was nur dann der Fall sein könnte, wenn der Durchmesser des Kreises dem kleineren Durchmesser der elliptischen Figur entspräche.

Der Periode der ersten Streckung des Follikels folgt nun unter fortwährendem, doch etwas langsamerem Wachsthum der Eizelle eine stärkere Vermehrung der Follikelzellen.

Fig. 9, 10, 11, 11 $几$, illustriren dieses Stadium. Die Analogie mit den übrigen Entwickelungvorgängen lässt als gewiss annehmen, das diese Vermehrung auf dem Wege der indirecten Kerntheilung vor sich geht. Die grossen hellen Follikelzellen von Fig. 10 sprechen dafür. Dass der Vorgang selbst bildlich nicht dargestellt werden kann ist leicht verständlich, wenn man bedenkt, dass die platten Zellen auf allen Durchschnitten in ihrem schmalen Durchmesser getroffen sind, dass hingegen diejenigen Zellen des Follikelepithels, deren grösste Ausdehnung Kariokinesen erkennen lässt, stets einem tangentialen Durchschnitt eines Follikels angehören müssen, und deshalb bei der Kleinheit des Gesammtobjects auch auf Serienschnitten nicht mit Sicherheit als zum Follikel gehorrig erkannt werden können.

Im weiteren Verlauf umgiebt sich die stets wachsende Eizelle mit einer mächtigen Lage von einschichtigem Cylinderepithel, das rasch mehrschichtig wird. In diesem Stadium lassen sich stets in grosser Anzahl kariokinetische Figuren erkennen, wie sie in Fig. 12 und 13 abgebildet sind. Die zahlreichen grösseren und helleren Zellen dürften wohl nichts anderes sein, als Vorstadien des mitotischen Processes.

Während sich diese Vörgange im Follikel abspielen, betheiligt sich auch das Stroma immer lebhafter an den WVachsthumsvorgängen. Die kurzen, kleinen Spindelzellen werien grösser, heller, langgestreckter, mehr und mehr zeigen sich auch in der Umgebung des Follikels die charakteristischen Mitosen, und zwar folgt die starke Anbildung stets dem Laufe der Gefässe, was sich leicht durch Vergleichung von Serienschnitten nachweisen lïsst.

$\mathrm{Da}$ diese Vorgänge sich besser im Zusammenhang an grösseren Objecten studiren lassen, sehn wir hier vorläufig davon ab und wenden uns wieder dem Follikel selbst zu. Nachdem das Follikelepithel, die Granulosa, eine gewisse Ausdehnung erreicht hat, lässt sich bald erkennen, dass die Zellen sich in zwei ziemlich regelmässig geschichtete Lagen theilen, deren ïussere (Fig. 14) als hohes, ziemlich regelmässiges Cylinderepithel die äussere Begrenzung des Follikels bildet, während die innere sich in regelmässiger Anordnung um die Eizelle gruppirt, von ihr geschieden durch die Zona pellucida, deren radiaere Streifung an den gehïteten und in Balsam eingebetteten Objecten selten mehr leutlich nachweisbar ist.

Zwischen diesen beiden Epithellagen bleibt eine mediane Zone übrig, in der die Zellen weniger regelmässig angeordnet sind und die Kerne durch die Volumzunahme der Zellen mehr auseinander gedrängt werden. Man sieht bald einzelne Kerne, die sich schwï- 
cher färben, innerhalb von Zellen, deren Conturen mehr und mehr von ihrer Schäres ein. büssen, bis schliesslich der Kern frei in einer grossen Vacuole zu schwimmen scheint.

Schon in Fig. 13 sind die ersten Anfänge dieser Verflüssigung einzelner Zellen zu sehn; in Fig. 14 sind bereits einzelne Hohlräume confluirt, wobei sie jedoch meist noch deutlich die Schattenbilder der vergrösserten Zellen erkennen lassen, aus denen sie entstanden sind.

In den am meisten nach links gelegenen Hohlräumen derselben Figur bemerkt man auch zwei lose in der Flüssigkeit schwimmende Kerne, die noch nicht verflüssigt sind, und noch mehr oder weniger deutlich die Contur der Zelle erkennen lassen, die ihnen angehörte.

Der Umstand, dass auf dem Durchschnitt die Kerne ebenso gross sind wie die der übrigen Follikelzellen, dass dagegen ihr Abstand von einander grösser ist, beweist, dass es nur das Protoplasma der Zelle ist, welches sich vergrössert, wodurch wieder auf jedem Durchschnitt nur einzelne Kerne der ihn bildenden Zellen zu sehn sind.

Dieser Verflüssigungsprocess, die Bildung des Liquor folliculi, findet in der ganzen Peripherie um die Eizelle hin statt, die kleineren Spalträume confluiren allmälılig zu grösseren, die von einem stets sich vermehrenden Lager von Granulosazellen umschlossen werden. (Fig. 15\%.

Je mächtiger die Masse des Liquor folliculi sich anbildet, desto mehr wird die Eizelle mit den sie umgebenden Epithelzellen von der äusseren Peripherie abgehoben, und schliesslich bleiben nur noch einzelne Epithelbrücken im Verband, von denen meist eine besonders mächtig entwickelt bleibt.

Der Cumulus proligerus bildet demnach bei Tupaja nicht, wie beim Menschen, eine wandständige Verdickung in der Granulosa, sendern bleibt stets mehr weniger central im Follikel gelagert.

Auch in den grössten Follikeln erreicht die Gesammtmasse des Liquor niemals eine solche Mächtigkeit, wie z. B. bei Tarsius und beim Menschen, seine Grenzlinie gegen das Granulosaepithel ist niemals scharf, sondern verliert sich in einzelne grössere und kleinere Spalträume zwischen einzelne Zellen hinein. Die Durchschnittsfigur bildet demnach bei seiner vollen Ausbildung je nach der Schnittrichtung die Form eines gezackten Halbmondes oder einer zackigen, in der Mitte durchbrochenen Scheibe, wie dies auf Taf. I an verschiedenen Beispielen zu sehn ist.

Während der Follikel in dieser. Weise sich vergrösselt, hat sich auch im Stroma mehr und mehr die dem Follikel zunächst liegende kugelmantelförmige Schicht in der Weise differenzirt, dass sie schon bei sehr schwacher Vergrösserung durch ihre viel hellere Färbung und durch die circuläre Streifung ihrer Elemente von deln übrigen Ovari. alstroma sich unterscheidet, weshalb sie auch als Theca folliculi vom übrigen Gewebe unterschieden wird.

Betrachten wir nul den reifen Follikel und Theca gemeinschaftlich, wie sie sicl in Fig. 17, 18, 19 und 20 darstellen. Dass ich mir erlaube, den hier abgebildeten Follikel als reif zu bezeiclinen, geschieht, weil es zunächst der grösste war, den ich überhaupt 
finden konnte, zweitens aber, weil er dem oben unter den Typen als Nu. 2 beschriebenen Ovarium entstammt, zu welchem ein menstruirender Uterus gehörte.

Wenn ich auch die Eizelle als reif bezeichne, so möchte ich das im Sinne HEAPE's aufgefasst wissen, der "ripe" und "mature" ovarian ovum unterscheidet.

Um diesem von HEAPE aufgestellten Unterschied gerecht zu werden, scheint mir die Bezeichnung "reif" und "befruchtungsfähig" am meisten dem Sinne entsprechend, den HEAPE mit "ripe" und "mature" gemeint hat.

Vergleicht man die in Fig. 17-20 abgebildeten Theile des reifen Follikels mit den früheren Stadien, so fällt zunächst die ausserordentliche Grössenzunahme der Eizelle auf. Sie hat noch immer eine etwas abgeplattete Kugelform, obschon sie sich mehr der Kugelgestalt nähert.

Das Protoplasma hat sich in zwei mehr oder weniger von einander differenzirte Schichten geschieden, deren äussere dunkler und körniger erscheint.

Zugleich sei darauf aufmerksam gemacht, dass der Eikern in diesem, wie in einigen analogen Fïllen stark excentrisch liegt, ein Umstand, worauf ich später noch zurückkomme.

Das Chromatin des Eikerns ist intensiver gefärbt, als bei den etwa gleichgrossen Eikernen der früheren Stadien.

Die Eizelle ist scharf gegen die Zona pellucida abgegrenzt. Das dieser wiederum aufgelagerte Epithel zeigt ziemlich regelmässigen cylindrischen Bau, doch ist die Zahl der Mitosen viel geringer als im reifenden Follikel.

Während die Kerne ungefähr dieselbe Grösse haben, ist dagegen der Umfang der Granulosazellen bedeutend grösser, namentlich die peripherisch gelegenen nehmen zum Theil solche Grössen an, dass eine Verwechselung mit jungen Primairfollikeln nicht ganz undenkbar erscheint.

Die scharfe Kreislinie, womit der Follikel gegen die Theca abgegrenzt ist, beweist die starke Spannung, unter der sein Inhalt steht, ein Umstand, worauf hier besonders aufmerksam gemacht sei.

Besonders interessant, gerade bei Tupaja, ist die Structur der Theca folliculi. Die in Fig. 17 bis 20 gegebenen Theile überheben mich einer ausführlichen Beschreibung. Wie aus diesen dioptrischen Zeichnungen auf das deutlichste hervorgeht, besteht die Theca ausschliesslich aus eineın dichten Flechtwerk von feinsten, in Wucherung begriffenen Capillaren, die zur Zeit der Follikelreife grösstentheils bereits mit Blut gefüllt sind, während an dem noch reifenden grösseren Follikel Fig. 15 die Gefissendothelien noch in lebhafter Wucherung verschiedene Mitosen zeigen, jedoch noch grösstentheils geschlossene, oder wenig ausgedehnte Lumina besitzen.

Angesichts solcher sprechenden Befunde klingt es beinahe wunderbar, dass man heutzutage darüber noch nicht einig ist, während Hı (12) bereits im Jahre 1865 schrieb (p. 171): „Im Umfang grösserer Follikel sind Bluträume, ror welchen die ichten corpora cavernosa wenig voraus haben. Das Entscheidende liegt nicht in der Weite der Gefässe, als darin, dass ausser der modificirten Gefässwand kcin Geweb vorhanden ist."

Ich habe mit den so sehr viel besseren Hülfsmitteln heute nicht melır finden kön. 
nen, als His vor 30 Jahren und kann seine Worte nur voll und ganz unterschrejben. Auf das Zutreffende der Vergleichung mit eimem Corpus cavernosum komme ich weitr.r unten zurück.

Weniger glücklich, wenn auch der Sache nach nicht allzu abstrus, ist die von einem amerikanischen Gynaecologen, Förster ') gewählte Vergleiclung del' 'Theca mit einem Endotheliom. Der pathologische Beigeschmack wirkt entschierlen stïrend.

Neben dieser Bestätigung der His'schen Befunde auch für 'Tupaja kehrten bei vel: schiedenen Präparaten zu wiederholten Malen Stellen zurück, wie eine in Fig. 19 abgebildet ist. Man sieht hier, wie sich eine wuchernde Endothelzelle der 'Theca zwischen das Epithel der Granulosa hineinschiebt. Dass es sich um eine Endothelzelle und nicht um ein weisses Blutkörperchen handelt, geht aus der Zeichnung ohne weiteres hervor.

Eine analoge Erscheinung hat Ruge (19) bei seiner schönen Beschreibung der degenerirenden Eier von Siredon pisciformis 'Taf. XIX, Fig. 21 abgebildet. In seinem Falle nimmt Ruge an, dass es sich um ein weisses Blutkörperchen handele, und das die Erscheinung aufzufassen ist, als ein Zeichen beginnender Degeneration.

Ich erwähne dies hier und behalte mir vor, auf diese scheinbare Differen\% in der Auffassung an sich ähnlicher Befunde weiter unten zurückzukommen.

Mit den oben beschriebenen Processen ist die völlige Ausbildung des Follikels noch nicht abgeschlossen. Allerdings haben mit der Reife sowohl Follikel als Eizelle ihre grösste Ausdehnung erreicht, doch steht ihnen noch eine letzte Metamorphose bevor, die den reifen Follikel befruchtungsfähig macht.

Fig. 21 und 22 (Taf. IV) geben die Eizelle und einen Theil der Wand des , hefruchtungsfähigen Follikels" wieder. Um mit der Eizelle zu beginnen, so kann man leicht erkennen, dass dieselbe belangreiche Veränderungen erfahren hat.

Zunächst ist ihr Unfang kleiner geworden, das Protoplasma zeigt eine schärfere, geschlängelte Körnung, die mehr weniger radiär nach dem Eikern zu verläuft, der vällig wandständig geworden ist.

Der Eikern hat seine scharfe Umgrenzung verloren, die Chromatinkörper liegen scheinbar fiei in der Eizelle, ihr gemeinschaftliches Volum ist geringer, ihre Färbung noch intensiver als bei dem reifen Follikel.

Der Eizelle dicht anliegend sieht man dicht nebeneinander zwei kleine scharf umschriebene intensif gefärbte Chromatinkugeln, - das ausgestossene Richtungskörperchen.

Die Zona pellucida s. radiata hat ebenfalls bedeutende Veränderungen erlitten. Es macht den Eindruck, als ob sie, in gewissem Sinne cogulirt ist. Längs der ganzen Peripherie finden sich längliche hellere Rüume, die durch etwas dunklere Zonen von einander geschieden sind. Diese letzteren contluiren in einer peripher gelegenen Schicht, welcher die bedeckenden Granulosazellen weit weniger regelmässig aufsitzen, jedoch zum Theil mit derselben zu verschmelzen scheinen.

Unter den Granulosazellen finden sich die oben beschriebenen durch ihre Grösse aus-

1) American journal of obstetrics 1893. 
gezeichneten, jetzt auch in der Ungebung der Eizelle, nicht nur in der Peripherie des Follikels.

Die peripheren Granulosazellen sind im allgemeinen wenig von denen des reifen Follikels unterschieden, doch finden sich noch weniger Mitosen und endlich finden sich Wucherungsprocesse der Thecagefässe zwischen den Follikelzellen noch häufiger; es lassen sich selbst mit Blutkörperchen gefüllte Gefässzapfen zwischen einzelnen Granulosazellen in der Peripherie nachweisen.

Wir begnügen uns hier vorläufig mit der Wiedergabe der an verschiedenen Objecten angetroffenen Befunde, der die Heape'schen Entdeckungen auch für Tupaja bestätigt.

Das hier gezeichnete Ei entstammt einem Ovarium, in welchem sich neben 4 reifen noch ein diesem analoges Ei befand. Im Uterus lagen abgestossene Epithelien, zahlreiche, zum Theil veränderte, Blutkörperchen und gelbliche Coagula, das Epithel der Alucosa war theils in Ambildung, theils schon regenerirt, die Gefässe waren strotzend gefüllt - alles Zeichen der abgelaufenen Menstruation. - Kein Zeichen einer stattgehabten Befruchtung war aufzufinden, weder ein befruchtetes Ei, noch Spermatozoën.

Auf Tafel IV, Fig. 23-27 ist ein eben geplatzter Follikel und dessen eben befruch. tetes Ei abgebildet.

Die Figuren 26 und 27 geben in einer Vergrösserung von 140 ein Uebersichtsbild der einschlägigen Verhältnisse.

Fig. 26 zeigt das Ei mit den ihm noch anhaftenden Follikelzellen in der Tube, in der sich auf andern Schnitten neben Haufen von Granulosazellen auch Stromagewebe und losgerissene Primairfollikel fanden. Fig. 27 zeigt den zugehörigen leeren Follikelbalg mit den angrenzenden Theilen des Ovariums.

Der Uebersicht halber ist das befruchtete Ei mit Richtungskörper, in dem sich männlicher und weiblicher Pronucleus noch nicht vereinigt gegenüberstehn, hier auch in Vergrösserung von 800 abgebildet. (Man vergleiche dasselbe bei Hubrecht, Phylogenese etc.) Hier sei nur darauf aufmerksam gemacht, dass das befruchtete Ei wiederum erheblich an Grösse eingebüsst hat, verglichen mit dem befruchtungsfähigen, sowohl als mit dem reifen Ei. Unter den Granulosazellen, die der Eizelle nur noch lose anhaften, zeigen verschiedene Zeichen von beginnender Degeneration.

Ausserordentlich wichtig für den vorliegenden Zweck ist das Verhalten des Follikelbalgs Was zunächst das Granulosagewebe betrifft, so lehrt uns schon Fig. 27, das der grösste Theil derselben im Ovarium zurückbleibt.

Bei stärkerer Vergrösserung selın wir, dass die einzelnen Zellen noch roluminöser und heller sind, als in den früheren Stadien, und dass ihr Verband loser erscheint, vielleicht nur in Folge der verıninderten Spannung.

Ein vergleichender Blick auf das Thecagewebe bestätigt besser als lange Erklärungen das Zutreffende des His'schen Vergleiches mit einem Corpus cavernosum.

Durch starke Füllung mit Blut in Augenblicke, wo durch das Springen des Follikels der Inhaltsdruck herabgesetzt ist, hat das Volumen der Theca um mehr als das doppelte zugenommen, wie die Figuren 24 und 25, verglichen mit Fig. 22, 15, 19 und 20 auf das schlagendste beweisen. 
Das weitere Schicksal der ausgestossenen Eizelle hat uns hier nicht weiter zu beschüftigen.

Von Wichtigkeit sind dagegen die Processe, die den Follikelbalg zum Corpus luteun umwandeln und schliesslich zu dessen Resorption führen.

Taf. V. Fig. 28, 29 und 30 enthalten verschiedene Stadien dieses Processess, und zwar gehören die beiden ersten Figuren einem ganz frischen Stadium an, das durch allerjüngste Embryonen im Lumen des Uterus zu bestimmen war. Fig. 30 zeigt lie Reste eines Corpus luteum nach einer Menstruationsperiode, da dasselbe sich in dem oben beschriebenen Ovarium zur Zeit der Menstruation neben neu herangereiften lol. likelı vorfand.

Was zunächst das erste Stadium betrifft, so beweist auch hier wieder ein Blick auf die Präparate mehr als lange Erklärungen.

Man sieht ohne weiteres, dass das Grundgewebe cles Corpus luteum aus den zurückgebliebenen Granulosazellen besteht, zwischen denen ein dichtes, von den Endothelzellen der stark wuchernden Theca ausgehendes Gefässnetz sich verzweigt.

Einzelne Durchschnitte, namentlich von Fig. 29, beweisen aufs deutlichste, dass es sich bei der Neubildung der Gefässverzweigungen um gewucherte Endothelsprossen handelt, die nachträglich hohl geworden sind und mit dem Muttergetäss communiciren, also derselbe Vorgang, wie er bei der Wundheilung beobachtet wird.

Die Granulosazellen sind mächtig gewachsen, doch ist auch hier wieder zu bemerken, dass die Vergrösserung nur die Zellen, nicht die Kerne betrifft, welche die gleiche Grösse als im reifen Follikel besitzen. In einzelnen Zellen sieht man Vacuolen sich bilden, andere verlieren die scharfe Contour und lösen sich allmählig auf.

Im späteren Stadium, das Fig. 30 darstellt, sind in der Umgebung der Gefässe hyaline Schollen angelagert, diese selbst sind grösstentheils hyalin degenerirt, ihr Lumen verkleinert, zum 'Theil selbst verödet, bis schliesslich das ganze Gewebe eine hyaline oder kleinkörnige Masse darstellt, die zuletzt als längerer Streifen zwischen den neugewucherten Follikeln, den Gefässen folgend, von der Peripherie nach dem Hilns hinzieht und bald ganz verschwindet.

Der Bluterguss in der Mitte des Corpus luteum ist bei Tupaja kein constanter Fac. tor, es ist im Gegentheil zu constatiren, dass sich weit mehr Corpora lutea ohne den. selben finden.

Obgleich das ausgebildete Corpus luteum, wie an den ersten zivei Tafeln ersichtlich, den reifen Follikel an Grösse übertrifft, so ist der Unterschied doch nicht so auffallend, wie bei andern Säugethieren und beim Menschen.

Wir begnügen uns deshalb hier mit der kurzen Erwähnung der hier constatirten Thatsachen, und behalten uns vor, auf die Morphologie bej Tarsius ausfülırlicher zurtickzukommen, dessen mächtig entwickelte Corpora lutea zum studium besonilers geeignet erschienen.

Es erübrigt nun noch, der Follikelatresie zu gedenken. Da dieselbe in der letzten Zeit bei den verschiedensten Thierspecies in sorgfültigster Weise untersucht worten ist, 
so handelt es sich im wesentlichen darum, die beobachteten Erscheinungen bei Tupaja auch nachweisen zu können.

Die verschiedenen hervorragenden Arbeiten auf diesem Gebiete, die mit HExNEGLY $(21,13)$ ihren Abschluss gefunden haben, sind eingangs bereits gewürdigt worden.

Wir können für Tupaja nur bestätigen, was bereits an andern Säugethieren ge. funden ist.

Die Fig. 31 bis 37 mögen als Belege dienen, dass sich auch bei Tupaja alle bekannten Formen der Follikelatresie in buntem Wechsel finden, und dass dieselben sowohl Eizelle als Granulosa, bald die eine, bald die andere in staerkerer oder schwăcherer Weise ergreifen. Dass auch die „dégénerescence par fragmentation", die Hexxegcr einführte, vorkomt, beweist Fig. 36 .

Eine kurze Besprechung verdient Fig. 38, die einen Zustand darstellt, der unseres Wissens noch nicht in dieser Weise beobachtet ist.

Die hier abgebildete Eizelle entstammt einem Ovarium (Utr. Mus. Cat. No. 201) in dem sich neben 4 grossen ganz frischen Corpora lutea 2 scheinbar normale reife Follikel fanden. Bei starker Vergrösserung zeigte der eine der Follikel eine reife Eizelle mit hyalin degenerirtem Eikern, der andere enthielt die hier abgebildete Eizelle.

Der zugehörige Uterus war leer, doch im Oviduct derselben Seite befanden sich vier befruchtete Eier im allerersten Stadium.

IVir haben es hier also mit einer Eizelle zu thun, die bereits im befruchtungsfähigen Stadium war, als sie anfing zu degeneriren. Ob das Richtungskörperchen bereits aus. gestossen war, liess sich auf den übrigen Durchschnitten nicht constatiren, da dieselben keine ununterbrochene Serie darstellen. Die Zeichnung spricht indessen dafür, dass dieser Vorgang eben im Begin ist und das Richtungskörperchen noch nicht die Eizelle verlassen hat.

Uin noch schliesslich der Löwenthal'schen Befunde zu gedenken, der chromatolytische Processe bis hinauf in die Eizellen des Deckepithels beobachtet haben will, so müssen wir sagen, dass wir seine Beobachtungen für Tupaja nicht bestätigen können.

Da das uns zur Verfügung stehende Material von Tupaja reicher war, als irgend ein vor einem früheren Untersucher benutztes, da wir dadurch in der Lage waren, jede einzelne der hier mitgetheilten Beobachtungen durch zahlreiche analoge Falle zu stützen und zu sichern, so glaubten wir uns berechtigt, all der Hand der bei Tupaja allein erhobenen Befunde die bisherigen Beobachtungen kritisch zu beleuchten, resp. zu erweitern, um dadurch die Controluntersuchungen an den übriger Species mehr abzurunden und gleichmässiger gestalten können.

Wir konnten dies um so ruhiger thun, als einzelne vorfăufig untersuchte Objecte der andern Species unsere Vermuthung bestätigten, dass wir im Grossen und Ganzen dieselben Resultate zu erwarten hatten.

Wir haben eingangs bereits erwähnt, dass bezüglich der postfötalen Entwickelung von Eizellen aus dem Deckepithel die Ansichten noch sehr getheilt sind.

Seit WALDEIERS klassischer Arbeit haben sich verschiedene Untersucher mit der 
Frage beschäftigt. Die letzten und wichtigsten derselben, die an den verschiedensten Thie.

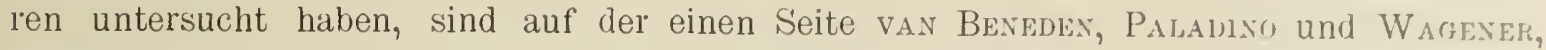
welche in allen Fällen die Waldeyer'schen Befunde bestatigen konnten, an der andern Seite Harz und SchotTländer, welche die Eizellen nicht stets oder gar nicht fanden.

Was zunächst Schottländers Befunde am menschlichen Eierstock Erwachsener betrifft, so ist oben bereits erwähnt worden, dass seine Objecte nicht einwandsfrei waren.

Er untersuchte 7 Eierstöcke; drei derselben entstammten Frauen, die im Puerperium an Sepsis gestorben waren, 3 andere Gebärenden, die einel Blutung erlegen wal'en, das letzte endlich einer Frau, die nach Operation eines Cervixmyoms starb.

Da myomatoese Processe, wie Bulius und Stratz an einem grossen Material nach. gewiesen haben; stets mit oophoritischen Processen gepaart sind, verliert das letzte der genannten Objecte sehr an Werth; die sechs andern entstammen Fällen, die durch Schwangerschaft und Puerperium nebst pathologischen Processen stark getrübt sind.

Den negativen Befunden von SchottuäNder stehn die stets positiven von Paladino an weiblichen Ovarien in jeder Phase, in jedem Lebensalter diametral gegenüber, und haben wegen des reicheren Materials, der sorgfältigen Beachtung der Nebenumstände (Schwangerschaft, die von ScHотTuäNDER nicht einınal berücksichtigt ist) entschieden mehr Werth.

Was die übrigen Befunde Schottländers, sowie einzelne von HARz betrifft, so lässt sich nur sagen, dass das Nichtfinden der Ei\%ellen noch kein Beweis ist, dass sie auch nicht vorhanden waren, umsomehr, als diesen Befunden andere von sorgfältigen Beobachtern gegenüberstehn, die zum Theil selbst an den nämlichen Objecten gearbeitet haben und die Eizellen stets fanden.

Was unsere Beobachtungen an Tupaja betrifft, so können wil zunächst bestätigen, dass auch wir die Eizellen im Keimepithel in jedem der untersuchten Ovarien, also in sämmtlicheı Phasen des Geschlechtslebens angetroffen haben.

Wir können ferner behaupten, dass dieselben um so zahlreicher waren, je jüngel das betreffende Individuum war, und fanden, dass die Zahl der Eizellen mit der Anzahl der Primairfollikel in directem Zusammenhang stand, d. h. je mehr Primairfollikel, desto mehr Eizellen in Keimepithel. Die bei Tupaja erhobenen Befunde bestätigen somit aufs neue die zuerst von PaLADiNo scharf formulirte Thatsache, dass im Säugethiereierstock ein "movimento perenne di rigenerazione" eine fortwährende Neubildung aus dem Keimepithel stattfindet.

Was die postembryonale Bildung von sogenannten Pflüger'schen schläuchen betrifft, so finden sich bei Tupaja nur selten analoge Gebilde, Fig. 2 gestattet jedoch die Annahme derselben. Mit Schotrläxder sind wil geneigt, dies als einen zufälligen Befund aufzufassen, dadurch entstanden, dass die Wucherung des Stromas mit der Wucherung des Deckepithels nicht gleichen Schritt gehalten und darum die einzelnen zusammen tiefer tretenden Follikel noch nicht von einander geschieden hat.

Es muss jedoch hervorgehoben werden, dass gerade bei Tupaja dieser Befund ein 
ziemlich seltener ist, da hier, wie bereits erwähnt, Stroma und Parenchym sehr gleich. mässig vertheilt sind.

Nackte Eizellen fanden sich auch bei Tupaja ziemlich häufig, doch liessen sich in den meisten Fällen deutliche Zeichen von Degeneration der Zelle, oder doch wenigstens ein scharfer hyalinel Ring um dieselbe hin nachweisen, als Zeichen, dass dieselben früher von Epithel umhüllt waren.

Gleich vax Bexeden und Schottläxder können wir bestätigen, dass es sich hiel lediglich um degenerative Processe von Primairfollikeln handelt.

Bezüglich der Eireifung bestätigen die Befunde bei Tupaja im Grossen und Ganzen Alles das, was Pfiüger, Waldeyer und Paladiyo beobachtet haben. Stroma und Parem. chym nehmen gleich lebhaften Antheil an der Follikelreifung.

Schon oben ist erwähnt, dass His bereits im Jahre 65 den Character der Thecafulliculi in mustergültiger Weise aufstellte. Hier muss jedoch noch herrorgehoben werden, dass wir, abgesehn von der vollen Bestätigung seiner Auffassung, auch noch im Stande waren, das Einwuchern von Gefässzapfen der Theca zwischen Granulosazellen nachzuweisen, und zwar bereits vor der vollkommenen Reife des Follikels sowohl, als bei völlig reifen und befruchtungstähigen Follikeln, mit grosser Regelmässigkeit, obgleich dieselben völlig normal waren.

Dem gegenüber steht der Befund von Ruge, der die Vascularisation bei Reptilieneiern als erstes Zeichen der Degeneration beschreibt. Ihm schliesst sich MrxGaRziri (27) an, der ebenfalls seine Beobachtungen hauptsächlich an Reptilien und Fischen gemacht hat.

Wenn wil demgegenüber bedenken, dass zahlreiche andere Forscher, die nur an Süugethieren untersucht haben, nicht zu denselben Resultaten gelangen, so scheint es am natürlichsten, gleich Henneguy den Schluss zu ziehn, dass gerade in dieser Erscheinung ein characteristischer Unterschied zwischen Säugethieren und Reptilien zu sehn ist.

Auch uns erscheinen die Ruge'schen Untersuchungen einerseits so über allen Zweifel erhoben, andererseits können wir auf Grund der beigefügten Abbildungen bei der beginnenden Vascularisation der Granulosa von Iupaja, atretische Erscheinugen mit Sicherheit ausschliessen, so dass wir behaupten können, dass es sich um einen für Säugethiere characteristischen Vorgang handelt.

Wir machen jedoch darauf aufmerksam, dass dieser Vorgang bei Tupaja keine eigentliche Vascularisation, sondern mehr die Vorbereitung einer solchen vorstellt, indem es sich bis zum Augenblick des Follikelsprunges lediglich um grössere oder kleinere, stumpfe Epithelzapfen handelt; erst nach erfolgter Berstung sprossen dieselben zu einem communicirenden Netzwerk aus.

Im Ganzen betrachtet, bidet demnach die Theca folliculi bei Tupaja eine hohle Kugel, deren Innenfläche mit einzelnen hervor'springenden Knoetchen besetzt ist.

Wie aus diesem Gebilde zusammen mit den übergebliebenen Granulosazellen das colpus luteum sich entwickelt, ist bereits oben beschrieben. Wir haben damit nur im Grossen und Ganzen die Befunde von IVALDEYER bestätigt und befinden uns dabei in 
Uebereinstimmung mit den neuesten Untersuchungen voN SOBOTTA ') der vorläufige Mittheilungen über das corpus luteum der Maus veröffentlicht hat.

Die Vorläufigkeit der Mittheilung gestattet uns hier nicht darauf näher cinzugehn, doch sei erwähnt, dass wir derselben nicht entnehmen konnten, auf welche Weise es SoßоттA möglich war, bis auf einzelne Stunden genau das Alter der corpora lutea zu bestimmen, noch, worauf er seine Behauptung stützt, dass bei der Maus das corpus luteum in drei Tagen sich bildet und in dieser Form sich monatelang hält.

Die von Benkiser im corpus luteum des Schweines und des Menschen beschriebenen kariokinetischen Figuren finden sich bei T'upaja ebenfalls, und zwar stets, wie auch BeNkiser beobachtete, in unmittelbarer Nïhe der Gefüsse.

Aus diesem Grunde halte ich dieselben, ebenso wie SовоттA, für ausschliesslich von Gefässendothelien gelieferte Gebilde, während BENKisER der Ansicht huldigt, dass auch Luteinzellen kariokinetische Figuren zeigen.

Dass dem Stadium der Reife des Eies ein Stadium der Befruchtungsfahigkeit regelmässig folgte, bestätigt die Befunde von van Beneden, Julin, Heape u.a. auch für Tupaja.

Es verdient hierbei hervorgehoben zu werden, dass die Eizelle, sowie der Fikern zur Zeit der Reife ihre höchste Ausdehnung erreicht haben, und darauf an Volum verlieren.

Nicht unwahrscheinlich ist es, dass die stets nachweisbare mehr excentrische Lage. rung des Eikerns bei reifell Follikeln als erste Vorstufe zur Bildung des Pronucleus und Richtungskörperchens aufzufassen ist, und nicht etwa, wie NAGEL u. a. geneigt sind, als Zeichen einer auftretenden Degeneration.

Dass wir uns auch bei der Follikelatresie im Allgemeinen damit begnügen mussten, die Befunde anderer Autoren auch für Tupaja zu bestätigen, ohne sonst viel Neues zu bringen, ist bereits erwähnt.

Eine kurze Besprechung verdienen noch die sog. Nährzellen Nagels, unter welchem Namen er grössere und hellere Zellen in der Granulosa beschreibt, welche zuerst von de Sinéty gesehen wurden. SchоттLäNder sieht darin nichts besonderes, sondern fasst dieselben als Eizellen auf, die aus den Waldeyer'schen Eiballen herstaminend in dem Follikel mit eingeschlossen sind.

Wie oben bereits angedeutet, sind wir geneigt keine dieser Erklärungen gelten zu lassen, sondern die Vermuthung auszusprechen, dass es sich hier lediglich um ein Vorstadium von Kariokinese handelt. Die Gründe, die dafür sprechen, liegen auf der Hand. Zunächst fallen alle in Kariokinese begriffenen Zellen sofort durch ihre Grösse auf, daneben sehn wir, in ganz ähnlichem Verhältniss zu den übrigen Zellen, die bewussten helleren mit hellerem und grösserem Kern, welche somit schon durch ihre Gestalt eine Uebergangs. form zwischen den ruhenden und den sich theilenden Kernen darstellen. WVozu nun eine viel verwickeltere Erklärung bei den Haaren herbeiziehn, wo diese einfache sich wie von selbst bietet.

Speciell für Tupaja wird die Nagel'sche, sowie die Schottländer'sche Errkliirung noch

1) 1895. Ueber die Bildung des corpus luteum bei der Maus. Anaton. Anzeiger. X, p. $4 \$ 2$. 
unhaltbarer, als sich hier die Primairfollikel stets sehr früh isoliren, und eigentliche Ei. ballen im Sinne WALDEYERS nicht zu constatiren sind.

Jedoch muss man wohl darauf achten, dass, abgesehn von diesen Zellen, sich noch andere im heranwachsenden Follikel finden, die sich durch ihre Grösse auszeichnen und zwar diejenigen, die sich später im liquor folliculi auflösen; doch sind dieselben sofort zu erkennen an ihren Kernen, die die Grösse der ruhenden Kerne nicht überschreiten und mit der Zunnahme der Zellumfangs sogar an Grösse einbüssen.

Während wir uns bisher darauf beschränken mussten, die Befunde Anderer zu bestätigen, oder doch nur unwesentlich zu vermehren, sind wir in der angenehmen Lage, dank sei dem schönen Material, über die Veränderungen des Ovariums von Tupaja durch das Geschlechtsleben eine viel vollständigere Uebersicht zu bieten, als bisher von anderen Autoren bei andern Säugethieren geschehn konnte.

Wie bereits oben erwähnt, sind Heape und de Sinéty eigentlich die Einzigen, die hierin bemerkenswerthe Resultate zu verzeichnen haben.

Aus diesem Grunde müssen wir hier die einschlägigen Beobachtungen etwas eingehender besprechen, und auch so weit nöthig zur Erklärung, die Befunde an Uterus und Tuben benützen.

Bei der Sichtung des vorhandenen Materials von Tupaja fiel es auf, dass unter den reifen Follikeln verhältnissmässig nur wenige angetroffen wurden, deren Eizelle noch keinerlei Erscheinungen von Degeneration zeigten. Als nun auch die zu ihnen gehörigen Uteri untersucht wurden, so zeigt sich, dass dieselben stets in congestionirtem Zustande angetroffen wurden, mit theilweise losgestossenen Epithelien, stark gefüllten Blutgefässen in der Mucosa, und mit einem Bluterguss in das Lumen der Uterushörner; sie zeigten m. a. W. die unzweideutigen Zeichen der Menstruation.

Die bisher unbekannte Thatsache an und für sich, dass ein so kleines Thier, wie Tupaja, eine regelmässige Menstruation besitze, erregte schon unsre Verwunderung, noch mehr aber der Umstand, dass dieselbe stets mit dem Nachweis eines oder mehrerer reifen oder beinahe reifen Follikel im Ovarium gepaart ging.

Der stets in gleicher Weise sich wiederholende Befund bestätigte die allgemeine Gültigkeit der gefundenen Thatsache.

Wir wagen es nicht, hier irgendwelche Zeitangaben, weder für die Dauer der Menstruation, noch für irgend eine andere geschlechtliche Function für Tupaja zu geben. Alle derartigen Bestimmungen haben keinen Werth, wenn man bedenkt, dass jedes Thier in der Gefangenschaft unter ungünstig seine Functionen beeinflussenden Bedingungen steht und eine nicht störend wirkende Beobachtung des freien Zustandes unmüglich ist, wenn sie zugleich gewissenhaft sein soll.

Wie dem auch sei, Tupaja besitzt eine Menstruation, wie lange sie dauert, in welchen Intervallen sie eintritt, wissen wir nicht.

Was wir jedoch für Tupaja mit Sicherheit beweisen können, ist las regelmässige Zusammenfallen des Beginns der Menstruation mit der Eireife. Niemals findet sich ein reifer Follikel ohne Menstruation. 
In drei Fällen konnten wir Ovarien mit "befruchtungsfähigen", nicht degenirten Eiern beobachten; in allen drei Fällen zeigte sich im Uterus Desquamation und Anbildung der Mucosa, Schwellung derselben und ihrer Gefisse, im Uteruslumen desquamirte Epithelien, gelbgefärbte, unregelmässig geformte Massen, und zahlreiche, zum Theil noch deutlich als solche erkennbare rothe Blutkörperchen, also die Zeichen der „abgelaufenґn Menstruation".

Aus der Coincidenz dieser Beobachtungen lässt sich somit constatiren, dass bei Tupaja zur \%eit der Menstruation regelmässig reife Eier im Ovarium sich finden, die bei Ablauf der Menstruation „befruchtungsfühig” geworden sind.

Jedoch finden sich fast nie zwei Eier genau in demselben Stadium; stets ist eines etwas weiter entwickelt als die übrigen. Den schlagendsten Beweis hierfür liefern die Genitalien von Tupaja, Utr. Mus. Cat. $\mathrm{N}^{0} .214$ (s. o.).

In der Vagina fand sich ein frisches Blutcodgulum, im Uterus desquamirtes Epithel und veränderter Blutfarbstoff.

In der Tube lag das Ei in der Befruchtung mit männlichem und weiblichem Pronucleus.

Im Ovarium fand sich zunächst ein ganz frisches corpus luteum, als Beweis, dass ein Ei bereits ausgestossen war, das offenbar unbefruchtet den Genitalkanal bereits wiedel verlassen hatte. Daneben lag der eben gesprungene Follikel des in der Tube befindlichen Eies, ferner ein Follikel mit befruchtungsfähiger, doch in beginnender Degeneration be. griffener Eizelle, und ein weiterer Follikel mit reifer, degenerirter Eizelle. Wir haben hiel somit vier Eier, die sich während einer Menstruation in regelmässiger Folge zum Ver. lassen ihres Mutterbodens anschickten.

Noch in anderer Beziehung ist dieser Fall wichtig, wie wir weiter unten sehen werden. Hier sei nur noch constatirt, dass sich in den drei ersterwähnten Fällen, in denen sich normale, befruchtungsfähige Follikel fanden, weder in der Scheide, noch im Uterus und der Tube Spermatozoen fanden, wodurch ein weiterer Beweis geliefert ist, dass das Ausstossen des Richtungskörperchen und die Bildung des weiblichen Pronucleus vor der Befruchtung stattfindet.

Noch zwei wichtige Thatsachen lehrt uns die Betrachtung von Tupaja 214, nämlich, dass nach erfolgter Schwängerung selbst befruchtungsfähige und reife Eizellen nicht mehr ausgestossen werden und dass dieselben sofort der Degeneration anheimfallen. Wir werden sogleich beweisen, dass dies Zusammentreffen kein zufälliges ist.

Zunächst jedoch muss erwähnt werden, dass dies Prïdominiren einer Eizelle eine constante Erscheinung ist und auch in der weiteren Entwickelung in utero seine Analogien findet.

Wie bekannt, findet sich im hochschwangeren Uterus von Tupaja in jedem Horn immer nur ein Fötes. Trotzdem hat Hubrecht (l. c.) constatiren können, dass sich im ersten Stadium der Schwangerschaft oft mehr, ja selbst viel befruchtete Eier im Lterus oder in der Tube fanden, so dass selbst in dem Falle, dass mehrere Eier befruchtet sind. auch die bereits befruchteten auf Kosten des Erstbefruchteten zu Grunde gehn müssen. 
Kehren wir zum Ovarium zurück, so können wir weiter feststellen, dass von dem Augenblicke der Schwängerung ab, kein normaler reifer Follikel im Ovarium mehr $\mathrm{zu}$ finden ist. Die ausserordentlich zahlreichen Fälle von beginnender Schwangerschaft, die wir untersuchten, zeigten ohne Ausnahme alle denselben Befund. Sämmtliche Eizellen waren mehr oder weniger hyalin degenerirt.

Neben denselben fanden sich stets ein oder mehrere frische corpora lutea, die, wie gesagt, nicht der Zahl der Embryonen oder der befruchteten Eizellen, sondern lediglich der Zahl der ausgestossenen Eizellen entsprecheu, gleichgültig was aus denselben ge. worden ist.

Es ist demnach die Regel, dass meist mehr corpora lutea als Embryonen vorhanden sind, was die oben angeführten Beispiele bestätigen.

Wie bereits oben erwähnt, nähern sich in jeder Menstruationsperiode durchschnittlich fünf Follikel der Reife; man kann demnach bei zwei Embryonen in jedem Ovarium je ein corpus luteum neben je vier reifen degenerirenden Follikeln antreffen, wenn gleich das erste ausgestossene Ei befiuchtet worden ist, oder je fünf corpora lutea, wenn nach der Ausstossung der beiden letzten Eier die Befruchtung erfolgt ist.

Da jedoch nicht nur die Follikel je eines Ovariums allein, sondern auch die Follikel des einen Ovariums früher reif werden als die des andern, so ist das Verhältniss mehr weniger inconstant.

Immerhin lässt sich wohl aus der Zahl der vorhandenen corpora lutea schliessen, das wievielste der ausgestossenen Eier befruchtet wurde. Im obenerwähnten Fall U. M. C. 214 wäre dies das zweite.

Verfolgen wir die Schicksale des Ovariums bei fortschreitender Gravidität weiter, so sehn wir, dass zunächst kein einziger Follikel mehr zu weiterel Entwickelung gelangt. Von den grösseren schreitet die Degeneration bald auch auf die mittleren und kleineren fort, so dass sümmtliche Ovarien aus der ersten Zeit del Gravidität sich aus mächtigen corpora lutea und lauter degeneriten Follikeln zusammensetzten.

In rer zweiten Hälfte der Gravidität verschwinden auch die corpora lutea mehr und mehr, so dass schliesslich im hochschwangeren Stadium das Ovarium nur noch aus spärlichen Resten der corpora lutea und degenerirten Follikeln, meist ron mittleren Umfang besteht.

Der Umstand, dass man hier niemals grosse Follikel in Atresie findet, dagegen zahlreiche kleinere mit unverhältnissmässig grossen Eizellen, die oft schöne chromatolyti. sche Spindeln zeigen, macht es wahrscheinlich, dass die Annahme Flemmings, es handele sich in diesen Fällen um ursprünglich viel grössere, reife Follikel, richtig ist; denn was sollte sonst aus den verschiedenen reifen Follikeln geworden sein, deren beginnende Atresie wir im Beginn der Gravidität constatiren konnten.

Sobald der Uterus sich seines Inhalts entledigt hat, beginnt auch wieder im Orarium eine lebhafte Neubildung. An ganz frisch puerperalen Uteris sehen wir Ovarien, die von einer grossen Anzahl mittelgrosser hyaliner und fettiger Schollen atrophirter Follikel durchsetzt sind, und daneben wieder eine Reihe völlig normaler kleinerer und mittelgrossel. Follikel aufweisen. 
Neist ehe noch die völlige restitutio ad integrum des Uterusepithels vollendet ist - auch hier enthalten wir uns einer Zeitbestimmung - finden sich wieder leife Fol. likel und bald darauf auch frische corpora lutea.

Wir könnell demnach das Gesammtresultat unserer stets analogen Ũntersuchungen dahin zusammen fassen, dress wöhrend der Schwangerschuft die Eireifung cessirt, aber virht die Eibildung. Is findet vielmehr eine fortwahrende Neubildung con Fiern stutl, welche, zu ciner gewissen Grösse gelangt, atresiren, was bewiesen wird durch die im Verhältniss zuın nicht schwangeren Zustand viel grössere Anzahl atresirter Follikel von mittlerer Grïsse iın hochschwangeren Ovarium.

Im Puelperium erreicht, wie gesagt, das Ovarialparemhym sehr bald wieder seine volle Functionsfähigkeit.

Hier war es sehr leicht durch die Untersuchung des Uterus die Diagnose zu stellen.

Sein Peritoneum war runzelig, die Gefässe erweitert und geschlängelt, die Wand mehr weniger gefaltet; im Lumen fand sich meist noch deutlich die Placentarstelle, naı/ı der hin die Drüsenlumina convergiren, die Mucosa war zum Theil abgestossen, in späteren Stadien in kräftiger Regeneration begriffen.

Während uns so in der Menstruation, der Befruchtung, der Schwangerschaft und dem Puerperium die Befunde am Uterus die nöthigen Anweisungen gaben, um die zugehörigen Ovarien zu classificiren, blieben nun noch diejenigen Fälle übrig, die keinerlei Veränderung des Uterus zeigten, demnäch Individuen angehölen mussten, die entweder noch nicht geschlechtsieif waren, oder in einem iutramenstruellen Stadium sich befanden.

Die ersteren wieder waren leicht zu erkennen an ihrem kleinen schlanken jung. fräulichen Uterus und den von Primairfollikeln strotzenden Ovarien.

Auch bei ihnen fanden sich stets, wenn auch in kleinerer Anzahl, atretische Follikel.

Bei den übrigen, dem intramenstruellen Stadium angehörigen Individuen fanden sich stets zwei Gruppen von Parenchymelementen, die der abgelaufenen und der herannahenden Menstruationsepoche angehörten, und zwar jeweils im Durchschnitt in der Zahl fünf.

Doch erregte es unsere Aufmerksamkeit, dass auch hier nicht stets fünf colpora lutea vorhanden waren, sondern oft nur zwei oder drei, in welchem Falle sich dann an Stelle der fehlenden ebensoviele grosse atresirende Follikel befanden.

Die fünf heranwachsenden Follikel, die der kommenden Menstruationsepoche angehörten, waren meist normale, sehr selten fand sich auch unter ihnen ein bereits degenerirender Follikel.

Was die Zeit betriffe in der die corpora lutea resorbirt werden, so konnten wir neben den frischen aus einer Menstruationsperiode stammenden, in einzelenen Fällen noch stark geschrumpfte Ueberreste von einem, äusserst selten von zwei corpora lutea constatiren, die offenbar aus einer früheren Periode stammten.

So weist auch das schon mehrfach genannte Paradeovarium 214 (Taf. I. Fig 10) neben dem ganz frischen ein altes, völlig hyalin geschrumpftes corpus luteum an. 
Wir sehn daraus, dass ebenso wie bei den Follikeln auch bei den corpora lutea meist eines sich vor seinen Kameraden dadurch auszeichnet, dass es einen langsameren Tod stribt und noch ein drittes Eiergeschlecht neben sich erstehn sieht.

Halten wir diese beiden Thatsachen zusammen, dass sowohl je eine Eizelle als je ein corpus luteum sich vor den andern auszeichnet, so ist als wahrscheinlich anzunehmen. dass beide aus einem Follikel hervorgegangen sind, der offenbar bereits von Anfang an im Ovarium unter günstigeren Lebensbedingungen stand, als seine Genossen.

Immerhin steht soviel fest, dass höchstens eines der vier bis fünf corpora lutea eine Menstruationsepoche überdauert, während die anderen drei bis vier innerhalb derselben resorbirt werden, und dass auch dieses resistentere corpus luteum in der nun folgenden Menstruationsperiode untergeht, lässt sich nicht bezweifeln, denn sonst müssten sich jetzt noch stärker atrophische Zustände an seiner Statt finden lassen, etwa wie die Corpora albicantia bei alten Frauen.

Wenn dies regelmässig stattfindet, so würde in der dritten, nicht durch Schwangerschaft unterbrochenen Menstruationsperiode sich finden lassen müssen ein sehr stark geschrumpftes corpus luteum der ersten Periode, ein hyalin degenerirtes der zweiten, und vier bis fuinf frische der letzten Periode.

Wir konnten dies niemals constatiren, und glauben damit den Beweis geliefert zu haben, dass in der dritten Menstruationsperiode keinerlei Elemente aus der ersten mehr erhalten sind.

Es ist früher allgemein angenommen worden, dass man beim Menschen sowohl als bei den Thieren, unterscheiden müsse zwischen corpora lutea vera und spuria, indem die grösseren vera sich nur bildeten nach stattgefundener Befruchtung und Schwangerschaft, die spuria dagegen nach der Menstruation. Die ersteren sollten bestehn bleiben, während die letzteren bald wieder verschwinden.

Bis in die neuste Zeit hat dieser Aberglaube gespuckt, und findet sich sogar noch in bekannten Lehrbûchern über Geburtshülfe, sowie in den Köpfen zalılreicher Hebammen.

Paladino hat einige Verwirrung in den Begriff vera und spuria gebracht, indem er mit corpora lutea vera die Follikelbälge der ausgestossenen Eier, mit spuria die Ueberreste der atretischen Follikel bezeichnete.

Es wäre wünschenswerth, um, wie dies ScHotrLäxider u. a. gethan haben, mit Paladino mitzugehn und die neue Auffassung des alten Begriffs ohne weiteras zu adoptiren.

Eine so eingewurzelte Anschauung indessen, wie die ältere, kann man nicht so ohne weiteres über Bord werfen und ist verpflichtet, erst das Unhaltbare derselben unwiderleglich darzuthun, bevor man zu den neuen Götterm betet. Hat doch selbst de Sinéty, wie erwähnt, aus der Beschaffenheit des corpus luteum der Frau gewisse Characteristica für das Schangerschaftsovarium abzuleiten sich bemüht.

Für Cavia und einige andere Thiere ist ilım dies nicht geglückt, und mir bei Tu. paja auch nicht.

Auf Grund der mitgetheilten Thatsachen können wir feststellen, dass sich bei Tu- 
paja das corpus luteum menstruationis von dem corpus luteum graviditatis in keiner Weise unterscheidet, es sei denn, dass das letztere etwas langsamer resorbirt wird, was wir nur dann mit Bestimmtheit sagen könnten, wenn uns sowohl die Zeit der Menstruation als die Zeit der Trächtigkeit von T'upaja bekannt wäre.

Dass schliesslich das corpus luteum graviditatis dauernd im Ovarium zurück bleibt, ist schon aus dem Grunde unmöglich, als sich bei allen hochschwangeren Uteris stets nur spärliche Reste desselben, und auch diese nicht einmal in allen Fällen finden lassen.

Fassen wir nun zum Schlusse die Antworten zusammen, welche die Untersuchung von Tupaja auf die eingangs gestellten Fragen gibt, so lauten dieselben:

1. Bei Tupaja findet eine Anbildung von Follikeln aus dem Deckepithel, während der ganzen Dauer des Geschlechtslebens statt, die Zahl der Eizellen im Deckepithel steht in directem Verhältniss zur Zahl der Primairfollikeln, wie der Follikel überhaupt.

2. Bei der Eireifung betheiligen sich die Eizelle, das Follikelepithel und das Stroma zugleich. Die Eizelle wächst durch gleichmässige Grössenzunahme, und erst im letzten Augenblicke theilt sich der Kern zum Zwecke der Bildung des Richtungskörperchen.

Das Follikelelepithel vermehrt sich fortwährend durch indirecte Kerntheilung, und zwar am lebhaftesten vor vollendeter Reife.

Das Stroma betheiligt sich durch Lieferung einer lebhaft wuchernden Gefässschicht in der ganzen Umgebung des Follikels Die Endothelien derselben vermehren sich durch indirecte Kerntheilung.

3a. Follikelatresie findet zu allen Zeiten statt, physiologisch atresiren alle Follikel in der Schwangerschaft. Die Atresie beginnt meist mit der Eizelle und dem Follikelepithel zugleich, und ist aus der Beschaffenheit der Eizelle am leichtesten zu erkennen. Das Stroma betheiligt sich erst secundair durch allmählige Vascularisation.

3b. Das corpus luteum bildet sich nach Ausstossung der Eizelle, sowohl aus dem übrigbleibenden Follikelepithel als aus der vom Stroma gelieferten Theca, dasselbe ist in der zweiten darauf folgenden Menstruationsepoche bereits völlig resorbirt, bei eintretender Schwangerschaft werden die corpora lutea der letzten Ovulationsperiode bereits in der ersten Hälfte der Schwangerschaft wieder resorbirt.

4 . Die Eireife fällt bei Tupaja mit dem Beginn der Menstruation zusammen, die Befruchtungsfähigkeit mit dem Ende derselben.

Duchschnittlich werden von jedem Ovarium innerhalb einer Menstruationsperiode fiinf Follikel gezeitigt, deren Eier jedoch nicht stets alle ausgestossen werden,

b. Beim Eintritt der Befruchtung atresiren sämmtliche noch übrigen Follikel in den Ovarien, und zwar die grössten zuerst, selbst dann noch, wenn sie bereits das Stadium der Befruchtungsfähigkeit erreicht haben.

c. Während der Schwangerschaft findet keine Eireifung statt. Sämmtliche neu sich bildenden Follikel atresiren, sobald sie eine gewisse Grösse erreicht haben.

Die Zahl der corpora lutea entspricht der Zahl der ausgestossenen Eizellen. Die Zahl der Embryonen ist meist geringer. 
Beim hochschwangeren Uterus finden sich in den Ovarien nur noch spärliche Reste von corpora lutea.

Unmittelbar nach der Geburt nähern sich sofort wieder einzelne Follikel im Ovarium der Reife, so dass sich bereits reife und selbst ausgestossene Eier finden in einer Zeit, wo die Involution des Uterus noch nicht beendet ist.

d. Je älter ein Thier ist, desto weniger finden sich Eizellen im Deckepithel und Primairfollikel. Mit der Abnahme des Parenchyms geht eine Zunahme des Stromas gepaart, zugleich verliert das ganze Organ an Grösse. 


\section{SOREX VULGARIS.}

Das Utrechtsche Museum besitzt z. Z. 143 weibliche Genitalien von Sorex vulgaris.

Wie HuвRеснт ${ }^{1}$ ) bereits früher erwähnte, sind dieselben das Ergebniss einer dreijährigen wohlorganisierten Jagd während der Heu- und Getreideernte, also gerade auch während der Brunstzeit der Spitzmäuse.

Der Wunsch lag nahe, um bei diesem mit Tupaja javanica so nahe verwandten Thiere eine vergleichende Untersuchung der Ovarien innerhalb und ausserhalb der Brunstzeit anzustellen, jedoch scheiterte der Versuch an der Unmöglichkeit, Spitzmäuse in anderen Jahreszeiten in genügender Anzahl erhalten zu können, so dass wvir uns damit begnügen müssen, das vorhandene Material aus der Brunstzeit zu betrachten und zu unserem Zwecke zu sichten.

Die Spitzmäuse erfreuen sich in so ausgiebiger Weise des Lebens, solang die Brunstzeit glüht, dass sie wert sind, zu den Anhängern des Buddha zu zählen, die bekanntlich die Menstruation dem Kindesmorde gleich rechnen.

Unter sämmtlichen untersuchten Exemplaren finden sich nur sehr wenige virgines. worunter eine so kleine, dass sie kaum als geschlechtsreif angesehen werden kann.

Alle übrigen waren entweder schwanger oder puerperal, oder auch beides zugleich, wie aus den älteren Placentarstellen in utero neben jüngsten Embryonen zu beweisen war.

Dank diesem ausserordentlich lebhaften Geschlechtsleben war es nicht möglich, sichere Anhaltspunkte über das Bestehen oder niclit Bestehen eines Menstruationsprozesses zu erhalten. Selbst die Ovulationsperiode liess keille so sicheren Schliisse zu als Tupaja, da sich stets als Zeichen der stattgefundenen Cohabitation Spermatozoen im Genitalschlauche fanden, in Fällen, wo derselbe wegsam war.

Der Gang der Untersuchung war aucl hier derselbe wie bei Tupaja; es wurden

1) De placentatie van de spitsmuis, verhdl. kgh. akadem. Amstrd. 1893. 
erst bei schwacher Vergrösserung eine grössere Anzahl Ovarien gezeichnet, und dann erst die zugehörigen Uteri zur Controle der gefundenen Resultate verglichen.

Auf Tafel I sind die stets wiederkehrenden Typen im Zusammenhang mit dem Geschlechtsleben geordnet.

\section{Pubertiitsorarium.}

Utr. Mus. Kat. $\mathrm{N}^{0}$. Sorex $\mathrm{N}^{0} .17$.

Kleines, wahrscheinlich noch nicht erwachsenes Thierchen.

Uterus: sehr klein, glatt.

Ocrien: keine corpera lutea, keine reifen Follikel, sehr zahlreiche mittelgrosse und Primairfollikel, beinahe keine Atresie a./d. Follikeln.

\section{Jungfräuliches 0 variunı. Taf. 1 fig. 1. \\ Utr. Mus. Kat. No. Sorex No. 139. Virgo.}

Ovarien: sehr viel grosse und kleine normale Follikel; sehr viel Primairfollikel, sehr wenig Follikelatresie. Keine corpora lutea.

Utr. Mus. Kat. No. Sorex No. $^{\circ}$.

Ausgewachsenes Thier. C'terus gut entwickelt, beide Hoerner gleichmässig, keine Gravidität, keine Placentarstellen.

Ovarien: (131 Serienschnitt).

Viele Primairfollikel, sehr zahlreiche grosse und mittelgrosse Follikel. Ein sehr grosser normaler Follikel, ein grosser Follikel in Atresie, wenig atretische Erscheinungen an den mittelgrossen Follikeln, kein corpus luteum.

\section{Orarium in Beginn der Schwangerschaft. Taf. 1 tix. *..}

Utr. Mus. Kat. Sorex No. 130. (vgl. Hubrecht Placentatie. l. c.).

Cterus: sieben Knoten, die Embryonen enthalten.

Ocurien: 5 corpora lutea jederseits. 3 grosse Follikel in hyaliner Degeneration. Mittelgrosse Follikel mit Zeichen von beginnender Atresie.

Utr. Mus. Kat. No. Sorex No. 110.

Cterus: im ersten Stadium der Schwangerschaft, nur Hyperaemie, noch keine Kno. tenbildung, allerjüngste Embryonen.

Ovarien: (400 Serienschnitt) rechterseits 1 grosses corpus luteum central, alle grossen und mittelgrossen Follikel hyalin degeneriert; sehr wenig Primairfollikel, worunter zahlreiche atretisch.

Utr. Mus. Kat. $\mathrm{N}^{0}$. Sorex $\mathrm{N}^{0}$. 51.

Ltcrus: 7 Knoten mit Embryonen.

Ovarien: (120 Serienschnitt) 3 grusse corpora lutea rechts, links Ovar. 4 . in jedem 
Ovarium zwei grosse und zahlreiche mittelgrosse und kleinere atretische Follikel; kein einziger Follikel normal, mässig viel Primairfollikel. Hyperaemie.

Utr. Mus. Kat. $\mathrm{N}^{0}$. Sorex $\mathrm{N}^{0} \cdot 122$.

Uterus: stark hyperaemisch und verdickt; beginnende Schwangerschaft; Knötchen. bildung.

Ovarien: (100 Serienschnitte) links 3 corpora lutea. 2 grosse Follikel degeneriert, zahlreiche mittelgrosse ebenfalls alle atretisch, kleinere mässig zahlreiche, normal und atretisch.

\section{Ovarinm am Ende der Schwangerschaft. Fig. 3.}

Utr. Mus. Kat. No. Sorex No. 100.

Uterus : hochschwanger.

Ovarien: keine corpora lutea, grössere Follikel zum Teil atretisch, zuın Teil normal, mittelgrosse und kleine meist normal, sehr zahlreiche Primairfollikel.

5. 0varium im Puerperium unmittelbar nach der Geburt. Fig. 4.

Utr. Mus. Kat. No. Sorex No. 107.

Uterus: frisch puerperal. 8 stecknadelkopfgrosse Knoten (Placentarstellen), an einzelnen Stellen liegt das bindegewebige Stroma mit geschundener Oberfläche bloss zu Tage. Das Epithel darüber ist noch nicht regeneriert.

Ovarium: 1 grosser, 2 mittelgrosse Follikel normal, die übrigen zum Teil atretisch, zahlreiche Primairfollikel, alle normal, keine corpora lutea.

6. Orarium im späteren Puerperalstadium. Fig. 5.

Utr. Mus. Kat. No. Sorex No 93.

Uterus: keine Gravidität. Placentarstellen noch deutlich, Epithel darüber bereits regeneriert.

Ovarium: (rechts) 125 S. S. 2 grosse Follikel hyalin degeneriert, 2 andere nebst allen mittelgrossen normal. Keine corpora lutea, zahlreiche Primairfollikel.

\section{\%. Ovarium bei Imprägnation im Puerperium. Fig. 6.}

Utr. Mus. Kat. Nu. Sorex $\mathrm{N}^{0} \cdot 35$.

Uterus: 7 Placentarstellen, noch nicht völlig mit Epithel bekleidet als Zeichen des frischen Puerperiums. Vagina, Uterus und Tuben gefüllt mit spermatozoen.

Ovarium: Alle grossen Follikel, mehr weniger atretisch, die meisten anderen, anch einige mittelgrosse Follikel normal. Ein grosser Follikel scheinbar normal, nach aussen geöffnet, in befruchtungsfähigem Zustande. Keinerlei Spuren von corpora lutea. 
8. Orarium bei Puerperium nebst Graviditï. Fig. 7.

Utr. Mus. Kat. $\mathrm{N}^{0}$. Sorex No. 16.

literus: Embryonen nebst alten Placentarflecken.

Ocarium: (120 Serienschnitte). 4 frische corpora lutea, sehr viel atretische grosse und mittelgrosse Follikel, 2 sehr grosse Folllikel mit ganz beginnender Atresie.

Bei der Beurteilung der gefundenen Thatsachen ist zunächst besonders auffallend, dass sich corpora luten nur in der ersten Hälfte der Schwangerschaft finden, bei hochschwangeren, puerperalen und nichtschwangeren dagegen kaum mehr Spuren nachweisen lassen.

Der bereits oben erwähnte Umstand, dass keine Exemplare ausserhalb der Brunstzeit zur Vergleichung herbeigezogen werden konnten, verbietet uns, daraus all zu weitgehende Schlïsse zu ziehen.

$\mathrm{Ob}$ demnach ausserhalb der Brunstzeit überhaupt eine Eireifung mit Ausstossung der Eizelle und Bildung eines corpus luteum stattfindet, ober ob in dieser Zeit alle heranreifenden Eier der Atresie verfallen, muss dahingestellt bleiben.

Was wir jedoch an den untersuchten Fällen constatieren können, ist das Factum, dass sich während der Brunstzeit nur nach stattgehabter Conception in der ersten Hälfte der Schwangerschaft corpora lutea vorfanden, dass dieselben jedoch keineswegs stets der Zahl der Embryonen entsprachen, sondern dieselbe meist übertrafen.

Bei Sorex nähern sich durchschnittlich 5 bis 10 Follikel in jedem Ovarium del Reife, also im Ganzen etwa 10 bis 20, während die Zahl der Embryonen zwischen 5 bis 10 schwankt.

Jedoch sind hier die verschiedenen Ovulationsperioden lange nicht so deutlich ge. schieden wie bei Tupaja, die ganzen Geschlechtsvorgänge spielen sich viel rascher, Schlag auf Schlag im Ovarium ab, es hat den Anschein, als ob die höchstmögliche Arbeit in möglichst kurzer Zeit vom Ovarium in der Brunstzeit geliefert würde.

So sehen wir, dass die corpora lutea lange nicht so voluminös werden und viel rascher resorbieren können, als bei Tupaja, dass sich bei Sorex bereits am Ende der Schwangerschaft reife und unmittelbar nach der Geburt bereits wieder hefruchtungsfähige Follikel finden, während bei Tupaja um diese Zeit erst mittelgrosse normale Follikel bestehen.

Endlich tritt sogar wieder Schwangerschaft ein zu einer Zeit, in der die Placentarstellen der früheren Geburt noch nicht völlig regeneriert sind.

Die Ovarien, die, der Grösse des Thieres entsprechend, etwa halb so gross sind als die von Tupaja, haben dieselbe unregelmässige Bohnenform, die nur wenig durch die rei. fenden Follikel und die corpus luteum.Bildung beeintlusst wird.

Im Verhältniss zum Parenchym ist das Stroma bei Sorex minder reichlich entwic. kelt, als bei Tupaja.

Abgesehen von diesen Unterschieden, die die mit derselben Vergrösserung (48 1) 
gezeichneten dioptrischen Bilder bei Vergleichung genügend illustrieren, bietet Sorex nur wenig Abweichung von Tupaja dar.

Wie gesagt, ist der wichtigste Unterschied, der, dass sich bei Sorex die geschlerht. lichen Vorgänge im Ovarium in viel rascherer Folge und viel lebhafter ahspielen und dass ein menstrueller Prozess, wenn er überhaubt bei Sorex stattfindet, durch Begattung, Schwangerschaft und Wochenbett völlig verdeckt resp. eliminiert wird.

Dies gilt selbstverständlich nur für Sorex in der Brunstzeit. Ob ausser dieser Zeit eine regelmässige Menstruation besteht, oder ob in der Ruhezeit nur eine träge Ovulation stattfindet, die statt mit dem Bersten des Follikels, mit legelmässiger Atresie des reifenden Follikels endet, lässt sich, wie gesagt, an der Hand des Materials nicht entscheiden.

Der einzige Umstand, der für die Wahrscheinlichkeit der letzteren Affassung spräche, ist der bei Sorex 94 gefundene grosse Follikel in Atresie. Bei diesem ausgewachsenen Thiere, einem der wenigen, das trotz der Brunstzeit weder schwanger noch puelperal war, ist es immerhin merkwüldig, dass sich trotz fehlender pathologischer Erscheinungen, kein corpus luteum, sondern ein atretischer Follikel neben einem fast reifen normalen befindet.

Mit der nötigen Reserve sei hier auch darauf aufmerksam gemacht, dass sich in einem Falle, Utr. Mus. Kat. No . Sorex No. 139, der folgende Befund ergab:

Ovarien: je ein reifer Follikel neben zahlreichen normalen mittelgrossen. Einige grössere und mittelgrosse Follikel in Atresie. Kein corpus luteum.

Im Uterus: Desquamation des Epithels ohne Bluterguss. Frühere Placentarstellen nicht nachweisbar.

Dieser Fall könnte als ein menstrueller Prozess aufgefasst werden, der mit Epitheldesquamation ohne Bluterguss verläuft. Da er abel einzig dasteht, so sei hier diesem einzelnen Factum keine zu weitgehende Wichtigkeit beigemessen.

Auf Tafel VI sind die wichtigsten Ergebnisse der Untersuchung mit stälkerer Vergrösserung wiedergegeben.

Gleichwie bei Tupaja, finden sich bei allen untersuchten Exemplaren im Deckepithel grössere Eizellen, die allmählig grösser werden, sich mit einer Lage von Follikelepithel bedecken und tiefer in das Stroma treten. Je zahlreicher in einem Eierstock die Primairfollikel sind, desto mehr an Zahl und Grösse differenzierte Eizellen findet man im Deckepithel.

Er lässt sich somit auch für Sorex behaupten, dass auch im geschlechtsreifen Eier. stock eine fortwährende Neubildung von Eizellen stattfindet, und dass dieselbe mit dem zunehmenden Alter àbnimmt, doch nicht aufhört, so lange die Geschlechtsfähigkeit dauert.

Häufiger als bei Tupaja finden sich jedoch bei Sorex grössere Conglomerate von Eizellen, die an die Waldeierschen Eischläuche und Eiballen erinnern, so häufig selbst, dass man es als Regel aufstellen kann, dass bei Sorex stets eine grössere Anzahl Eier zugleich in schlauchförmiger Anordnung in die Tiefe des Stromas eindringen.

Diese Anordnung erklärt sich leicht aus dem Umstande, dass bei Sorex das Keimepithel im Verhältniss zum Stroma viel mächtiger entwickelt ist, als bei Tupaja, sodass 
zunächst keine völlige Umwachsung und Isolierung der einzelnen Primairfollikel durch das Stroma erreicht wird.

Taf. VI fig. 1 und 2 zeigen einzelne Eizellen im Deckepithel sowie einige jüngste allmählig sich ablösende Primairfollikel.

In fig. 3 sieht man dicht unter dem Deckepithel, zum Teil demselben noch ange. hörend, einen Eiballen aus fünf Primairfollikeln.

Fig. 4 endlich zeigt einen zwischen grösseren Follikeln (die nicht mitgezeichnet sind) in die Tiefe hinabreichenden Schlauch, der aus 12 Primairfollikeln zusammengesetzt ist. Deutlich ist hier zu sehen, wie mit zunehmender Grösse die Primairfollikel sich mehr und mehr selbstständig entwickeln und durch das Stroma von einander geschieden werden.

Ebenso wie bei Tupaja ergiebt sich aus der Vergleichung der Durchschnittsbilder für Sorex, dass die Eizellen der Primairfollikel mehr weniger die Form einer von oben und unten abgeplatteten Kugel besitzen, die mit zunehmender Grösse und Spannung immer mehr der Kugelgestalt sich nähert.

Beim Heranwachsen der Follikel gilt gellau dasselbe, wie bei Tupaja, nämlich dass sich Keimepithel und Stroma in gleicher Weise am Wachstum beteiligen.

Auch hier vermehrt sich das Follikelepithel sehr rasch durch indirecte Kernteilung. Auch hier wird durch Verflüssigung einiger Zellen der liquor folliculi gebildet, jedoch in noch geringerer Menge als bei Tupaja, so dass selbst bei den grössten Follikeln stets noch mächtige Epithelbrücken zwischen dem central liegenden cumulus proligerus und dem Randepithel des Follikels bestehen bleiben.

Der liquor folliculi bildet im reifen Ei mehrere rundliche mehr oder weniger confluirende Höhlen, wie Fig. 6 darstellt. Abgesehen von der geringeren Liquorbildung, unterscheidet sich das Follikelepithel bei Sorex auch dadurch von Tupaja, dass es weder um das Ei hin, noch längs dem Follikelrand deutliche cylindrische Anordnung zeigt. Die Follikelzellen sind kleiner, doch haben sie im Verhältniss grössere Kerne als Tupaja.

Eine Zona pellucida ist bei grösseren Eizellen stets deutlich entwickelt, doch besitzt sie keine so ausgeprägte radiäre Streifung, wie bei Tupaja.

Die lediglich aus gewucherten Gefässen bestehende, vom Stroma gelieferte Tunica propria folliculi ist bei Sorex schon früh (Fig. 5.) sehr deutlich wahrnehmbar.

Auch bei Sorex finden sich ebenso wie bei Tupaja, am reifen, nicht degenerierten Follikel schon lange vor der Berstung kleine Epithelzapfen, die sich zwischen die Follikelzellen ins Innere vorschiebell.

Auf Fig. 6 links unten sieht man neben einander zwei dieser Epithelzapfen; unter dem einen derselben ein bereits stark erweitertes Gefässlumen der Tunica.

Die Umwandlung des „reifen" in den "befruchtungsfähigen" Follikel liess sich bei Sorex nicht mit derselben Sicherheit bestimmen als bei Tupaja, da, wie gesagt, nur sehr wenige erwachsene Exemplare aus der Brunstzeit vorhanden waren, bei denen Puerperium und Befruchtung mit Sicherheit auszuschliessen waren.

Obgleich es demnach kaum einem Zweifel unterliegt, dass auch bei Sorex ebenso wie bei allen bisher näher beobachteten Säugethieren die Ausstossung des weiblichen 
Pronucleus auch ohne Befruchtung stattindet, so ist es doch nicht gelungen, dafïr ein einwandsfreies Object aufzufinden.

Von grösster Wichtigkeit dagegen ist das Ovarium von Sorex 35 (T'afel 1 Fig. fi) dessen Details bei 800facher Vergrösserung in Fig. 7. 8. und 9. wiedergegeben sind.

Im Uterus fanden sich, wie oben erwähnt, die alten Placentarstellen als Beweise eines stattgehabten Partus; zugleich fanden sich als Spuren der bald darauf erfolgten Cohabitation Spermatozoiden in der Vagina, im Uterus und in den 'Tuben.

In Fig. 7. sieht man einige derselben, die sich in der Uterushöhle befanden.

Im Ovarium fand sich ein eben gesprungener Follikel, der folgenden interessanten Befund bot.

In der Nähe der offenen Stelle befanden sich auf verschiedenen Schnitten zahlreiche Spermatozoen.

Auf. Fig. 8. ist der Kopf des einen, der der Oeffnung am nächsten war, noch im Gesichtsfelde links oben.

Das Deckepithel ist durch den Riss in seiner Continuität unterbrochen, die Granulosazellen liegen demselben rechts dıcht an, während sie links durch etwas stromagewebe, das einen Primairfollikel enthält, von demselben geschieden sind.

Dicht darunter schiebt sich ein Blutgefäss der tunica propria zwischen die Granulosazellen, deren Verband sehr lose geworden ist. Am unteren Rande des Gesichtsfeldes sieht man die Contur der Eizelle, zwischen zahlreichen losen Granulosazellen, kleinere intensiv gefürbte Körperchen, die den in Fig. 7. abgebildeten Spermatozoen an Form und Grösse entsprechen.

Durch Verschiebung der Mikiometerschraube und Vergleichung mehrerer Schnitte lässt sich nachweisen, dass einzelne dieser Spermatozoen auch noch den Schwanz erhalten haben, während er bei den meisten nicht mehr zu finden ist.

Fig. 9, endlich zeigt uns die Eizelle dieses Follikels. Ein Blick auf die Zeichnung erklärt den Befund besser, als eine längere Beschreibung.

Man sieht einen grösseren Kern, der von aussen eindringt gegenüber einem kleine. ren Kern, dessen Chromatin sich an den äusseren Seiten in zwei intensiv gefärbten Kügelchen gesammelt hat, während das Protoplasma dahinter koerniger erscheint.

An derselben Seite ist die Eizelle nabelförmig eingezogen; der Raum zwischen ihr und der Zona pellucida ist durch eine scheibenförmige (im Durchschnit etwa mondsichelförmige) Masse angefüllt, deren oberer T'eil auf diesem Schnitte ganz am Rand eine dunklere Partie erscheinen lässt. Auf dem folgenden Schnitte zeigt sich, dass diese dunklere Partie das Segment eines intensiv gefärbten Kernes ist, der einer kleineren, der Eizelle anliegenden spindelförmigen Zelle angehört, also analog ist dem von der weiblichen Eizelle bereits ausgestossenen Richtungskörperchen.

Obgleich nun dieses Bild nicht völlig den bisher er hobenen Befunden der Befruch. tung entspricht, so glauben wir doch berechtigt zu sein, zu der Annalime, dass es sicll hier um einen analogen Prozess handelt.

Was jedoch ohne jeglichen Zweifel aus dem erhobenen Befunde liervorgeht, ist das 
Factum, dass die Spermatozoen nach stattgefundenem Coitus an das Ovarium und bis in den gesprungenen Follikel hinein vordringen, dass demnach die Befruchtung im Ovarium selbst noch vor Ausstossung des Eies stattfinden kann.

Bezüglich der Bildung des corpus luteum können wil uns damit begnügen, die für Tupaja erhobenen Befunde auch fül Sorex zu bestätigen und verweisen bezüglich der ferneren Befunde auf die später zu beschreibenden grösseren Objecte von Tarsius.

Fig. 11 zeigt bei einem ganz frischen corpus luteum einen Theil der tunica propria, deren Gefässsprossen sich bereits tief zwischen die gequollenen Zellen der Granulosa hineinschieben. Rechts am Rande, sowie in der Mitte sieht man zwei Zellen, die den deutlichsten Beweis liefern, dass das Lumen der jungen Gefässe durch Hohlwerden der Endo. thelzellen an den Sprossen gebildet wird.

In Fig. 10 sind bereits geräumige, mit Blut gefüllte Lumina zu sehen, die wie ein Netzwerk zwischen den zum Teil bereits degenerierten Granulosazellen sich hinziehen.

Auch die atretischen Erscheinungen bei Sorex sind völlig dieselben wie bei Tupaja. Einfache Atresie, hyaline, fettige und chromatolytische Degeneration findet sich hier ebensogut wie die dégéneration par fragmentations.

Die Fig. 12-15 illustrieren einzelne del beobachteten Formen. Hierbei verdienen die beiden in Fig. 13 und 14 reproducierten Gebilde einer besonderen Erwähnung, da es bei Betrachtung derselben nicht unmöglich seheint, dass Fig. 13 einem Follikel entspricht, der nach bereits stattgefundener Befruchtung atretisch wurde, während Fig. 14 denken lässt an einen nach Ausstossung des Pronucleus atretisch gewordenen befruchtungsrähigen Follikel.

Für die erstere Möglichkeit sprechen die links seitlich durch intensivere Färbung ausgezeichneten Detritusmassen, die analog den Spermatozoen sich stark von den übrigen Zellkernen abheben, für die letztere, die neben dem stark wandstïndigen, degenerierten Eikern ebenfalls dunkler gefärbten Körnchen, deren Lage der eines Pronucleus entspricht. Doch seien beiden Annahmen mit aller Reserve aufgestellt.

Fassen wir, ebenso wie bei Tupaja, die gewonnenen Befunde für Sores zusammen, so lautet der Bescheid:

1. Bei Sorex findet (ebenso wie bei Tupaja) eine Anbildung von Follikeln aus dem Deckepithel während der ganzen Dauer des Geschlechtslebens statt, die Zahl der Eizellen im Deckepithel steht in directem Verhältniss zur Zahl der Primairfollikel, wie der Follikel iiberhaupt.

2. Bei der Eireifung beteiligen sich (ebenso wie bei Tupaja) die Eizelle, das Follikelepithel und das Stroma zugleich.

Die Eizelle wächst durch gleichmässige Grössenzunahme und stösst einen Pronucleus aus, der zur Zeit der Befruchtung bereits gebildet ist.

Das Follikelepithel vermehrt sich fortwährend durch indirecte Kernteilung, und zwar am lebhaftesten vor vollendeter Reife.

Das Stroma beteiligt sich durch Lieferug einer lebhaft wnchernden Gefïssschicht in der ganzen Umgebung des Follikels. Die Endothelien derselben vermehren sich durch indirecte Kernteilung. 
3a. Follikelatresie findet in allen Zeiten statt; physiologisch atresieren alle Follikel im Beginn der Schwangerschaft. Die Atresie beginnt meist mit der Ei\%elle und dem follikelepithel zugleich, und ist aus der Beschaffenheit der Eizelle am leichtesten zu erkennen. Das Stroma beteiligt sich erst secundär durch allmählige Vascularisation.

3b. Das corpus luteum bildet sich nach Ausstossung der Eizelle sowohl aus dem übrigbleibenden Follikelepithel, als aus der vom Stroma gelieferten Theca.

Bei eintretender Schwangerschaft werden alle corpora lutea in der ersten Hälfte völlig resorbiert.

4a. Ueber Menstruation von Sorex liessen sich keine sicheren Anhaltspunkte gewinnen.

Während der Brunstzeit scheint zur Zeit der Eireife eine Desquamation des Uterusepithels stattzufinden; ein mit Sicherheit nach Menstruation gebildetes corpus luteum liess sich nicht nachweisen.

4b Bei der Befruchtung dringen die Spermatozoen bis in das Ovarium vor, woselbst bereits Befruchtung stattfinden kann. Nach stattgehabter Befruchtung atresieren sümmt. liche noch übrige Follikel.

4c. In der ersten Hälfte der Schwangerschaft findet keine Eireifung statt. Sämmtliche neu sich bildenden Follikel atresieren, sobald sie eine gewisse Grösse erreicht haben Die Zahl der corpora lutea entspricht der Zahl der ausgestossenen Eizellen, jedoch nicht der Anzahl der Embryonen, die meist geringer ist.

Gegen Ende der Schwangerschaft finden sich bereits wieder reife Follikel, jedoch keine Spuren von corpora lutea mehr.

Unmittelbar nach der Geburt kann schon wieder Schwangerschaft eintreten, zu einer Zeit, wo die Placentarstellen noch zweifellos als solche zu erkennen sind.

4d. Je älter ein Thier ist, desto weniger finden sich Eizellen im Deckepithel und Primairfollikel.

Mit der Abnahme des Parenchyms geht eine Zunahme des Stromas gepaart, zugleich verliert das ganze Organ an Grösse. 


\section{TARSIUS SPECTRUII.}

Obgleich das Utrechtsche Museum mehr als 600 Exemplare wohl conservierter weiblicher Genitalien von Tarsius spectrum besitzt, so war aie Verwertung derselben wegen der Grösse der Objecte mit ungleich grüsseren Schwierigkeiten verbunden, als die der beiden ersten Species.

Es mag als ein glücklicher Zufall betrachtet werden, dass es gelang, in verschiedenen Exemplaren die allerersten Stadjen von Schwangerschaft in den zahlreichen, gros. sen Serienschnitten zu entdecken; andrerseits aber ist die Möglichkeit nicht ausgeschlossen - ja sogar manchmal sehr wahrscheinlich - dass in einzelnen Fällen eine eventuelle Schwangerschaft übersehen worden ist.

Zur Verwertung des Materials für unsern speciellen Zweck mussten wir daher einen anderen Weg einschlagen, als in den vorausgeschickten Serien von Beobachtungen.

Einen festen Anhaltspunkt zur Beurteilung einzelner Ovarien lieferte zunïchst das Alter des in Utero angetroffenen Foetus, einen weiteren, die deutlichen Zeicnen des Puerperiums in utero, einen dritten, dıe seltenen Fälle von virgines intactae.

In einem einzigen Falle (277) liess sich mit sicherheit ein menstrueller Prozess constatieren, in einem weiteren (127) konnte Gravidität ausgeschlossen werden, da Úterus und Scheide mit einer serösen Flüssigkeit gefiillt waren, bei intactem Epithel. In allen anderen Fällen mussten wir uns begnügen, mit Rücksicht auf das negative Resultat der Jagd nach dem Foetus, dieselben als "wahrscheinlich nicht gravid" zu bezeichnen.

Liessen nun auch die Analogien mit den anderen Thieren mancherlei Schlüsse zu, so müssen doch zunächts die gefundenen Thatsachen als solche angefühıt werden, bevor wir zur Verwertung derselben übergehen.

Die gewählten Vorbilder, die aus einer grossen Zahl ïhnlicher Befunde herausgegriffen sind, wurden der Controle wegen mit verschiedenen Vergrösserungen gezeichnet, soviel möglich mit denselben, wie Tupaja und Sorex, nümlich mit $t$ Sfacher und soofacher 
Vergrösserung, welche somit eine directe Vergleichung gestatten. Nur die das corpus luteum betreffenden Objecte sind auf 256 vergrössert, um bei genügender Deutlichkeit धin grösseres Gesichtsfeld zu bieten.

Die beigefügten Nummern in Klammern beziehen sich auf die Nummern im Utrecht. schen Museums-Katalog.

\section{A. Ovarien, die hoechst wahrscheinlich von nichtschwangeren Tieren abstammen.}

Die zum Teil abgebildeten Durchschnitte, 48mal vergrössert, entstammen den folgenden Fällen:

1. Jungfräuliches Ovarium. Taf. II, Fig. $16 a$ (311).

Uterus: klein, glatt, Hörner nicht verdickt.

Ovarium $d_{.}$: zahlreiche Primairfollikel; mittelgrosse zum Teil degenerirt. Kein corpus luteum.

Ovarium sin: zahlreiche Primairfollikel, mittelgrosse zum Teil degenerirt, einer davon mit einer Richtungsspindel. Ein grosser Follikel in beginnender Degeneration, kein corpus luteum.

Das Ovarium von (409) bietet völlig analogen Befund; das makroroskopische Bild nebst uterus findet sich in natürlicher Grösse abgebildet.

\section{Ovarium eines nicht schwangeren (?) Uterus. (113).}

Uterus: klein, Hoerner nicht verdickt, auf zahlreichen Serienschnitten kein Embryo gefunden.

Ovarium $d .:$ kleine und mittelgrosse Follikel, worunter sehr viele normal. Ein grosses corpus luteum mit grosser centraler Höhle, die von coagulirten, zum Teil organisierten Massen gefüllt ist, welche rote Blutkörperchen enthalten.

Ovarium sin: Viele mittelgrosse und kleine Follikel, meist normal. Kein corpus luteum.

\section{Idem. (114).}

Uterus: analog 2 (113), nichts von Schwangerschaft gefunden.

Ovarium d.: Zahlreiche mittelgrosse und kleine Follikel, meist normal, nur einzelne degenerirt. Ein compactes, stark zurückgebildetes corpus luteum.

Ovarium sin: Zahlreiche kleine Follikel in Degeneration, nur einzelne normal. Ein grosses, cystisches corpus luteum, centrale Höhle mit seröser Flüssigkeit gefuillt; kein Blut darin.

\section{Idem. (127).}

Uterus und Vagina: Durch seröse Flüssigkeit ausgedehnt. Keine Zeichen von Gravidität und Puerperium.

Ovarium sin: Ein sehr grosser, reifer normaler Follikel, zahlreiche mittelgrosse und 
kleinere, meist normal, zum Teil in Degeneration; ein mittelgrosser Follikel mit sehr schöner Richtungsspindel und ausgestossenem Richtungskörperchen (?) Kein corpus luteum.

Ovarium d.: Zahlreiche kleine und mittelgrosse Follikel, meist normal. Kein corpus luteum.

๖. Orarium bei Menstruation. Taf. II, Fig. 166 (277).

Uterus: Leicht gefaltet, wie ein puerperaler, jedoch ist keine Placentarstelle zu constatieren. In der Uterushöhle viel Blut und desquamirtes Epithel.

Ovarium d.: Ein grosser reifer nicht degenerirter Follikel, daneben stark resorbierte Ueberreste eines corpus luteum. Kleinere und mittelgrosse Follikel, zum Teil normal, einzelne degenerirt.

\section{B. Ovarien von schwangeren Tieren in verschiedenen Stadien.}

1. Ovarium bei Impraegnation. Taf. II, Fig. 17 (๖̌

Das befruchtete Ei mit noch nicht vereinigtem männlichen und weiblichen Vorkern in der Tube.

Ovarium: Frisch geplatzter, noch nicht geschlossener Follikelbalg.

Zahlreiche mittelgrosse und kleinere Follikel, alle im Degeneration. Ein stark resorbiertes corpus luteum,

2. Idem. Taf. II, Fig. 18. (43).

Befruchtetes Ei mit noch nicht vereinigtem männlichen und weiblichen Torkern in der Tube.

Ovarium: Frisches corpus luteum, Narbe an der Rissstelle bereits gebildet, cystisch; in der Cysts freie Ballen von Follikelepithel, keine Blutkürperchen. Zahlreiche kleine, sehr wenig mittlere Follikel, alle degenerirt.

In einem weiteren Falle (259) fand sich ebenfalls in del Tube das befruchtete Ei mit noch nicht vereinigten Kernen. im Orarium ein corpus luteum mit grosser Höhle völlig analog dem Falle (114).

3 Orarium im frïhesten Stadium der Schwangerschaft. Taf. II, Fig. 19, (81).

In Ctero ein foetus im Morulastadium.

Ovarium d.: Zwei grosse Follikel im ersten Stadium hyaliner Degeneration. Unter den kleineren noch einige normal aussehend, die meisten in Degerneation. Kein corpus luteum.

Ovarium sin: Mittlere und kleine Follikel, alle degenerirt; ein grosses frisches corpus luteum mit centraler Höhle ohne Blut, mit mächtiger Wand.

4. Orarium aus der ersten Zeit der Schwangerschaft. (90).

Ovarium d.: Ein grosses corpus luteum, stark mit Blutgetässen durchsetzt mit kleiner 
centraler Höhe und mächtiger Wandschicht, zahlreiche mittlere und kleine Follikel, alle hyalin degenerirt.

Ovarium sin: Kein corpus luteum, ein grösserer, zahlreiche mittlere und kleinere Follikel, alle in Degeneration.

\section{Ilem. (91).}

Uterus: Embryo analog 4.

Ovarium $d$. : Ein grosses, compactes corpus luteum mit centralem, zum Teil bereits vascularisirtem Thrombus und starken Gefüsslumina. Alle kleineren und mittelgrossen Follikel atretisch.

Ovarium sin: Bildet einen schlaffen Sack, dessen innere Fläche grüsstenteils von einer stellenweise mit flachem unregelmässigem Epithel ausgekleideten Cysts (degenerirtes corpus luteum?) eingenommen wird. Spärliche kleine Follikel, welche alle degenerirt sind.

\section{Ovarium im congestiven Stadium beginnender Schwangerschaft. (86).}

Im rechten Horn des Uterus ein Embryo angeheftet. Die congestionierten Drüsenschläuche convergieren nach dem Embryo hin.

Ovarium sin: (a) Ein grosses, völlig compactes corpus luteum; zahlreiche mittlere und kleine Follikel, alle atretisch.

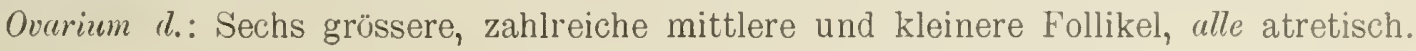

7. Idem. (120).

Embryo im rechten Hol'n analog (86). Uterus congestioniert.

Ovarium d.: Kein corpus luteum, ein reifer Follikel mit Zeichen beginnender Degeneration. (Kern nicht in der Serie gefunden). Zwei grössere Follikel in hyaliner Degeneration, mittelgrosse und kleinere, alle atretisch.

Ovurium sin: Grosses compactes corpus luteum, Zwei grössere, zahlreiche mittel. grosse und kleinere Foliikel, alle in beginnender oder fortgeschrittener Atresie.

8. Item. Taf. II, Fig. 20h. (372).

Keimblase im Uterus angeheftet Congestion.

Ovarium sin: Zwei grössere Follikel, mehrere mittelgrosse und zahlreiche kleinere, alle in hyaliner Degeneration, ein altes, beinahe resorbiertes corpus luteum. ein frisches compactes corpus luteum, das völlig ectropionirt, wie ein Champignon nur mit einem Stiel am Ovarium haftet.

Einen völlig analogen Befund boten verschiedene Exemplare bei denen der Embryo bereits weiter entwickelt war.

Es fand sich nämlich bei je einem Embryo-neben Atresie sămmtlicher Follikel (abgesehen von den Primairfollikeln) je ein compactes, oder mit einer kleinen centralen Höhle versehenes corpus luteum in sämmtlichen Fällen. - 
$(338,129,173,126,64,174,26,181,46,354,257,49)$, in einem Falle (38) war ein corpus luteum vorhanden, jedoch in jedem Horn ein Embryo.

9. Orarium bei weiter entwickelter Schwangerschaft. Taf. II, Fig. 20a. (110).

Junger Embryo im rechten Horn.

Ovarium $d$. : Ein grosses compactes corpus luteum. Zahlreiche grössere mittlere und kleinere Follikel, alle atretisch.

Ovarim sin: Wie bei 10 .

10. Idem. (60).

Junger Embryo im rechten Horn.

Orarium d.: Völlig analog 9.

Ocurium sin: zahlreiche mittelgrosse und kleinere Follikel, alle in Atresie, Primair follikel normal.

11. Orarium am Encle der Schwangerschaft. Taf. II, Fig. 21. (74).

Im Uterus ein beinahe ausgetragenes Foetus.

Ocarium d.: Kein corpus luteum, ulle kleineren und mittelgrossen Follikel atretisch, zahlreiche normale Primairfollikel.

Ocarium sin: Ein sehr kleines, beinahe resorbiertes corpus luteum, alle Follikel degeneriert, meist hyalin, zahlreiche Primairfollikel. Sämmtliche übrigen Fälle von hochschwangeren Tieren zeigten denselben Befund.

\section{Ovarien von puerperalen Tieren.}

\section{Ovarium von frisch puerperalem Uterus. (77).}

Uterus: Frisch puerperal. Placentarstelle makroskopisch sichtbar. Epithel noch nicht regeneriert.

Ovarium sin: Kein corpus luteum, zahlreiche grössere und kleinere Follikel, worunter die meisten normal.

Ovarium d.: Derselbe Befund, wie links.

๖. Idem. Taf. II, Fig. 23, (6).

Uterus: Wie 1.

Ovarium d.: Ein grosses, compactes, frisches corpus luteum. Mittlere und kleinere Follikel, worunter zahlreiche normale, verschiedene atretisch, meist hyalin.

Ovarium sin: Kein corpus luteum, Follikel grösstenteils normal. 


\section{Ilem. (41).}

Bietet denselben Befund wie 1 und 2, nur ist das corpus luteum gross cystisch, mit serösem, kein Blut enthaltendem Coagulum.

4. Ovarium ron spätpuerperalem Uterus. Taf. II, Fig. 22, (16).

Uterus: gerunzelt, Epithel regeneriert, Placentarflïche rauh.

Ovarium $d$. : Viele kleinere und mittelgrosse Follikel, worunter die meisten normal. Kein corpus luteum.

Ovurium sin: Ein sehr grosses cystisches corpus luteum; in der Höhle ein Coagulum, das rote Blutkörperchen enthält. Zahlreiche mittelgrosse und kleinere Follikel, worun. ter viele normale.

Vier weitere Exemplare von frischen postpartum uteri zeigten alle stark resorbierte corpora lutea oder Spuren derselben neben einzelnen normalen kleineren und zahlreichen atretischen Follikeln bis zu mittlerel Grösse; diesel Befund wurde erhoben bei 13, 162. $171,256$.

Auf Tafel VII sind bei 800facher Vergrösserung noch so viele Detailbilder wiedelgegeben, als nötig schi $€ n \in n$, um die Analcgie mit Tujaja und Sorex möglich zu machen Tafel VII, Fig. 1 bis 6 zeigt die Entwickelung der Primairfollikel aus dem Deckepithel.

Wir konnten auch für Tarsius die Beobachtungen von Waldeyer, Paladino u. a. bestätigen, dass während des ganzen Geschlechtslebens eine Neubildung von Eizellen vom Deckepithel aus stattfindet, und zwar um so lebhafter, je jünger das Individuum ist.

Ebenso wie bei Tupaja haben die Eizellen eine plattgedrückte Kugelgestalt. Die Scheidung der einzelnen Follikel durch das Stroma geht langsamer als bei Tupaja, doch schneller als bei Sorex von statten.

Darum treffen wir die jüngsten Primairfollikel häufig in Eiballenform, selten schon deutlich isoliert und auch selten in Form von Drüsenschläuchen an. Ein vergleichender Blick auf die hier abgebildeten (Fig. 3, 4, 5,) und die von Sorex und Tupaja gemachten analogen Bilder beweișt mehr als lange Worte.

Auch bei 'Tarsius erfährt der von Keimepithel umgebene Primairfollikel erst eine Periode der Streckung, bei der das dicke Epithel flacher und durch die sich vergrössernde Eizelle ausgezogen erscheint, ohne dass die Zahl der Zellen vermehrt wird. Der unterste Primairfollikel von Fig. 5 illustriert dies deutlich; trotz seines grösseren Úmfanges sind auf dem Durchschnitt nur acht Keimepithelzellen angeschnitten, während bei dem dicht darüber liegenden kleineren ebenfalls nur acht, bei dem obersten sogar neun Keimepithelzellen auf der Schnittfläche erscheinen.

In Fig. 6 zeigt sich das Epithel an einzelnen Stellen bereits mehrschichtig, verschiedene Zellen haben kariokinetische Bilder auf dem Durchschnitt.

In Fig 7 sieht man einen mittelgrossen Follikel, dessen Epithel sich anschickt, de1) liquor folliculi zu bilden. Hier ist auch die tunica bereits in lebhafter Entwickelung, ja 
es beginnt dieselbe sogar an der mit einem Kreuz versehenen Stelle eine kleine Sprosse zwischen das Follikelepithel zu treiben.

Fig. 8 zeigt die Eizelle eines beinahe reifen Follikels mit häufiger Kariokinese des Follikelepithels darum hin. In diesem Stadium hat sich ein deutlicher Cumulus proligerus neben einer geräumigen mit viel Liquor gefüllten Höhle gebildet, der ganze Follikel hat auffallende Aehnlichkeit mit dem des Weibes.

Auf Tafel VII, Fig. 9-12 sind verschiedene Vorbilder für die bunten Bilder der Atresie, die oben bereits genügend besprochen worden ist, um sich hier mit einem kiurzen Hinweis zu begniigen.

Auf Fig. 11 sei indessen speciell aufmerksam gemacht; neben der Richtungsspindel bemerkt man rechts unten noch innerhalb der Eizelle eine schwach gefärbte, mit doppeltem Kern versehenen Zelle. Das ganze macht sehr den Eindruck einer Eizelle, die, wie Flemming sich ausdrückt, in dem Augenblick "erstarrt ist" in dem sie das Richtungs kürperchen ausstiess.

Der Befund sei hervorgehoben, die Deutung ist problematisch.

Sehen wir vorläufig von der feineren Untersuchung des reifen Follikels ab, um dieselbe später im Zusammenhang mit der Bildung des corpus luteum zu besprechen, so bleibt uns noch ïbrig, um die hier mitgeteilten Befunde in Einklang zu bringen mit den früheren und die Eingangs gestellten Fragen zu beantworten.

Ad. 1. Bezüglich der Primordialeier gilt dasselbe wie von Tupaja und Ŝorex, dass sich diesclben zu allen Zeiten des Geschlechtslebens aus dem Deckepithel stets neu formen, und zwar um so lebhafter, je jünger das Tier ist.

Ad. 2. Bei der Follikelreifung beteiligen sich Eizelle, Follikelepithel und Stroma gemeinschaftlich. Während die erstere an Grösse zunimmt, vermehren sich Follikelzellen, sowie die Zellen der die tunica interna bildenden Gefässendothelien, sowohl durch indirecte Kernteilung, als auch durch Grössenzunahme.

Noch früher und lebhafter als bei Tupaja und sores findet eine Sprossung von Endothelien der Gefässe zwischen die Follikelzellen statt.

Ad. $3 a$. Die Eollikelatresie ist als ein physiologischer Vorgang anzusehen, dem stets eine grosse Anzahl reifender Follikel anheimfallen.

Bei eingetretener Schwangerschaft atresieren sämmtliche Follikel mit Ausnahme der Primairfollikel.

Um die Frage 3h. nach der Bildung des corpus luteum zu beantworten, müssen wir nun etwas ausführlicher auf die feineren Verhältnisse desselben eingehen.

Da, wie gesagt, bei 'Tarsius der negative Beweis der Nichtschwangerschaft keine festen Schlüsse auf das Alter des corpus iuteum zuliess, so musste die Untersuchung beginnen an corpora lutea von schwangeren Uteri, bei denen das Alter des Futus einen gewissen Anhaltspunkt gab.

Der Uebersicht wegen ist das Bild des grüssten noch nicht gesprungenen normalen Follikels, der angetroffen wurde, beigefügt.

Die Tafeln VIII und IX dienen zur Illustration der gefundenen Verhältnisse. 


\section{Tafel VII. Fig. 1. Der reife Follikel.}

Aus Serienschnitten lässt sich nachweisen, dass die zum Follikel tretenden Gefässe einen Hilus bilden, von welchem aus die stärksten Stämme sich in die Tunica propria verzweigen und darin auflösen, nur wenige kleinere Gefässe treten an anderen Stellen in die Tunica propria ein.

Auf Tafel IXa ist derjenige Teil des Follikels von demselben Schnitt, der den cumulus proligerus enthält, in 256 facher Vergrösserung abgebildet.

Hier ist deutlich zu sehen, dass von der tunica intima, die ein dichtverzweigtes Gefässnetz formt, Sprossen, die bereits mit Blut gefüllt sind, sich zwischen die Granulosazellen einschieben. Die Granulosazellen selbst zeigen noch zahlreiche kariokinetische Bilder.

\section{Fig. 2. Frisch gesprungener follikel.}

Am Hilus hat sich das stark verdickte Stroma mit grossen Gefüssen nach innen gedrängt. Die Reste der Granulosa sind stark gequollen und überall am Rande auseinander gedrängt durch stark ausgedehnte mit Blut gefüllte Sprossen der intima.

Tafel IX $b$ zeigt den Rand des Risses in 256facher Vergrïsserung, man sieht hier deutlich, wie sich die Gefässe der Tunica überall zwischen die Granulosazellen vorgeschoben haben, die selbst grüsser und heller zu werden anfangen, als diejenigen des reifen Follikels.

Ueberall zwischen den Granulosazellgruppen schieben sich noch nicht mit Blut gefüllte Endothelsprossen der intima hindurch.

Fig. 3. Corpus luteum mit vernarbender Rissstelle, mit seröser Fliissigkeit gefïllt.

Die Rissstelle ist vernarbt; in der Narbe finden sich einzelne Ballen von Granulosa. zellen, die von fibrinösen Massen eingeschlossen sind.

Der Hilus mit krüftigen Gefässen befindet sich der Narbe gegenüber. Die Grösse des ganzen Gebildes entspricht ungefähr der des reifen Follikels.

Auf Tafel IXc ist die Narbe 256mal vergrössert dargestellt.

Hier sieht man, dass die Gefässe bereits tiefer durch die Reste der Granulosa hin. gewachsen sind, und dass selbst eines dicht neben der frischen Narbe durch grosses Lumen sich auszeichnet. Die Granulosazellen sind grösser und mehr durch das wachsende Stroma in Gruppen abgeteilt. An der Innenseite sieht man lose Kerne und Zellen mit verschwimmendem Umrisse, als Beweis, dass noch stets einige Granulosazellen zur Anbildung ron Liquor folliculi beitragen.

Die Höhle der Cyste ist mit einem albuminoiden Coagulum gefüllt, das keine roten Blutkörperchen enthält, und auch nicht bräunlich oder gelb gefärbt ist.

Fig. 4. Corpus luteum mit völlig vernarbter lissstelle, zu einer verhältuissmässin diinuwandigen Cyste insgedehnt.

Die Narbe ist völlig geschlossen, aber noch als dünner fibrinöser Strang wahrzu- 
nehmen. Das Volum hat, dank sei dem serösen Inhalt, mächtig zugenommen. Die Wand ist etwas dünner als vorher, und besteht, wie aus Tafel IX $l$ ersichtlich, aus den stark vergrösserten Granulosazellen zwischen denen sich ein mächtiges Gefässnetz mit grossen Lumina aus der intima entwickelt hat, das in diesem Stadium die Reste der Granulosa bereits überall durchwuchert und in schärfere Gruppen, die aus weniger Zellen bestehen, scheidet.

Die Höhle der Cyste enthällt eine coagulierte hyaline Masse, die Reste von Zellkernen, zeigt jedoch keine Blutkörperchen.

\section{Fig. 5. Corpus luteum nit gewucherter Wand nnd rerkleinerter Höhle.}

In diesem Stadium ist auch noch die vernabte Rissstelle als fibrinöser Strang deutlich zu sehen. Das Volum des ganzen Gebildes hat abgenommen, dagegen sind die Hilusgefässe mächtiger entwickelt, und ihnen entsprechend die die Wand durchziehenden Gefässe der früheren Intima. Die Zellen der Granulosa stehen meist in radiär geordneten Gruppen, zwischen den Gefässen, die sich von der Peripherie aus, wo sie am mächtigsten sind, radiär nach dem Centrum begeben, um in der Nähe der Höhle zahlreiche Anastomosen einzugehen.

Das Innere der Höhle ist mit serösem Coagulum gefüllt.

\section{Fig. 6. Corpus lntenm in demselben Stadinm, jedoch mit coagulirtem Blntergnss in der Hïhle.}

Dieses Stadium entspricht histologisch röllig dem unter j beschriebenen, mit dem einzigen Unterschiede, dass sich innerhalb der Hühle zahlreiche rote Blutkürperchen findelı, einzelne frei, andere eingebettet in ein fibrinöses, zum Teil organisiertes Coagulum.

Tafel IXe zeigt den Befund mit 256facher Vergrisserung. Absichtlich haben wir dieses Bild zur Darstellung gewählt, da daraus ersichtlich ist, dass unbeschadet des Blutergusses die weitere Entwickelung des corpus luteum gleichmässig weiterschreitet, und lass es die Lage der Blutgefïsse erklärlich macht, warum erst jetzt, vermöge ihrer oberflächlichen Lage, ein Bluterguss in das Innere stattfinden kann, zugleich aber zeigt sich dabei, dass derselbe in den meisten Fällen ucht stattzufinden braucht. wie das de facto constatiert werden kann.

\section{Fig. \%. Corpus lutenm mit starkgewncherter Wand und stark rerkleinerter Hôle.}

Aus der stärkeren Vergrüsserung in Tafel IX $f$ ist ersichtlich, dass das Wachstum der Granulosazellen seine Grenze bereits überschritten hat, während das Gefässnetz sich mehr und mehr organisiert und längs seiner Wandungen eine lebhafte Anbildung von bindegewebigen Zellen beginnt. Das Volumen des corpus luteum beginnt wieder abzunehmen. 
Fig. 8. Corpus lutemm mit kleiner centraler Hiihle.

Das Volum des corpus luteum hat zugenommen auf Kosten der Höhle, die beinahe geschwunden ist.

Die Structur ist dieselbe wie im vorigen Stadium.

Fig. 9. Corpus luteum mit centralem organisierten Fibriupropf.

Stadium analog dem von 8, mit dem einzigen Unterschiede, dass es sich hier um einen centralen Bluterguss handelt, der dieselbe Beschaffenheit zeigt, wie ein organisirter Thrombus.

Fig. 10. Compactes corpus luteun.

Die centrale Höhle ist völlig zugewachsen, das corpus luteum bildet eine compacte Masse von derselben Grösse wie die letzten cystischen Stadien, die Gefässe bilden ein dichtes Flechtwerk, das mehr weniger radiär angeordnet ist.

\section{Fig. 11. Compactes corpus Iuteum in Schrumpfung.}

Volum vermindert, Bindegewebsbildung längs der Gefässe stark vermehrt.

\section{Fig. 12. Rest des corpus Inteuu.}

Aus Tafel IXg ist ersichtlich, dass schliesslich analog den atretrischen Vorgängen im Follikel hyaline Degeneration die meisten Zellen zerstört und verschmilzt, dazwischen sind noch einige Granulosazellen stark geschrumpft vorhanden, andere befinden sich in fettiger und koerniger Degeneration. Die Gefässe der früheren Intima gehen mehr und mehr in das sie umgebende bindegewebige Stroma auf und nur noch wenige Aeste durchziehen den eben noch durch seine hellere Farbe erkennbaren Rest des corpus luteum.

Zur Feststellung dieser Typen diente, wie gesagt, in erster Linie als Anhaltspunkt das Alter des Embryo. Daneben jedoch auch die Grösse und Wachstumszunahme der zu Luteinzellen sich entwickelnden Granulosazellen; dieses letztere Moment war von besonderer Wichtigkeit, da es sich zeigte, dass ein und demselben Stadium des Embryo nicht stets dasselbe colpus luteum entsprach, was sich so erklären lässt, dass in dem einen Falle das Ei sofort nach dem Verlassen des Follikels befruchtet wurde, in einem anderen erst etwas später.

Der Uebersicht halber seien die Fälle jüngstel Embryonen nebst dem Befunde am corpus luteum hier zusammengestellt.

1. Impraegnation. Befruchtetes Ei uit getrenntem miinnlichen und weihlichen Korn i d. 'Tube.

a. $(547)=$ Tafel VIII, 2.

frisch gesprungener Follikel. Rissstelle noch offen. 
b. $(43)=$ Tafel VIII, 3 .

Corpus luteum geschlossen, frische Narbe. Cyste vd.

Grösse des reifen Follikels.

c. $(259)=$ Tafel VIII, 4 .

Corpus luteum cystisch, mit Liquor gefüllt, grosse Cyste.

\section{Furchungsstadium in utero.}

a. $(84)=$ Tafel VIII, 5 .

Corpus luteum cystisch mittelgross.

b. $(160)=$ Tafel VIII, 6 .

c. $(462)=$ Tafel VIII, 7 .

Corpus luteum kleincystisch mit dicker Wand.

d. $(530)=$ Tafel VIII, 8.

Corpus luteum compact, kleine centrale Höhle.

\section{Morulastadium in utero.}

a. $(81)==$ Tafel VIII, $\boldsymbol{\tau}$.

ᄂ. $(218)=$ Tafel VIII, 8 .

c. $(30)=$ Tafel VIII, 8.

in der centralen Höhle ein gelbgefärbter Fibrinpfropf (Extravasat).

d. (87) idem.

e. $(250)=$ Tafel VIII, 9 .

Sämmtliche weiteren Stadien von Schwangerschaft haben compacte corpora lutea analog Tafel VIII, 9 und 10.

Daraus ist ersichtlich, dass die Bildung des corpus luteum ausserordentlich rasch vor sich geht, und das Grössenmaximum bereits ganz im Beginn in der Cỵstenform erreicht ist.

Dem möglichen Vorwurf, dass bei der Klassificierung der corpora lutea willkürlich zu Werke gegangen ist, lïsst sich mit Leichtigkeit durch Hinweis auf die Thatkachen begegnen

Dass zunächst der frisch gesprungene Follikel das erste Stadium vorstellt, leuchtet von selbst ein.

Fïr die Bestimmung der folgenden Stufe diente die frische Narke und das Aussehen der Luteinzellen die noch wenig grösser waren als die der ersten Stufe.

Für die dritte Stufe, das grosscystische corpus luteum, war wieder einerseits massgebend das Aussehen der Luteinzellen, ferner die bessere Consolidierung der Rissnarbe. Massgebend für die Stellung dieser grosscystischen Form ror den späteren kleincrstischen war wieder das Stadium der Schwangerschaft (Impraegnation) in diesem Falle, und ferner die geringere Entwickelung des Gefässnetzes zwischen den Luteinzellen.

Für die spätere Entwickelung liegen die Thatsichen viel einficher: grüssere Cỳsten fanden sich überhaupt nur im Furchungsstadium. Im Morulastadium dagegen waren alle 
corpora lutea kleincystisch oder bereits compact geworden. Mit dem Kleinerwerden der Höhle geht eine stärkere Entwickelung des Gefüssnetzes Hand in Hand.

Von da ab bleiben sie compact, werden mehr und mehr bindegewebig und sind am Ende der Scliwangerschaft resorbiert.

Fassen wir nun die gefundenen Pesultate für die Bildung zunächst.des "corpus luteum graviditatis" zusammen, so lassen sich dieselben in Kurzem in Folgendem resumielen.

Die Elemente des corpus luteum sind:

1. Die wandständigen Zelllagen der Granulosa.

2. Das die tunica intima bildende, von stroma gelieferte Gefässnetz.

Bereits vor der Reife des Follikels sendet dasselbe blutführende Endothelsprossen zwischen die Granulosazellen hinein.

Beim Bersten des Follikels schwillt das Gefüssnetz der intima wie ein corpus cavernosum an und die Zellen der Granulosa vergrissern sich ebenfalls.

Nach Vernarbung der Rissstelle bildet das corpus luteum eine grosse, mit seröser Flüssigkeit gefüllte Cyste, deren Wand aus, zu Luteinzellen sich vergrössernden, Granulosazellen und den stark wuchernden Gefässen der intima besteht.

Allmählig verkleinert sich die Cystenhöhle, während die Wand an Dicke zunimmt. "In dieser Zeit kunn rin Bhutextravasat in die Cystenhöhle hinein stattfinden", dasselbe ist jedoch in den meisten Fällen nicht vorhanden.

Schliesslich formt das corpus luteum eine compacte Masse, längs den Gefässen findet eine starke Bindegewebsneubildung statt, die eine allmählige Schrumpfung mit fettiger und hyaliner Degeneration einleitet.

Wir sehen dieselben Zustände, wenn auch nicht so scharf ausgepräigt, bei Tupaja und Sorex ebenfalls. Jedoch ist bei jenen Tieren die primaire Cystenbildung nicht so stark entwickelt als bei Tarsius.

Dass analoge Zustände auch ausserhalb der Schwangerschaft bei Tarsius stattfinden, ist sehr wahrscheinlich; doch können wir den absoluten Beweis dafür nicht beibringen, aus den ọben erwähten Gründen.

Bei dem einzigen Exemplare (277), dessen Uterus deutliche Spuren einer Menstruation zeigte, ist kein corpus luteum gefunden.

Was sehr für die Annahme einer analogen menstruellen Corpus-luteum-bildung spricht, sind die Exemplare der frischpuerperalen Ovarien.

Hier finden wir sämmtliche beschriebene Stadien des corpus luteum zurück, olne dass der geringste Anhaltspunkt für eine neue Schwangerschaft besteht.

Eine weitere Stütze liefern die Ovarien von Tafel II, 16 $\imath$ deren Uteri trotz sehr sorg. fältiger Untersuchung keine Schwangerschaftszeichen erkennen liessen.

Als eine besondere, schon mehr dem pathologischen sich nähernde Form des colpus luteum, die auf Tafel II, 20', wiedergegeben ist, sei hier noch einmal hingewiesen. Wir haben es hier mit einem Ektropium des corpus luteum zu thun, das offenbar dadurch zu Stande gekommen ist, lass die Rissstelle nicht rechtzeitig vernarbt ist. Dieser Befund 
dürfte theoretisch von Wichtigkeit sein zur Erklärung mancher gutartiger Papillome des Ovariums beim Weibe.

Es erübrigt nun noch, die letzte der Eingangs gestellten Fragen zu beantworten: Wie verhält sich das Ovarium von Tarsius zur Menstruation, zur Befruchtung, zur Schwangerschaft, zum Puerperium und zum Lebensalter.

Bezüglich der Menstruation künnen wir allein sagen, dass dieselbe besteht, und dass in dem einen Falle der zur Untersuchung kam, bei bereits eingetretener Blutung und Desquamation sich ein zwar reifer, doch noch nicht befruchtungsfähiger Follikel fand.

Es ist anzunehmen, dass ebenso wie bei Tupaja die Befruchtungsfāhigkeit des Fol. likels mit dem Ende der Menstruation zusammenfällt.

Wie es scheint, nähert sich mindestens ein, selten zwei Follikel der Reife, womit das Factum übereinstimmt, dass Tarsius meist ein, selten zwei Embryonen zugleich trägt.

Bei der Befruchtung decken sich die Befunde mit denen von Tupaja. Sobald dieselbe eingetreten ist, atresieren sämmtliche grösseren und kleineren Follikel, und dabei zeigen dieselben in buntem Wechsel alle verschiedenen Arten von Degeneration, mit Torliebe jedoch die der hyalinen.

In der Schwangerschaft findet keine Eireifung statt, sämmtliche Follikel atresieren, sobald sie eine bestimmte Grösse erreicht haben. Stets fand sich nur ein corpıs luteum, auch in einem Falle, in dem zwei Embryonen gefunden wurden. Dasselbe erreicht seine grösste Ausbildung im allerersten Beginn der Schwangerschaft und wird während dersel. ben grösstenteils wieder resorbiert.

Am Ende der Schwangerschaft finden sich wieder zahlreiche normale Primairfollikel

Im Puerperium sind auch auf ganz frischen post partum uteri wieder normale Fol likel von mitteler Grösse zu finden.

Mit zunehmendem Alter nimmt die Zahl der Primairfollikel ab. sowie die Zahl der Follikel überhaupt, das Stroma nimmt zwal zu, jedoch das Volum des ganzen Organs wird kleiner mit der Abnahme der Geschlechtsthätigkeit. 


\section{SCHLUSSBETRACHT UN GEN.}

Bei jeder wissenschaftlichen Forschung geht es zu, wie in der Walpurgisnacht: „da muss sich manches Räthsel lösen, doch manches Räthsel knüpft sich auch," wie Göthe sagt.

Nur mit Widerstreben entschliesst man sich, alle lockenden Perspectiven, die sich dem forschenden Auge aufthun, nicht weiter $\mathrm{zu}$ verfolgen, und sich mit dem zu begnügen, was man gefunden hat. So geht es auch hier, einzelne Fragen, die eine gute Ausheute versprachen, müssen wir ungelöst lassen.

Es wäre von grossem Interesse gewesen, zu untersuchen, ob in der That, so wie es den Anschein hat - bei Sorex in der Brunstzeit allein Eizellen aus dem Ovarium ausgestossen werden, in der Ruhezeit dagegen im Follikel atresirt zu Grunde gehn. Ebenso reizten die menstruellen Vorgänge von Tarsius zu weiteren Untersuchungen, sowohl bezüglich des Reifens der Eizelle als auch mit Bezug auf die Bildung des cor. pus luteum ').

Wie dem auch sei, wir hoffen, dass es uns gegliickt ist, das Gebäude der Lehre über das Ovarium mit einigen neuen Bausteinen zu bereichern und wollen in aller Bescheidenheit versuchen, dieselben hier am geeigneten Platze einzufügen.

Was zunächst die Erfahrungen über Follikelatresie betrifft, so decken sich die Befunde bei Tupaja, Sorex und Tarsius voll und ganz mit denen Hexnegur's (21, 23।. Die von ihm beschriebene "Dégénérescence par fragmentation" hat sich bei allen drei Species in gleicher Weise gefunden. Die von Hevnegur, Paladivo und uns gefundenen Resultate stellen es sicher, dass die Atresie der Follikel in allen Stadien ein physiologischer Process ist, dem eine grosse Anzahl reifender und selbst reifer Eier im Kampf um's Dasein zum Opfer fällt.

1) Inzwischen hat sich bei Tarsius No. 597 ein Ei in hefruchtungsfühigem Zustand unit ausgestossenem Richtungskörper gefunden. 
Wir haben weiter für unsere drei Species nachweisen können, dass die Atresie sïmintlicher zur Zeit vorhandenen Follikel eintritt bei der Befruchtung, und dadurch dem Ovarium des schwangeren Uterus ein characteristisches Gepräge giebt.

Bezüglich des corpus luteum können wir die von Sobotta bei der Maus gemachten Beobachtungen bestätigen und erweitern.

Dank sei dem reichen Material war es für alle drei Species, (besonders deutlich jedoch für Tarsius und Tupaja,) möglich, das Entstehn des corpus luteum aus der wuchernden Theca dem Granulosaepithel zweifellos nachzuweizen. Da, wie auch Sobotta bemerkt, die ersten Stadien des corpus luteum sehr rasch auf einander folgen, so war es von grösster Wichtigkeit, ein grosses Material dafür zu haben.

Gleich Sobotta nehmen wir an, dass die so widersprechenden Angaben so vieler bekannter Autoren nur darauf zurückzuführen sind, dass die meisten nicht in der Lage waren, gerade die allerfrühsten Stadien zu untersuchen, und meist ein fertiges, ja oft ein regressiv metamorphosirtes Gebilde ihren Beobachtungen zu Grunde legten.

Um alle Verhältnisse zu übersehn, war es nöthig, nicht nur auf den noch nicht gesprungenen, sondern selbst auf den reifenden Follikel zurückzugreifen, bei dem die allerersten Stadien von Gefässsprossen der Theca die Bildung des colpus luteum schon vorbereiten.

Noch einmal sei hier der treffende Ausspruch von His angeführt, der die Theca mit einem "corpus cavernosum" vergleicht, wobei das entscheidende Merkmal nicht in der Weite der Gefässe liegt, sondern eben daran, dass „ausser der modificirten Gefässwand” kein Gewebe vorhanden ist.

Den treffenden Beweis für diese Thatsache liefert die Tergleichung der Bilder des sprungreifen und des eben gesprungenen Follikels, wobei die mit Blut gefüllte Theca vüllig dem Bilde der Erection des corpus cavernosum beantwortet. Die allmählige Auswucherung der Gefässsprossen zwischen den Granulosazellen hin, deren Betheiligung an der Bildung des corpus luteum unter Vergrösserung und Hellerwerden der einzelnen Zellen, ist aus der Folge del gegebenen Bilder unzweifelhaft zu elkennen.

Wie rasch gerade die ersten Stadien, der Schluss der Narbe und die primaire Corpusluteumcyste mit Verkleinernng auf Kosten der wuchernden IVand auf einander folgen, ist besonders deutlich bei Tarsius $\mathrm{zu}$ beweisen, wobei sich alle ersten Stadien finden in der Zeit der Imprägnation, und im Furchungsstadium nur noch viel reifere stadien des corpus luteum angetroffen werden.

Was den Bluterguss betrifft, so liess sich für Tarsius nachweisen, diss derselbe erst secundair in der Höhle der bereits gebildeten Corpusluteumcyste aus den gewucher. ten Gefässen der Theca stattfindet. Ferner ist sicher, dass derselbe nichts Wesentliches bei der Bildung des corpus luteum ist und in mindestens $50 \%$ o der Falle bei Tarsius, in noch mehr Fällen bei Tupaja und Sorex nicht vorhanden ist.

Dabei ist nicht ausgeschlossen, dass bei der Ruptur des Follikels auch wohl primair ein Blutaustritt aus dem zerrissenen Gervebe stattfindet, der jedoch stets unbedeutend ist, weil daselbst keine grösseren Gefässe liegen. In meinen Präparaten habe ich denselben niemals constatiren können. 
Dass die Ruptur des Follikels oft sehr gewaltsam stattfindet, beweist das Präparat von Tupaja 214, wo sich in der Tube losgerissene Fetzen von Ovarialgewebe mit Primair. follikeln finden.

Bei allen drei Species liess sich nachweisen, dass das corpus luteum menstruationis innerhalb zwei Menstruationsepochen wieder völlig resorbirt ist, da sich nie mehr als zwei verschiedene Stadien von corpora lutea neben einander in demselben Ovarium finden: ganz frische neben beinahe resorbirten, niemals eine dritte Generation dazwischen.

Während der Schwangerschaft wird das corpus luteum - vielleicht langsamer ebenfalls bald resorbirt, jedenfalls findet man höchstens noch Spuren davon bei hochschwangeren Thieren.

Die Resorption des corpus luteum ist völlig analog der Atresie der Follikel, hyaline, fettige und körnige Degeneration beherrschen das Bild. Mit der Degeneration der grossen Luteinzellen geht eine Bindegewebsanbildung längs der Gefässe der umgebildeten Theca Hand in Hand, so dass der Process auch viel von der Vernarbung bei Wundheilung an sich hat.

Durch die Veröffentlichungen von SoBo'T'A hat in der jüngsten Zeit die bereits von Waldeyer und Paladino vertretene Auffissung des doppelten Ursprungs del Elemente des corpus luteum aus granulosa und theca eine neue Stütze und allgemeinere Anerken. nung gefunden. $\mathrm{Zu}$ ihr bekennen sich auch Schäfer und Symingtor.

Die entgegengesetzte Ansicht, dass nur die theca mit wuchernden Zellen und Ge. fässen das corpus luteum bildet, ist zuletzt von ScHotTLäsder, neuerdings wieder von NAGEL wenigstens für den Menschen aufrecht erhalten.

Auf Grund der erhobenen Befunde stützen wir mit Tupaja, Sorex und Tarsius die Sobotta'schen Befunde bei der Maus.

Ob angesichts dieser Thatsachen die Möglichkeit bestehn kann, dass speciell beim Menschen die granulosa nicht zur Bildung des corpus luteum beiträgt, ist uns sehr zwei felhaft. Jedenfalls sind die bisherigen Veröffentlichungen nicht als unumstössliche Beweiseanzusehn Die letzten Nagel'schen Bilder können für die eine, sowie für die andere Auf fassung sprechen. Auf Grund der Analogie mit den erhobenen Befunden von SoBotTA und uns sind wir geneigt, sie zu unsern Gunsten auszulegen.

Postfötale Entwickelung von Ureiern aus dem Deckepithel fanden sich stets bei Tupaja, sowie bei Sorex und Tarsius: nur sehr alte Exemplare zeigten sie nicht.

Paladino fand sie stets bei Menschen, Schweinen, Pferden, Kühen, Schafen, Ziegen, Hasen, Katzen, Hunden und Kaninchen, van Beneden bei Fledermäusen, WAgexer bei Hunden.

Wir bestätigen somit alle die Befunde Waldeyers.

HARz fand sie nicht bei einem Fohlen, einer Stute, einem Schwein, einem Hasen und einem menschlichen Fötus, ScHotTuäNDER ebensowenig bei sieben pathologischen Ovarien von Weibern.

Angesichts der grossen Zahl positiver Befunde haben die viel weniger zahlreichen negativen schon wenigel Beweiskraft; in Schotruäsders Fïllen ist das pathologische Mo. ment erwiesen, in den Harz'schen Fällen jedenfalls nicht ausgeschlossen. 
Wir dürfen wohl annehmen, dass WALDEYERS Beobachtung, dass eine fortwährende Neubildung von Ureiern während des ganzen Geschlechtslebens bei allen Säugethieren stattfindet, zu Recht bestehn bleibt.

Seit der prächtigen Monographie vay Benedexs über die Eireifung bei Ascaris sind verschiedene bedeutungsvolle Entdeckungen auch bezüglich der Säugethiereizelle gemacht worden. Den eifrigen Bemühungen von vas Beneden und Julis, vos Reis, WV. Heape und von Бовотта gelang es, den Nachweis zu liefern, dass auch im Säugethierei schon vor der Befruchtung ein bis zwei Richtungskörperchen ausgestossen werden und ein weib. licher Pronucleus sich formt.

Dies muss als der normale Vorgang und zugleich als Zeichen der befruchtungsfähigkeit des Ei's angesehn werden.

Bei Tupaja ist es uns gelungen verschiedene Exemplare aufzufinden, die sich in diesem Stadium befinden.

Bei Sorex fand sich nur ein Fall, in dem der weibliche Pronucleus gebildet war; doch ist hier das Bild durch den Befruchtungsvorgang getrübt.

Es ist uns nicht im geringsten zweifelhaft, dass sich analoge Bilder bei Sorex ebenso wie Tarsius finden müssen, doch das muss eben als ein glücklicher Zufall angesehn werden, der uns nicht zu Theil fiel ').

Die vielen Hinweise, die auch wir fanden, sind bereits oben zu Protokoll gegeben.

Betrachten wir nun zum Schlusse das Ovarium als Ganzes in seinem Verhältniss zu Menstruation, Gravidität und Wochenbett.

Tupaja, sowie Tarsius besitzen eine Menstruation mit blutigem Ausfluss, bei Sorex konnte die Frage nicht entschieden werden.

Bei Tupaja fällt die Zeit der Eireife mit dem Beginn, die Zeit der Befruchtungs. fähigkeit mit dem Ende der Menstruation susammen; in dem einen beobachteten Fall von Tarsius fiel ebenfalls die Eireife mit dem Beginn der Menstruation zusammen.

Die Zahl der corpora lutea entspricht der Zahl der ausgestossenen Eizellen. Nicht alle Eizellen, die reif, ja selbst befruchtungsfähig sind, werden ausgestossen; einzelne derselben verfallen auch dann noch der Atresie.

Das corpus luteum menstruationis unterscheidet sich in keiner Weise von dem corpus luteum graviditätis, dem sog. corpus luteum verum.

Bei Sorex scheint eine Menstruation stattzufinden, die sich durch Losstossung des Uterusepithels und serüse Exsudation kennzeichnet; dass auch Blutung eintritt, liess sich nicht nachweisen.

Characteristisch für die Ovarien sämmtlicher drei Species ist es, dass sofort nach Eintritt der Befruchtung alle Follikel atretisch werden, und dass während der schwanger. schaft keine Eireifung stattfindet, sondern, dass alle Follikel atresiren, sobald sie eine gewisse Grösse erreicht haben.

Die Zahl der corpora lutea entspricht der Zahl der ausgestossenen Eier, sie kiann

1) Bei Tarsius (597) inzwischen gefunden! 
demnach grösser sein als die Zahl der F̈̈̈ten in dem Fall, dass nicht alle ausgestossenen Eier befruchtet sind.

Demnach giebt weder die Form noch die Zahl etwa aufgefundener corpora lutea irgend welchen Aufschluss, sowohl bei der Frage nach Schwangerschaft überhaupt, noch für die Zahl der Föten.

Ganz gegen das Ende der Schwangerschaft nähern sich wieder verschiedene kleinere Follikel der Reife, ohne atretisch zu werden, so dass wir im Puerperium wieder reife Follikel antreffen zu einer Zeit, zu der der Uterus noch keineswegs involvirt ist.

Aus diesen Beobachtungen lassen sich - vorläufig nur für die drei untersuchten Species - folgende Schlüsse machen:

Finden wir in einem Ovarium - von pathologischen Zuständen natürlich abgesehn alle Follikel atretisch, zu können wir annehmen, dass es sich um Schwangerschaft handelt.

Trifft man mit demselben Befund ein frisches corpus luteum an, so handelt es sich um ein sehr frühzeitiges Stadium von Schwangerschaft.

Haben wir endlich neben zählreichen atretischen Follikeln und einem frischen corpus luteum auch einige normale Follikel entdeckt, so müssen wir an einen puerperalen Zustand denken, dem bereits eine Menstruation gefolgt ist.

Eine grosse Anzahl atretischer Follikel neben wenigen normalen deutet ebenfalls auf Puerperium.

Die Beobachtungen bei Sorex machen es wahrscheinlich, dass diejenigen Thiere, die eine" Brunstperiode besitzen, in der Zwischenzeit nicht zur Ovulation kommen, sondern ihre Eier durch Atresie vor dem Follikelsprung verlieren.

Die Entscheidung dieser Frage musste unerledigt bleiben. 



\section{I T E R A T U R.}

Hauptwerke der ältcren Literatnr bis 1874.

1. Regnenus de Graar de mulierum organis generationi inserrientibus tractatus novas. Leiden, 1672.

2. Idem.

Opera omnia. Leiden, 1677.

3. von BaEr.

De ovi nammaliuı et hominis genesi. Leipzig, 1827.

4. Cos're.

Histoire générale et particulière du développement des corps organisés. $1847-1859$.

5. Idem.

Recherches sur la génération des mammifères. Paris, 1834.

6. WaGiner,

Einige Bemerkungen und Fragen über das Keimbläschen. MëLLER's Archiv, 1835. pag. 373.

7. VALENTIN.

Ueber die Entwickelung der Follikel in dem Fierstock der Sïugethiere. MÜLLER's Archiv, 1838.

8. Scuroen.

Beitrag zur Kenntnis der Anatomie und Physiologie des Fierstocks iler Siugrethiere. 1863. Zeitschrift für wissenschaftl. Zoolog. Bd. 12.

9. PFrüger.

Die Eierstöcke der Süugethiere und des Menschen. Leipzig, 1863. Literaturangabe.

10. Waldeyer.

Eierstock und Ei. Leipzig, 1870. Reiche Literaturangabe.

11. Idem.

12. His.

Eierstock und Nebeneierstork. 1871. Stricker's Handbuch, p. 54t.

Beobachtungen ïber den Bau des Süugethiereicrstockes. 1865. Archir mikroskrop. Anatom. Bd. I. p. 151.

13. H. LuDwir.

Ueber die Fibildung im Thierreiche. Arbeiten Zoolog · Zootom. Instit. Wiirzbg. Bd. I. p. $267-510$.

$$
\text { Follikelatresie. }
$$

14. ReInharit't.

Ueber dic Entstehung der Körnchenzcllen. Vircnow's Archiv. 1. 18t7.

15. Grone.

Bau und Wachsthun des menschlichen Eierstocks. 1863 Vurcinow's Arehir. 26.

16. Slavianskit.

Recherches sur la regression des follicules de de (inas chez la frimme. Archives de Physiolog. 1874. 
17. Flemmisg. Ceber die Bildung ron Richtungsfignren in Säugethiereiern beim Lntergang Grase'scher Follikel, 18ะ5. Archiv Anatom. u. Entwickelg. p. 221. Literatur über Follikelatrophie.

18. Palabrio. Ulteriori ricerche sulla distrnzione e rinnoramento continuo del parenchimo ovarico nei mammiferi. Napoli, $188 i$.

19. Ruge. Torgänge am Eifollikel der Wirbelthiere. 1889. Morpholog. Jahrb. 15. p. 461.

20. Scuotrcïxder. Beitrag zur Kenntniss der Follikelatresie uebst einigen Bemerkungen über die nnveränderten Follikel in den Eierstïkken der Sängethiere. 1891. Arehir Anatom. u. Entwickelg. 37.

21. HeNTEguY.

Recherches sur l'Atrésie des follicules de DE GraAr chez les mammiferes et quelques autres vertèbres. 1894. Jonrnal de l'Anatomie et de la physiol. t. 30. p. 1.

22. Idein.

Le corps vitellin de Balbiani dans l'oeuf des rertèbres. Journal de l'Anat. et la physiol t. 29.

23. Idem.

Sur la fragmentation parthénogénésique des ornles des mammiféres pendant l'atrésie des follicules be Graaf. Comptes rendus de la Société de Biolog. t. 5.

24. JАХOSIK.

Atropic folliculu a rolastni chorani se bunky rajecné. Bullet. Acad. Prag. 1892.

25. Idem.

26. Crery.

27. Mingarzini.

Sur la structnre de l'oeuf des mammiféres. Bibliog. Anatomique, t. I.

Sulla degenerazione fisiologica del vitello delle ore dei mammiferi. Ricerche fatti nel laborator. di anatom. norm. d. R. Unicersita di Roma III. 1893.

28. Loewexthal.

Corpi lutei veri e falsi dei rettili. ibid. 1893 .

Ceber die Rüickbildung der Fizellen und das Vorkommen von Leucocythen im Keimepithel und in deu Eischläuchen. Intern. Monatsschr. Anat. \& Physiol. Vl.

Corpus luteum (vide 3. 8. 9. 10.11. 12. 18 .

29. Slavtansky. Zur normalen und pathologischen Histologie des Graarschen Bläschen des Menschen. 1870. Vircuow's Areliv. Bd. 51.

30. Bexckiser. Zur Entwickelungsgeschichte des corpus lutcum. 18st. Archir fïr Gynäcologie. 23. Literatur des corpus luteum bis 1sst, nebst Besprechnng derselben.

31. Idem.

Ueber das Vorkonunen vou indirecter Kerntheilung im corpus Inteum. liš. Archiv für Gynäcologie, 25.

32. Schotruivoer. Ueher den Grasł'schen Follikel, seine Entstehung beim Menschen und seine Schick. sale bei Mcnsch und Säugethieren. 1893. Archiv Mikroskp. Anat. 41. p. 219.

33. Vas Bexedex. Contribution à la connaissance de l'oraire des mammiféres. 1880. Vespertilio murinus. rhinoloplus. Archives de Biologie I. Reiche Literatur ron 1826 ab.

34. Leopold. Studium iiber die Lterusschleimhant willend Menstruation, Schwangerechaft und Wochenbett. 1sī. Arch. f. Gruäc. XI.

35. Idem. Studium über Menstruation und Orulation. 1883. Taf. II. III. Archir f. Gỹä. XXI.

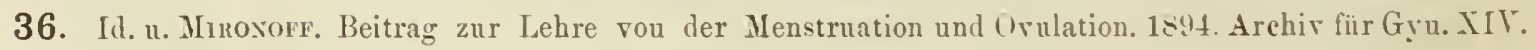

$$
\text { Primordialeier im Keimepithel. (ride 10. 16. 33.) }
$$

37. HARz. Beiträge zur Histologie des Orariums der siüugethierc. 1893. Archir Mikro. Anat. 2.2. d. 374.

38. Wagexer. Bemerkungen iiber den Eierstock und den gelben Kürper. 1879. Archir anat. und Entw. 


$$
\text { I) as reife lierstooksei. (vide 9). }
$$

39. Van Beneiex. Recherches sur la maturation de l'oeuf et la fécondation. 18*:3. Ascaris megalocephala, Archives de Biolog. IV. p. 265-6:32.

40. Van Benenen \& Julin. Observations sur la maturation, la fécondation et la seginentation de l'seuf chez les Cheiroptires. 1880. Archives de Biologie I. p. 55.

41. REIN.

Beitrïge zur Kenntnisz der Reifungserschcinungen und Befruchtungsvorgainge am Sïugethierei. 1863. Archiv für Mikr. Anat. 2\%.

42. W. Heape. The developement of the Mole, the ovarian ovun and segmentation of the ovum. 1886. Quart. Journ. Microsc. Srienc. t. 26. p. 157.

43. KöLLIKER. Entwickelungsgeschichte. $2^{\text {te }}$ Aufl. 1879. Reiche Literatnrangabe.

44. Van Bambecke. Contribution à l'histoire de la constitution de l'oeuf. 188\%. Archives de biolog. IV. p. 803.

45. Batibnanl. Sur l'origine du follicule et du noyau vitellin de l'neuf chez les géophiles. 18x:3. Zoolog. anat. 155-156.

46. Nagel. Das menschliche Ei 1887. Archiv. Mikr. Anatom. 31 p. 342-423. Literaturangabe von 103 Nummern.

$$
\text { Epoophoron. (vide 18, 33, 37. }
$$

47. Mac Leov. Contribution à l'étnde de la structure de l'ovaire des mammiferes. 1880. Archires de biolog. I. p. 241.

48. Born.

Ueber die Entwickelung der Eierstöcks des Pferdes. 1874. Archiv. anat. u. Phy̧siol. Ovarium bei Menstruation, Gravidität u. Puerperium.

$(\nabla$ i d e $34,35,36,18,32)$.

49. Heape. The Menstruation of semnopithecus entellus. 1894. Procedings royal society. vol. 54. 50. De Sinétry. De l'ovaire pendant la grossesse. 1877. Comptes rendus. Acad. de sciences.

51. Schulin. Morphologie des Ovariums 1881. Archiv. Mikr. Anat. 19. p. 442-512. Kíritische Besprechung der Literatur bis 81 .

52. Авву Ueber glatte Muskelfasern im Ovarium und Mesovarium von Wirbelthieren. 185!. Archiv. Anat. u. Physiol. p. 675. 



\section{ERKLAERUNG DER TAFELN.}

Sämntlichc Objecte siud, bis auf alle Zellkernc genau, dioptrisch iibertragen. Bei der für die Reproduction nöthigen photographischen Uebertragung der Originale auf die Platten ist bei der Vorkleinerung nicht immer derselbe Maassstab eingehalten, so dass eine dircete Vergleichung der Grïssenverhältnisse, wie sie ursprünglich angestrebt war, nun nicht mehr möglich ist.

Tafel I. Uebersichtsbilder von Ovarien von Sorex und Tupaja, roth $=$ Follikel, gelb $=$ corpora lutea ursprüngliche Vergrüsserung $=48$.

Fig. 1-7. Ovarieu von Sorex.

1. Jungfriuliches Ovarium. 2. Ovarium in Beginu der Schwangerschaft. 3. Ovarium am Ende der Schwangerschaft. 4. Ovarium in frischeu Puerperium. 5. Im späteren I'uerperium 6. Impraegnatiou im Puerperium. 7. Uvarium bei Puerperium + frischer Graviditit.

Fig. 8-15. Ovarien vou Tupaja.

8. Jungfrïuliches Ovarium. 9. Ovarium bei der Menstruation. 10. Ovarium bei der Befruchtung. 11. Im Beginn der Schwangerschaft. 12. Iu der ersten Hälfte. 13. Am Ende dor Sehwangersehaft. 14. Im Beginn des Puerperiums. 15. Seniles Ovarium.

Tafel II. Uebersichtsbilder von Ovarien vou Tarsius. Ursprüngliche Vergrösserung $=48$.

16 $a$. Jungfrïuliches Ovarium. 16b. Ovarium bei Henstruation. 17. Ovarium bei Impraegnation.

18. Id. 19. Ovarium im allerfriihesten Stadium. - 20a. Im weiter entwickelten Stadinm. -

20b. Im congestiven Stadium der Schwangerschaft. - 21. Ovarium am Ende der Schwan-

gerschaft. - 22. Ovarium im Beginn. - 23. Im weiteren Verlauf des Puerperiums.

" III. (Ursprüugliche Vergrïsserung 800). Entwickelung der Follikel von Tupaja bis zur Reife.

" IV. (Urspr. Vergr. 800, Fig. 26 u. 27. Vergr. 256). Befruchtungsfithiger Follikel u. bcfruch. tetes Fi von Tupaja.

V. (Urspr. Vergr. 800). Corpusluteunbildung und Follikelatresie bei Tupaja.

11

VI. (Urspr. Vergr. 800). Entwickelung des l'ollikels, Befrnehtung, Corpusluteumbilduug und Follikelatresie bei Sorex.

VII. (Urspr. Verær. 800). Entwickelung und Atresie des Follikels bei Tarsius.

VIII. Uebersichtsbilder der Corpusluteumbildung bei Tarsius.

IX. (Urspr. Vergr. 256). Corpusluteumbildung bei Tarsius.

Die Details der Zeichnungen crgeben sich ans dem Text, die beigefiggten Ziffern bezieluen sich anf die Nummern in Katalog des Utrechtschen Museums. 


T.AY II

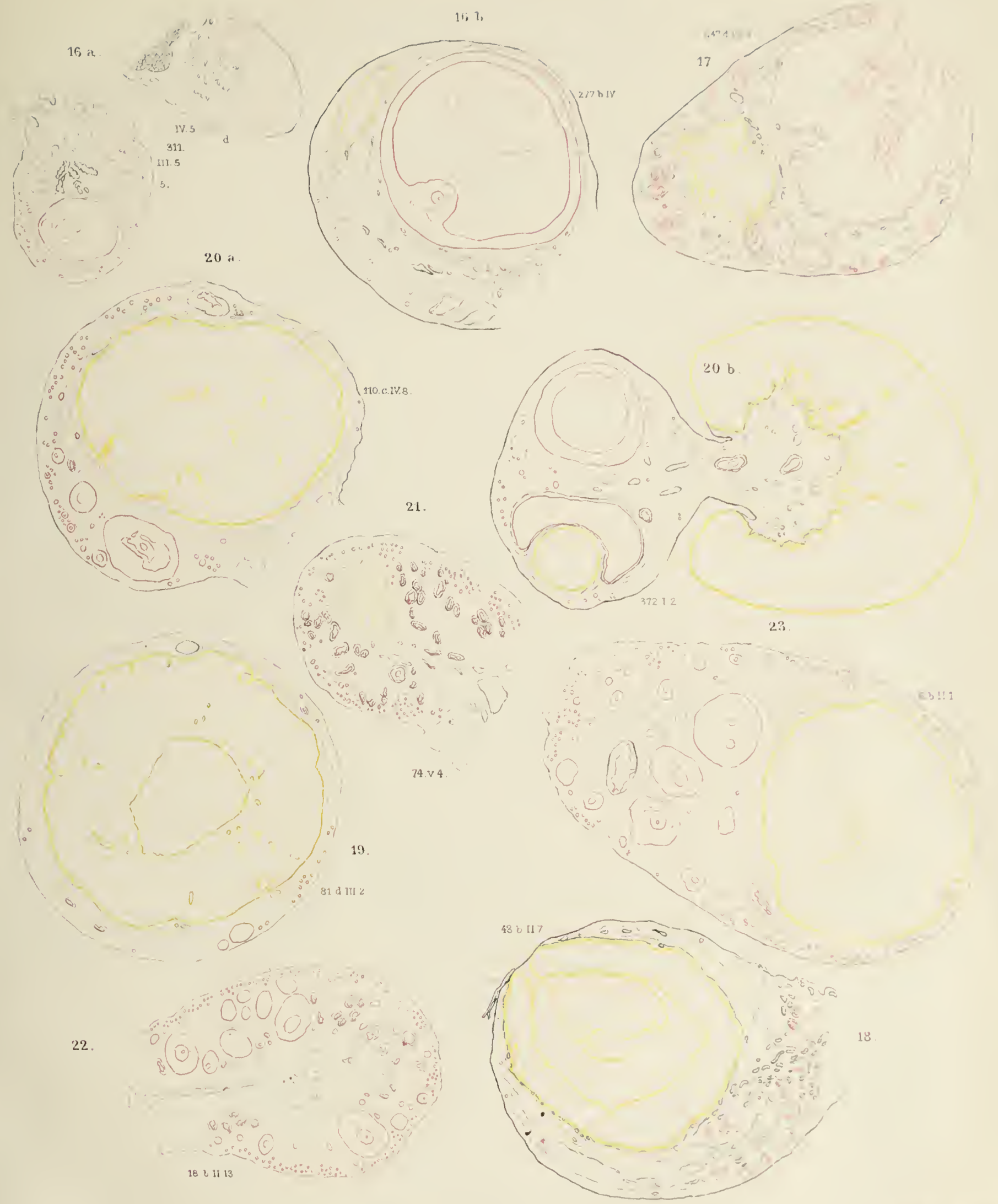

C.H.Strate del. 



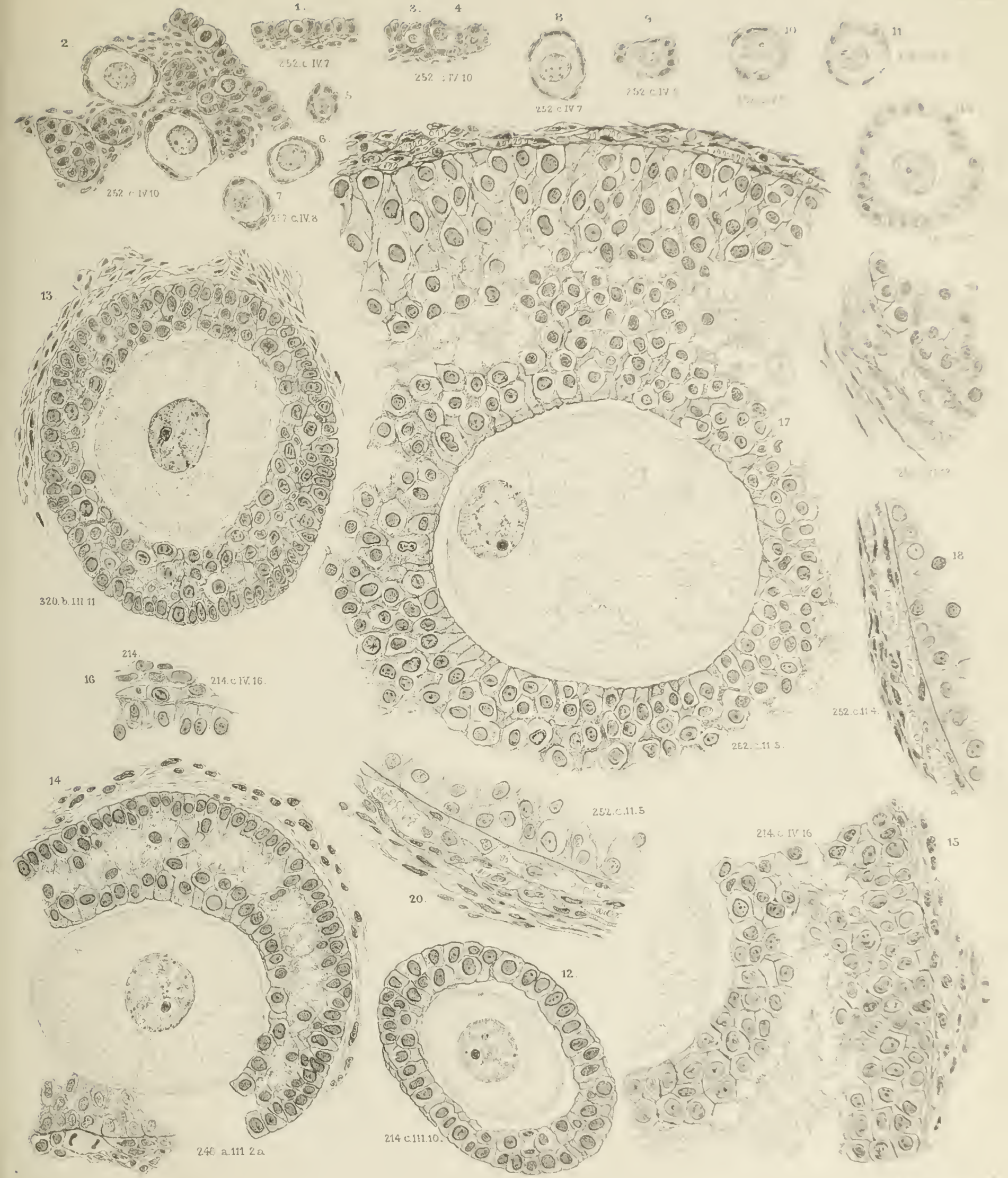

Ch.Stratz del. 



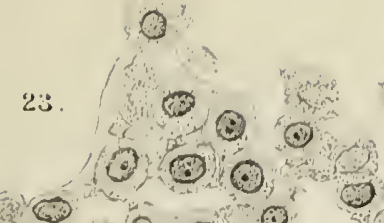

10. 00000

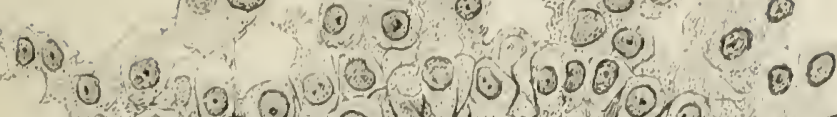

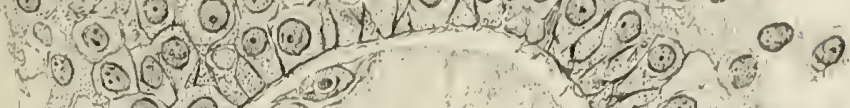

(1) (1) (3)

(3) (1)

(1) 0

(3)

(-) 3

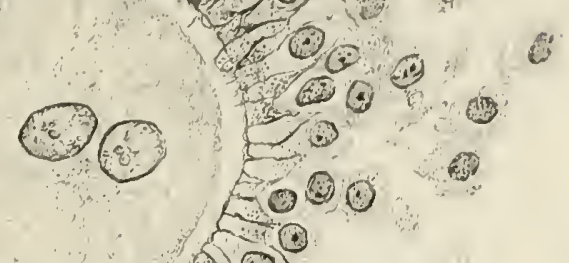

$(10)$

10?

(3) 01000000

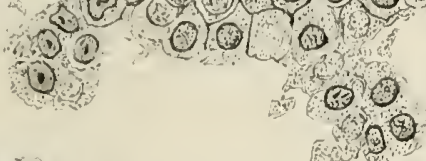
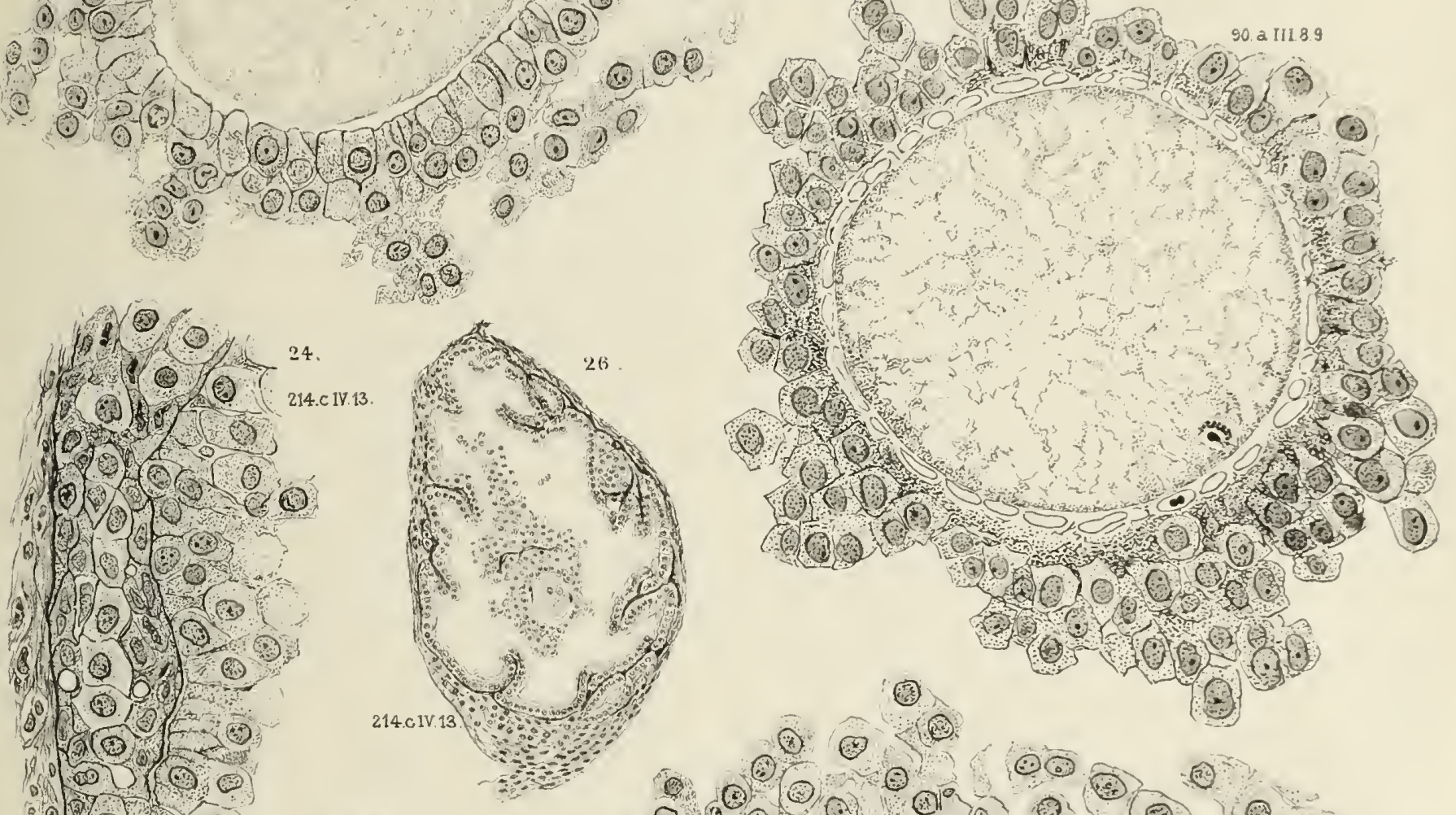

o.

(-) (1)

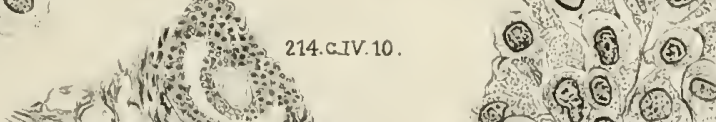

n.t.

w y o w

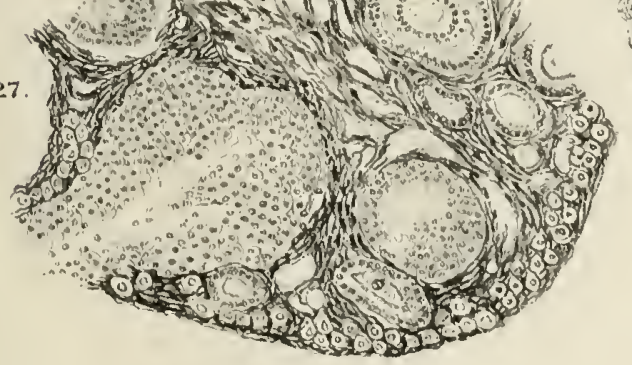

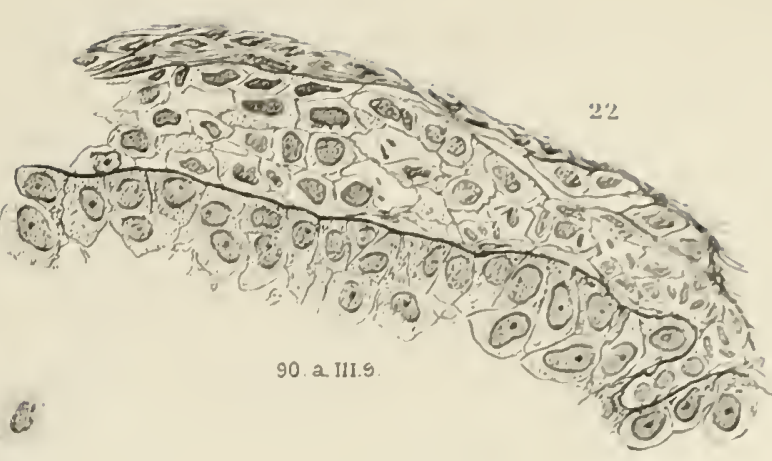

21 



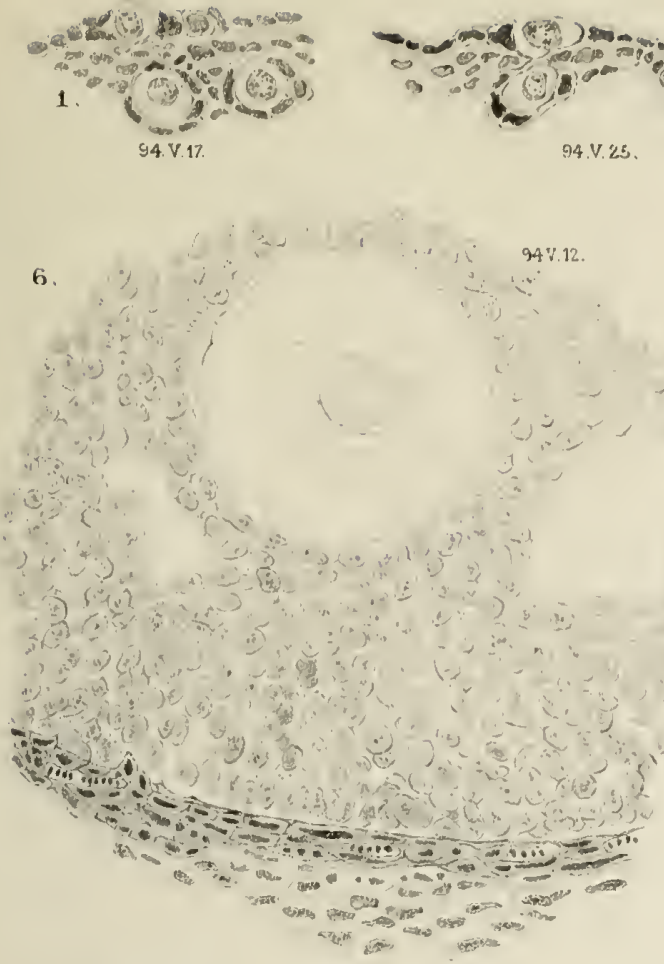

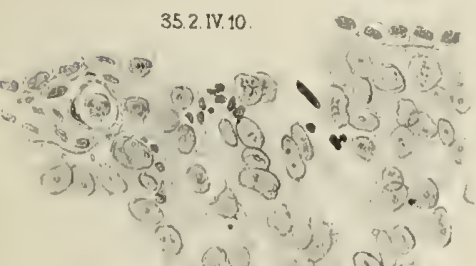

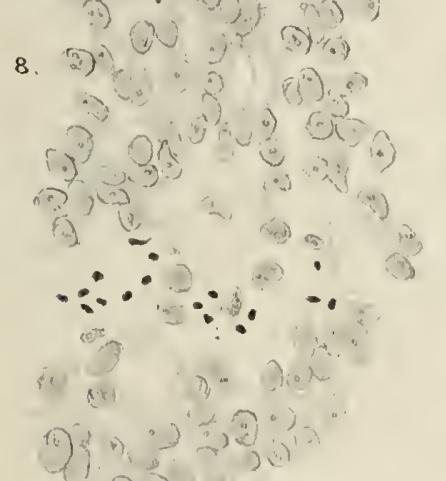

$$
\text { (n) }
$$

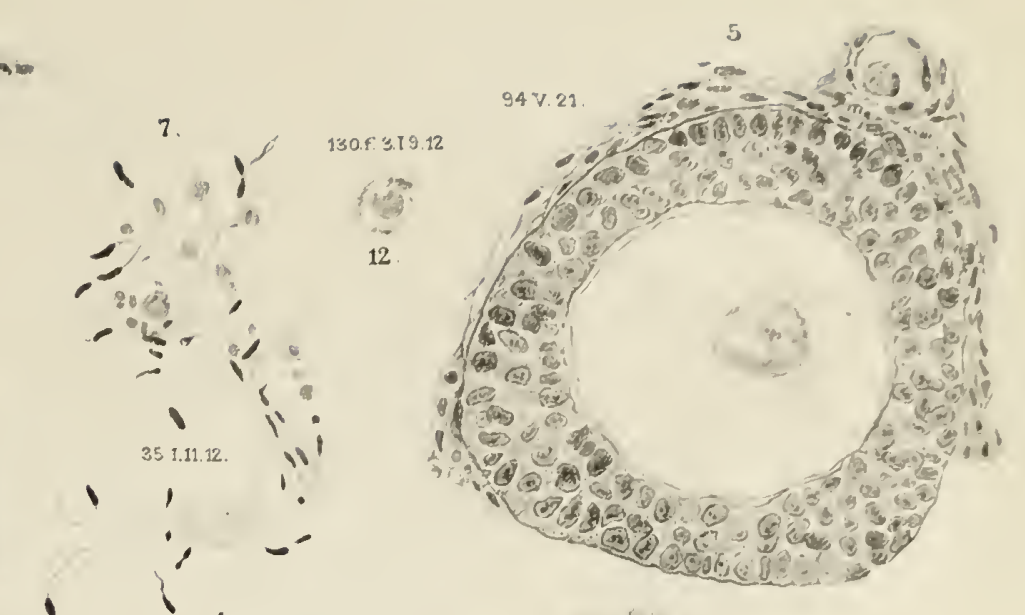

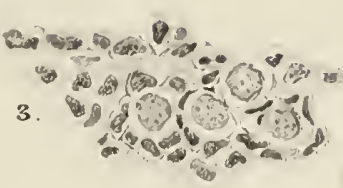

94. IV. 11
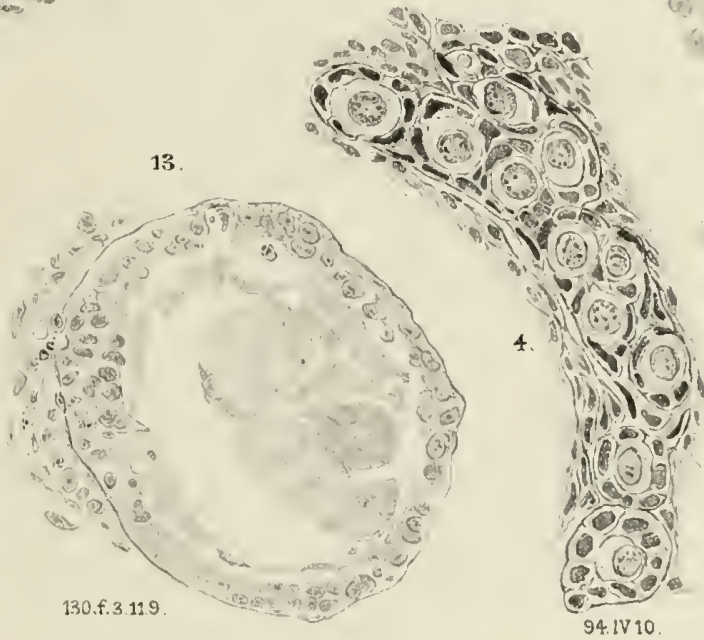

13.

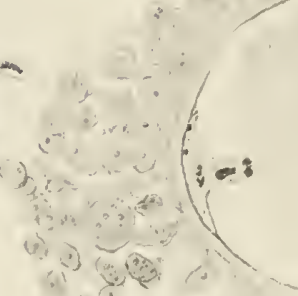

(3) int? ifor?

9.

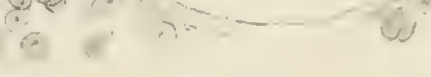

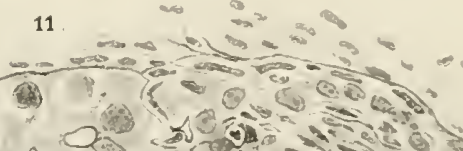
(4) $\hat{3}_{0} 0$ a 122.21 .16 .

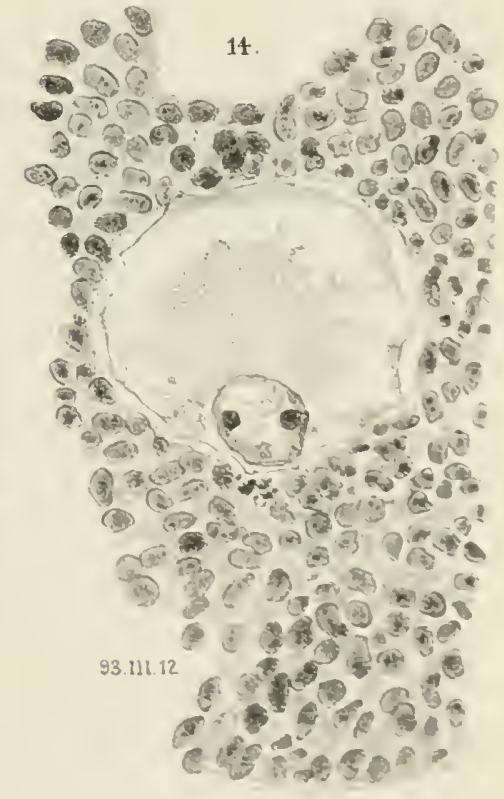




TAF. VIII

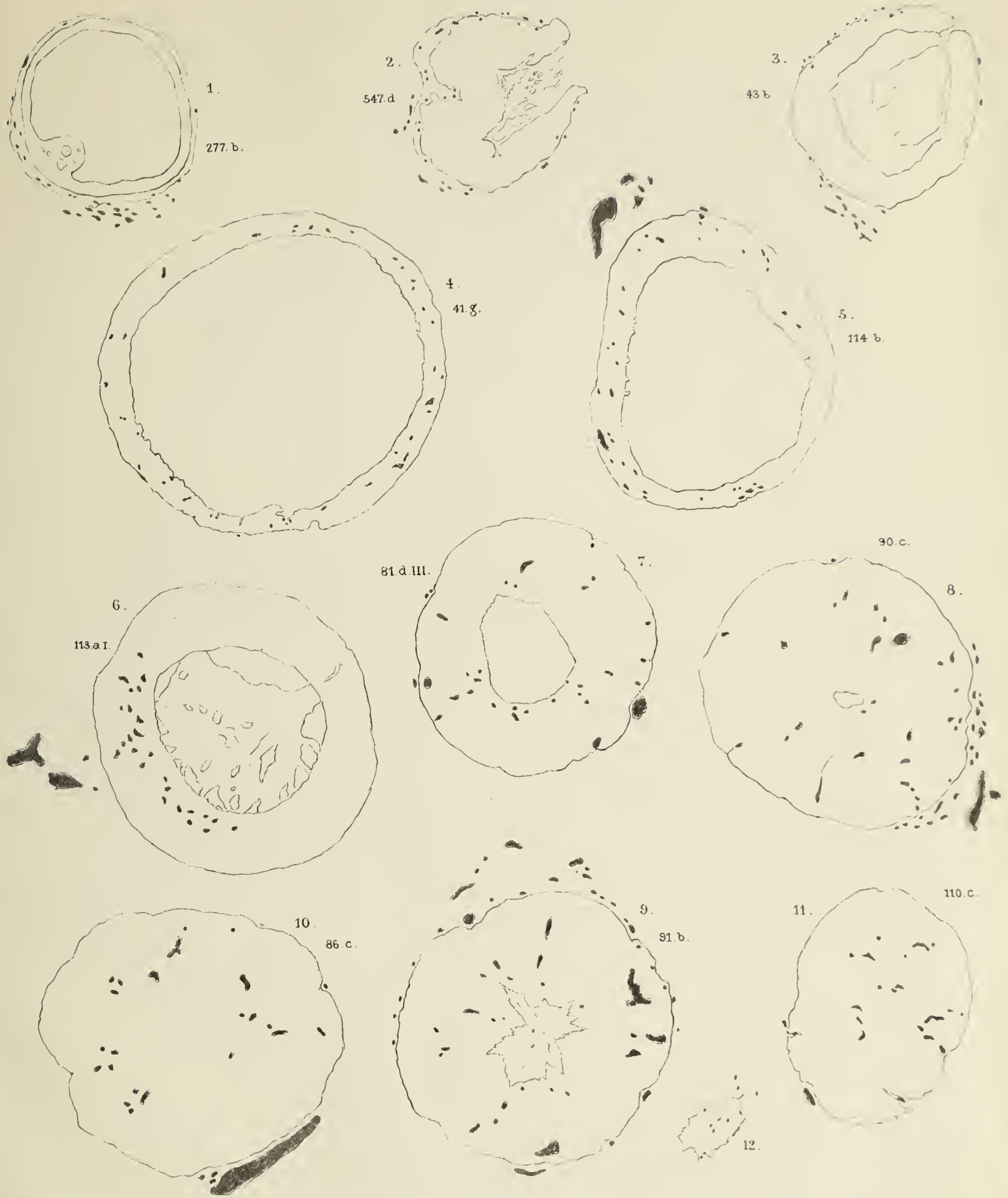

C.H.Stratz del

PWUTTE? Imp 


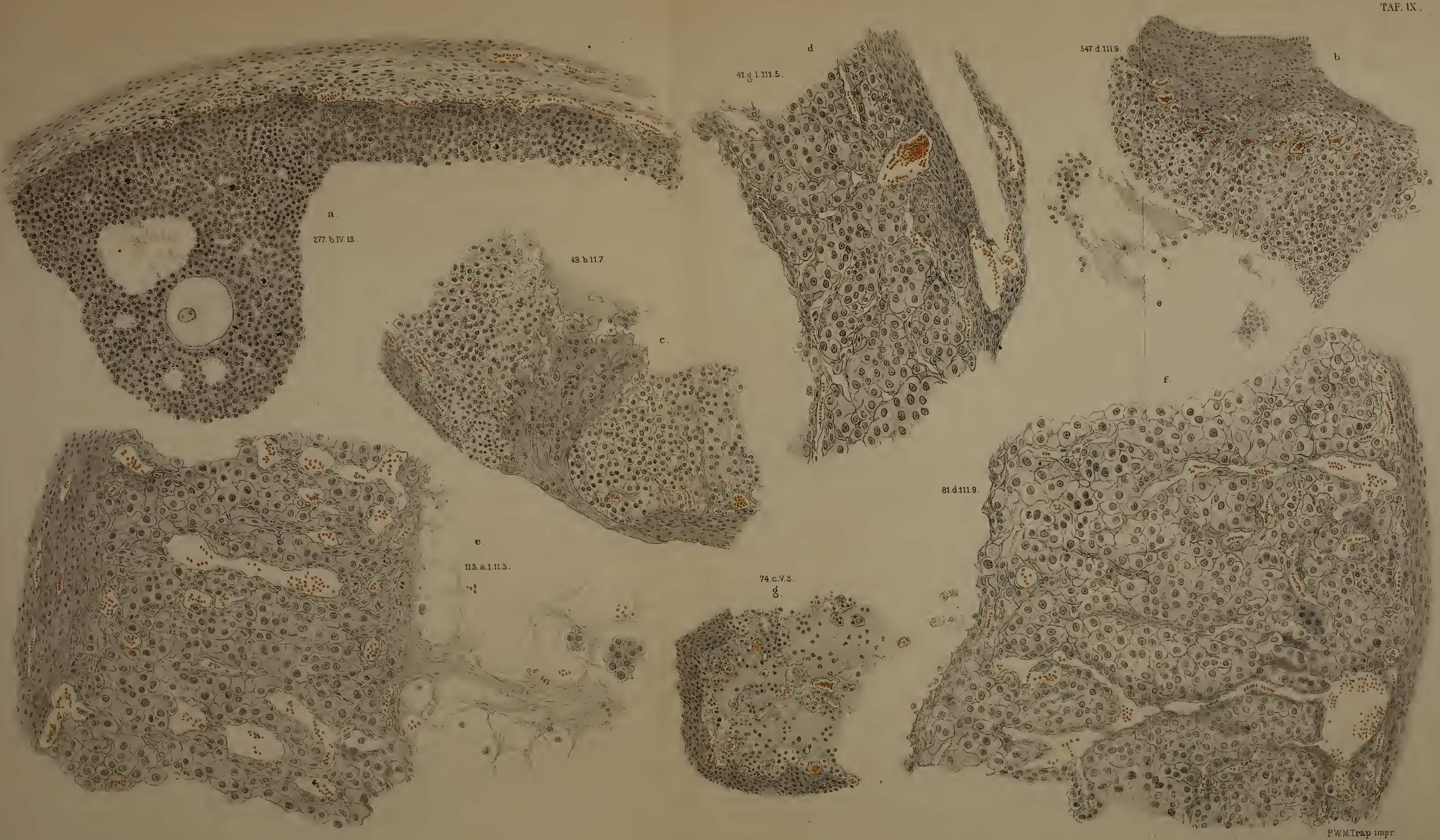

CH.Stratz del.

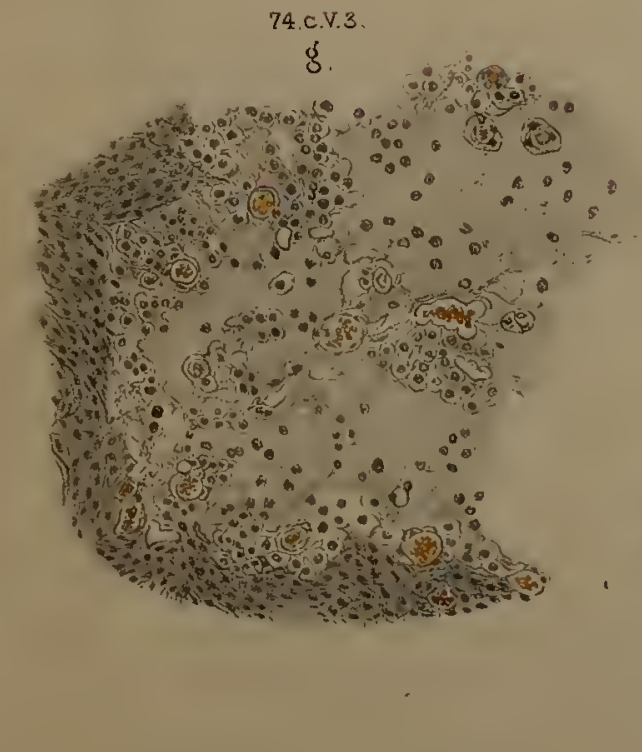
(a)

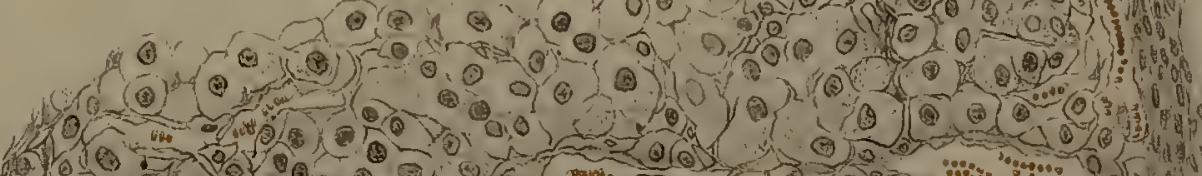

mamo $10 \% 0 \%$

4 (1)

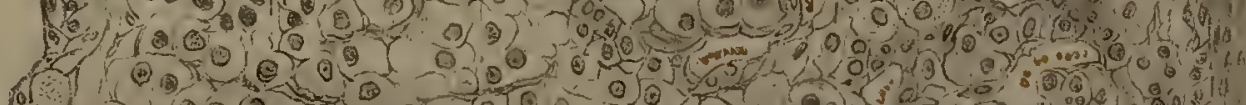

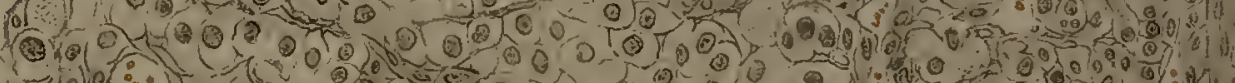

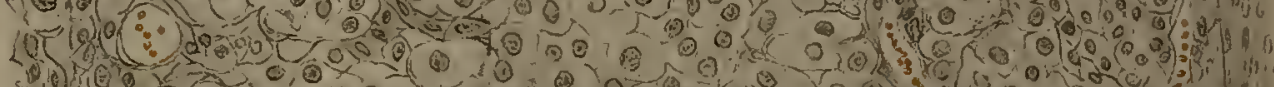
9.

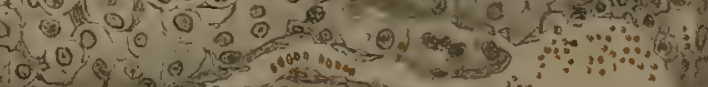

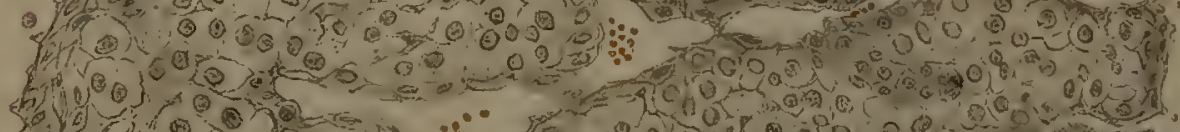
b.

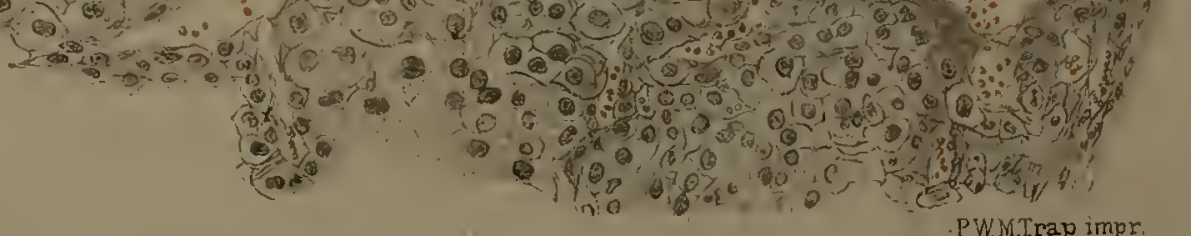






$$
\text { |||||||||||||||||||||||||||||||||||||||| }
$$


an

s.

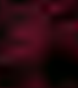

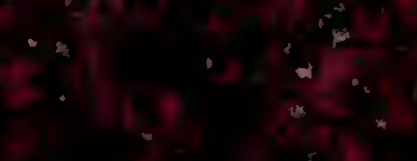

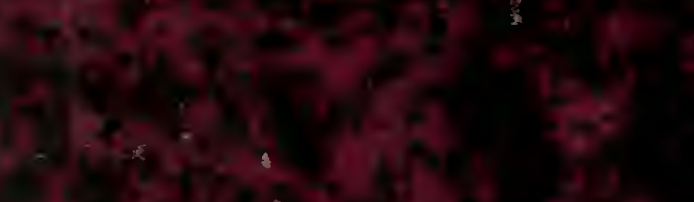

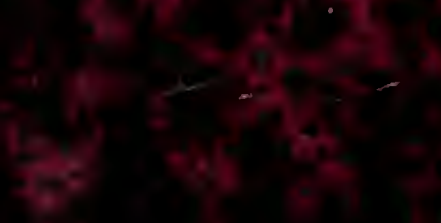

